\title{
A vegetação do Parque Estadual Turístico do Alto Ribeira (PETAR), São Paulo, Brasil
}

\author{
Natália Macedo Ivanauskas', Roseli Lika Miashike ${ }^{1}$, João Ruffin Leme de Godoy², \\ Flaviana Maluf de Souza ${ }^{1,5}$, Marina Mitsue Kanashiro ${ }^{3}$, Isabel Fernandes de Aguiar Mattos ${ }^{3}$, \\ Maria Teresa Zugliani Toniato ${ }^{4}$ \& Geraldo Antônio Daher Corrêa Franco ${ }^{1}$ \\ ${ }^{1}$ Instituto Florestal, Seção de Ecologia Florestal, \\ Rua do Horto, 931, CEP 02377-000, São Paulo, SP, Brasil, http://www.iflorestal.sp.gov.br \\ ${ }^{2}$ Faculdade de Engenharia São Paulo, Av. 9 de Julho, 5520, São Paulo, SP, Brasil \\ ${ }^{3}$ Instituto Florestal, Seção de Introdução, \\ Rua do Horto, 931, CEP 02377-000, São Paulo, SP, Brasil, http://www.iflorestal.sp.gov.br \\ ${ }^{4}$ Instituto Florestal, Estação Experimental de Bauru, \\ Av. Rodrigues Alves, 38-25, CEP 17030-000, Bauru, SP, http://www.iflorestal.sp.gov.br \\ ${ }^{5}$ Autor para correspondência: Flaviana Malufde Souza, e-mail: flavianams@yahoo.com.br
}

IVANAUSKAS, N.M., MIASHIKE, R.L., GODOY, J.R.L, SOUZA, F.M., KANASHIRO, M.M., MATTOS, I.F.A., TONIATO, M.T.Z. \& FRANCO, G.A.D.C. The vegetation of the Alto Ribeira Touristic State Park (PETAR), São Paulo, Brazil. Biota Neotrop. 12(1): http://www.biotaneotropica.org.br/v12n1/en/abstract?inv entory+bn01911032011

\begin{abstract}
The Alto Ribeira Touristic State Park (PETAR) is part of the ecological continuum of the Paranapiacaba Range, one of the most preserved sites of the Atlantic Forest in São Paulo State. However, studies exploring its floristic structure and compostition are rare. The objective of this study was to map the vegetation and characterize the flora of the different vegetation types of PETAR to contribute to its management plan. Aerial photographs were used to produce a general and a detailed map of the park. Data collected through field surveys were combined with secondary data to characterize PETAR's flora. It was found that the Ombrophilous Dense Forest is the predominant vegetation type in PETAR (65\%), which mostly occurs at elevations that correspond to the Montane (78.2\%) and Lower Montane $(19.4 \%)$ types. There are also areas of High Montane $(0.1 \%)$ and Alluvial vegetation $(1.7 \%)$. The Ombrophilous Open Forest with bamboos, where large patches of bamboos have replaced the tall closed forest, occurs in approximately $13 \%$. Sites of secondary vegetation, which have been regenerating after past clearcuts comprise about $17 \%$. The detailed map showed 12 different vegetation types, which were characterized according to vegetation height and density of cover. The most perserved sites, characterized by tall trees and a closed canopy structure, comprised about $37 \%$ of the park's vegetated area. Primary and secondary data were pooled and resulted in a list of 680 native plant species, with the field surveys adding 162 new records for the park. It was found that 40 species belong to some category of threat according to the official red lists of São Paulo State, Brazil, and of the world. Forty-four exotic species were identified, of which 14 were classified as invasive.
\end{abstract}

Keywords: flora, Ombrophilous Dense Forest, Atlantic Forest, Paranapiacaba Range, karst

IVANAUSKAS, N.M., MIASHIKE, R.L., GODOY, J.R.L, SOUZA, F.M., KANASHIRO, M.M., MATTOS, I.F.A., TONIATO, M.T.Z. \& FRANCO, G.A.D.C. A vegetação do Parque Estadual Turístico do Alto Ribeira (PETAR), São Paulo, Brasil. Biota Neotrop. 12(1): http://www.biotaneotropica.org.br/v12n1/pt/abstract?inve ntory+bn01911032011

Resumo: O Parque Estadual Turístico do Alto Ribeira (PETAR) faz parte do contínuo ecológico de Paranapiacaba, um dos trechos mais bem conservados de Floresta Atlântica no estado de São Paulo. Entretanto, há pouquíssimos estudos sobre a composição florística e a estrutura da vegetação dessa área, que apresenta peculiaridades como a localização sobre regiões cársticas. O objetivo deste trabalho foi mapear a vegetação e caracterizar a flora das diferentes fitofisionomias existentes no PETAR, a fim de fornecer subsídios para a elaboração do seu plano de manejo. Para isso, fez-se o mapeamento geral e detalhado do Parque por meio de interpretação de fotografias aéreas, além de levantamentos de campo e de dados secundários para a caracterização da flora. No PETAR, predomina a Floresta Ombrófila Densa (65\%), com a maior parte ocorrendo nas cotas altitudinais correspondentes à Montana $(78,2 \%)$ e Submontana $(19,4 \%)$, sendo encontradas também pequenas áreas de Floresta Ombrófila Densa Alto-montana $(0,1 \%)$ e Aluvial (1,7\%). Aproximadamente $13 \%$ são ocupados por Floresta Ombrófila Aberta com bambus, onde a vegetação arbórea de porte alto dá lugar a grandes manchas de bambu e pouca regeneração natural. Trechos de vegetação secundária, que sofreram corte raso e encontram-se em regeneração, somam cerca de $17 \%$. No detalhamento, foram mapeados 12 tipos vegetacionais, subdivididos de acordo com o porte e a densidade da cobertura vegetal. Os trechos mais conservados, com vegetação de porte arbóreo alto e estrutura de dossel fechado, compreendem aproximadamente $37 \%$ da área vegetada do Parque. A união dos registros de campo com os dados secundários resultou em uma lista de 680 espécies de plantas nativas, sendo que o levantamento de campo acrescentou 162 novos registros para o Parque. Quarenta espécies encontram-se em alguma das categorias de ameaça das listas oficiais de espécies ameaçadas de extinção no estado de São Paulo, no Brasil e no mundo. Foram identificadas 44 espécies exóticas, das quais 14 foram consideradas invasoras. Palavras-chave: flora, Floresta Ombrófila Densa, Mata Atlântica, Serra de Paranapiacaba, carste. 


\section{Introdução}

No Brasil, apenas 9,3 dos 11,73\% de vegetação que ainda restam da Mata Atlântica têm a sua proteção garantida em unidades de conservação (UC) de proteção integral (Ribeiro et al. 2009). Um dos trechos mais bem conservados é o contínuo ecológico de Paranapiacaba, formado pelo Parque Estadual Turístico do Alto Ribeira (PETAR), Parque Estadual Carlos Botelho (PECB), Parque Estadual Intervales (PEI) e Estação Ecológica de Xitué (EEcX). Esse conjunto de unidades de conservação soma cerca de 120.000 ha (Souza et al. 2006), compondo uma das sete maiores áreas contínuas de Mata Atlântica identificadas no país (Ribeiro et al. 2009).

Apenas no sudeste do estado de São Paulo e nordeste do Paraná, na região do Vale do Ribeira e Alto Paranapanema, são encontradas áreas de Floresta Ombrófila Densa sobre regiões cársticas, com destaque para o Parque Estadual Turístico do Alto Ribeira (PETAR), o Parque Estadual Intervales e o Parque Estadual Caverna do Diabo. Dentre estes, o PETAR é reconhecido internacionalmente pelo número, beleza e complexidade das suas cavernas: até o momento foram levantadas mais de 400 cavernas, compondo cerca de $80 \mathrm{~km}$ subterrâneos, em fase de desenvolvimento há aproximadamente 1,7 milhões de anos (Karmann 1994). O PETAR situa-se em uma área montanhosa, com dolinas, paredões rochosos, cones cársticos, rios subterrâneos e lápies em relevos cársticos e com montanhas onduladas sobre granitos intrusivos e filitos (Aidar 2000, Godoy 2001). As lentes de calcário apresentam geomorfologia diferenciada e originam solos mais férteis, com altos teores de cálcio e magnésio, mas pouco profundos e que dão origem a florestas diferenciadas do padrão encontrado sobre os solos mais ácidos, menos férteis e com teores de alumínio mais elevados, característicos das encostas da Serra do Mar (Aidar et al. 2001, Godoy 2001).

A presença de áreas contíguas com vegetação em bom estado de conservação no contínuo ecológico de Paranapiacaba se deve à dificuldade de ocupação humana em decorrência de condições físico-climáticas desfavoráveis na região, como relevo montanhoso, declividades acentuadas, solos pobres em nutrientes e clima superúmido (Aidar 2000). Ocupadas sobretudo pela Floresta Ombrófila Densa, essas áreas merecem atenção especial para a conservação da biodiversidade brasileira, pois este tipo de floresta contém mais da metade da riqueza $(60 \%)$ e a maior parte dos endemismos (80\%) encontrados na Mata Atlântica lato sensu (Stehmann et al. 2009). Além disso, a região do Vale do Ribeira e Alto Paranapanema permanece fora dos principais eixos de desenvolvimento econômico paulista, com predominância de população rural sobre a urbana e os piores índices de desenvolvimento humano do estado de São Paulo. Nessa região, estão abrigadas comunidades com evidências de tradicionalidade de grande valor sociocultural e histórico (ex.: quilombolas) e, ao mesmo tempo, em situação de extrema pobreza, com baixa dinâmica econômica resultante dos altos índices de vulnerabilidade social (Fogaça et al. 2010). Diante das limitações socioeconômicas e das restrições ambientais, o turismo representa importante papel para o Vale do Ribeira e Alto Paranapanema, desde que sejam compatibilizadas as ações de conservação e o desenvolvimento regional. Nesse contexto, a necessidade de planejamento se faz premente, de forma a ordenar o uso do território pelos diferentes públicos (Magro et al. 2010).

$\mathrm{O}$ uso da área e o manejo dos recursos naturais de qualquer unidade de conservação são regulamentados pelo seu plano de manejo, documento que fornece um diagnóstico multidisciplinar para orientar a gestão. A caracterização da vegetação é um dos elementos fundamentais do plano, uma vez que ela constitui a grande unidade da paisagem na qual se inserem todos os demais seres vivos que também devem ser protegidos. É com base no mapeamento da vegetação e em suas características que se realizam as propostas de zoneamento da UC, determinando as classes de uso e conservação em suas diferentes porções. Diante da importância desse conhecimento para promover a conservação da biodiversidade de forma eficiente e em harmonia com as demais atividades de uma UC, este trabalho teve como objetivo mapear a vegetação e caracterizar a flora das diferentes fitofisionomias existentes no PETAR, a fim de fornecer subsídios para a elaboração do seu plano de manejo.

\section{Métodos}

\section{1. Área de estudo}

O PETAR possui uma área de $35.884,28$ ha e abrange parte dos municípios de Iporanga, Apiaí e Guapiara, na região sul do estado

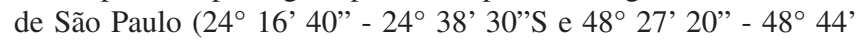
00" O; Figura 1). Localizado em uma região de confluência de vários sistemas de circulação atmosférica (atlântico, polar, tropical), o PETAR tem seu clima classificado, segundo o sistema de Köppen (1948), como Cfb-Subtropical úmido sem estação seca e com verão fresco, com a temperatura média do mês mais frio menor que $18^{\circ} \mathrm{C}$ e a temperatura média do mês mais quente superior a $22^{\circ} \mathrm{C}$ (SMA, não publicado). Dados de precipitação para a região de Iporanga indicam uma média anual variando de 1.500 a $2.000 \mathrm{~mm}$, com a maior precipitação média mensal ocorrendo no mês de janeiro e a menor em agosto (Lepsch et al. 1990).

O PETAR encontra-se em uma área de relevo montanhoso com grande amplitude altitudinal, variando de 80 a $1.146 \mathrm{~m}$. O relevo pode apresentar formas mais arredondadas sobre granitos intrusivos e filitos, ou mais dissecadas nas áreas sobre calcário, caracterizando um relevo residual cárstico (Godoy 2001). O calcário decompõe-se facilmente com a umidade dos climas tropicais, restando apenas as partes mais duras sob a forma de rocha, formando cones cársticos, declividades exageradamente acentuadas, pronunciados sulcos, e cristas e platôs na meia encosta. Depressões circulares, ou dolinas, com até $150 \mathrm{~m}$ de profundidade podem se formar devido a escavações causadas pelas correntes subterrâneas (Walter 1986; Baillie 1996). Devido à presença de grandes porções de rochas calcárias, porosas e de fácil dissolução ou desgaste pela água em conjunto com ácidos orgânicos e inorgânicos, o Parque apresenta um expressivo número de cavernas. Os solos predominantes são os Cambissolos háplicos, seguidos de Neossolos litólicos e Latossolos (Vermelho, Amarelo e Vermelho-Amarelo), ocorrendo em menores proporções os Argissolos amarelos e os Gleissolos (Rossi \& Pires-Neto 2010).

\section{Mapeamento da vegetação e caracterização da flora}

Para o mapeamento da vegetação foram utilizadas fotografias aéreas verticais em colorido natural, na escala aproximada de 1:35.000, realizadas pela AEROCARTA-BASE-ENGEFOTO para a SMASP-PPMA-KFW em 2000/2001, e o mosaico aerofotogramétrico digital do mesmo vôo. Foram utilizadas também as fotografias do vôo aerofotogramétrico do Litoral Sul na mesma escala, realizadas pela Terrafoto S.A. para a CESP, e a imagem do satélite SPOT 4 de 2005, com resolução de $5 \times 5 \mathrm{~m}$, para atualização das informações obtidas pela fotointerpretação das fotografias de 2000/2001. A análise das fotografias foi realizada com base nos procedimentos adotados por Lueder (1959) e Spurr (1960), que identificam e classificam a vegetação utilizando os elementos da imagem fotográfica como cor, tonalidade, textura, entre outros. A observação de atributos como porte, densidade da vegetação e abundância de bambus complementaram essa análise e orientaram a definição das manchas de vegetação, possibilitando a realização de um mapeamento detalhado. As informações foram digitalizadas e transportadas para as bases cartográficas digitais de 


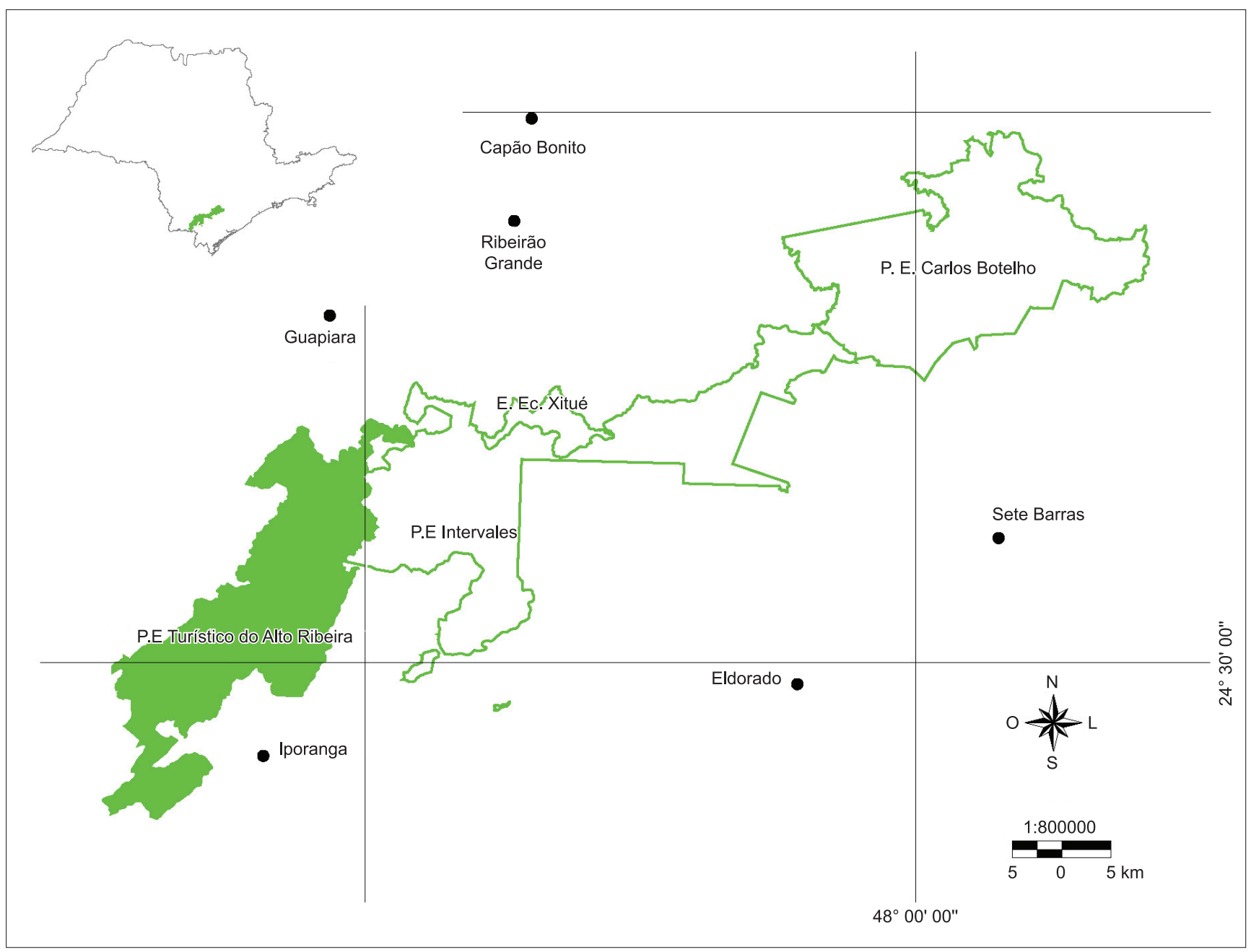

Figura 1. Localização do Parque Estadual Turístico do Alto Ribeira, na região do contínuo ecológico da Serra de Paranapiacaba, estado de São Paulo.

Figure 1. Location of the Alto Ribeira Touristic State Park in the region of the ecological continuum of the Paranapiacaba Range, São Paulo State, Brazil.

Mina do Espírito Santo (SG-22-X-B-II-4) - 1974, Ribeirão Itacolomi (SG-22-X-B-III-3) - 1974 e Iporanga (SG-22-X-B-V-2) - 1987, do Instituto Brasileiro de Geografia e Estatística (IBGE), elaborando-se, assim, um mapa preliminar. Durante os trabalhos de campo, fez-se a verificação dos padrões estabelecidos pela fotointerpretação, apontando-se eventuais divergências para a realização de ajustes e elaboração do mapa final. O sistema de classificação da vegetação utilizado foi o de Veloso et al. (1991).

O levantamento das espécies de plantas vasculares foi feito unindo-se dados secundários e dados obtidos em campo. Para a obtenção de dados secundários, foram consultados estudos florísticos ou fitossociológicos desenvolvidos no Parque, incluindo-se artigos científicos, dissertações e teses. Também foram incluídos os registros informatizados das exsicatas depositadas em herbários e disponíveis nas bases de dados SpeciesLink (2010) e SinBiota (Sistema de Informação Ambiental do BIOTA 2010). Os dados foram obtidos diretamente no material impresso ou online, não tendo sido feita a verificação do material testemunho. Apenas as identificações com binômio completo foram consideradas. Para a inclusão das citações provenientes dos registros de herbários, foram utilizados também os seguintes critérios: a) exsicatas certamente registradas dentro dos limites do Parque (coletas com coordenadas geográficas); b) registros que continham, em algum dos campos (ex.: localidade e notas), informações de que a coleta havia sido realizada dentro do
Parque; c) coletas nos municípios de Apiaí e Iporanga, admitindo-se que provavelmente a UC tenha sido a área preferencial para coletas botânicas nos municípios abrangidos pelo Parque e que a ausência ou imprecisão de coordenadas se deva ao fato de serem coletas antigas ou a falhas de equipamento.

O levantamento de campo foi feito percorrendo-se 22 trilhas em quatro viagens, com duração total de 26 dias. As trilhas estavam distribuídas por cinco núcleos do Parque (Tabela 1), de forma a abranger a maior variedade de fitofisionomias possível. Ao longo do caminho foram amostrados predominantemente os indivíduos arbustivos e arbóreos. O material botânico coletado foi identificado por meio de comparação com exsicatas existentes em herbários, com o uso de bibliografia específica ou por consulta a especialistas. Após a identificação, o material fértil foi incorporado ao herbário $\mathrm{D}$. Bento Pickel, do Instituto Florestal (SPSF). A classificação em família das plantas Psilotopsida, Equisetopsida, Marattiopsida e Polypodiopsida seguiu a proposta de Smith et al. (2006). Em relação às plantas Spermatophyta, para as Magnoliophyta (Angiospermas) foi utilizado como base o trabalho de Souza \& Lorenzi (2008) com atualização das famílias de acordo com a publicação do APGIII (Angiosperm Phylogeny Group III 2009) e, para as Pinophyta (Gimnospermas), as famílias seguiram os nomes classicamente encontrados na literatura. A lista final de espécies, resultante da união dos dados primários e secundários, seguiu a grafia e sinonimização do Catálogo de Plantas e 
Ivanauskas, N.M. et al.

Tabela 1. Trilhas percorridas para o levantamento da vegetação no Parque Estadual Turístico do Alto Ribeira, estado de São Paulo.

Table 1. Trails sampled for the vegetation survey in the Alto Ribeira Touristic State Park, São Paulo State, Brazil.

\begin{tabular}{|c|c|c|c|c|}
\hline \multirow[t]{2}{*}{ Núcleo } & \multirow[t]{2}{*}{ Código } & \multirow[t]{2}{*}{ Trilha } & \multicolumn{2}{|c|}{ Latitude (S)/Longitude (W) } \\
\hline & & & Início & Fim* \\
\hline \multirow[t]{3}{*}{ Bulha d'água } & 1 & Estrada & $24^{\circ} 20^{\prime} 12^{\prime \prime} ; 48^{\circ} 30^{\prime} 04^{\prime \prime}$ & $24^{\circ} 19^{\prime} 23^{\prime \prime} ; 48^{\circ} 30^{\prime} 30^{\prime \prime}$ \\
\hline & 2 & Trilha do Bueno & $24^{\circ} 20^{\prime} 01^{\prime \prime} ; 48^{\circ} 30^{\prime} 16^{\prime \prime}$ & $24^{\circ} 20^{\prime} 23^{\prime \prime} ; 48^{\circ} 30^{\prime} 41^{\prime \prime}$ \\
\hline & 3 & Cachoeira do Pilões & $24^{\circ} 20^{\prime} 13^{\prime \prime} ; 48^{\circ} 30^{\prime} 03^{\prime \prime}$ & $24^{\circ} 20^{\prime} 29^{\prime \prime} ; 48^{\circ} 30^{\prime} 01^{\prime \prime}$ \\
\hline \multirow[t]{2}{*}{ Areado } & 4 & Serra do Facão & $24^{\circ} 20^{\prime} 01^{\prime \prime} ; 48^{\circ} 36^{\prime} 16^{\prime \prime}$ & $24^{\circ} 20^{\prime} 27^{\prime \prime} ; 48^{\circ} 35^{\prime} 23^{\prime \prime}$ \\
\hline & 5 & Ribeirão Bonito & $24^{\circ} 19^{\prime} 43^{\prime \prime} ; 48^{\circ} 35^{\prime} 07^{\prime \prime}$ & $24^{\circ} 20^{\prime} 04^{\prime \prime} ; 48^{\circ} 34^{\prime} 48^{\prime \prime}$ \\
\hline \multirow[t]{9}{*}{ Caboclos } & 6 & Araucária & $24^{\circ} 24^{\prime} 30^{\prime \prime} ; 48^{\circ} 34^{\prime} 29^{\prime \prime}$ & $24^{\circ} 24^{\prime} 30^{\prime \prime} ; 48^{\circ} 34^{\prime} 24^{\prime \prime}$ \\
\hline & 7 & Água Sumida & $24^{\circ} 27^{\prime} 03^{\prime \prime} ; 48^{\circ} 35^{\prime} 48^{\prime \prime}$ & $24^{\circ} 27^{\prime} 11^{\prime \prime} ; 48^{\circ} 36^{\prime} 04^{\prime \prime}$ \\
\hline & 8 & Casa de Pedra & $24^{\circ} 26^{\prime} 57^{\prime \prime} ; 48^{\circ} 35^{\prime} 10^{\prime \prime}$ & $24^{\circ} 27^{\prime} 46^{\prime \prime} ; 48^{\circ} 35^{\prime} 04^{\prime \prime}$ \\
\hline & 9 & Chapéu & $24^{\circ} 26^{\prime} 03^{\prime \prime} ; 48^{\circ} 35^{\prime} 07^{\prime \prime}$ & $24^{\circ} 26^{\prime} 05^{\prime \prime} ; 48^{\circ} 35^{\prime} 25^{\prime \prime}$ \\
\hline & 10 & Pedra do Chapéu & $24^{\circ} 25^{\prime} 28^{\prime \prime} ; 48^{\circ} 34^{\prime} 41^{\prime \prime}$ & $24^{\circ} 25^{\prime} 10^{\prime \prime} ; 48^{\circ} 34^{\prime} 51^{\prime \prime}$ \\
\hline & 11 & Pescaria e Desmoronada & $24^{\circ} 25^{\prime} 00^{\prime \prime} ; 48^{\circ} 34^{\prime} 15^{\prime \prime}$ & $24^{\circ} 24^{\prime} 32^{\prime \prime} ; 48^{\circ} 33^{\prime} 28^{\prime \prime}$ \\
\hline & 12 & Temimina & $24^{\circ} 24^{\prime} 30^{\prime \prime} ; 48^{\circ} 34^{\prime} 29^{\prime \prime}$ & $24^{\circ} 23^{\prime} 25^{\prime \prime} ; 48^{\circ} 34^{\prime} 16^{\prime \prime}$ \\
\hline & 13 & Transpetar & $24^{\circ} 26^{\prime} 40^{\prime \prime} ; 48^{\circ} 37^{\prime} 01^{\prime \prime}$ & $24^{\circ} 27^{\prime} 25^{\prime \prime} ; 48^{\circ} 37^{\prime} 55^{\prime \prime}$ \\
\hline & 14 & Estrada & $24^{\circ} 23^{\prime} 55^{\prime \prime} ; 48^{\circ} 36^{\prime} 11^{\prime \prime}$ & $24^{\circ} 24^{\prime} 30^{\prime \prime} ; 48^{\circ} 34^{\prime} 29^{\prime \prime}$ \\
\hline \multirow[t]{5}{*}{ Santana } & 15 & Laje Branca & $24^{\circ} 33^{\prime} 01^{\prime \prime} ; 48^{\circ} 43^{\prime} 07^{\prime \prime}$ & $24^{\circ} 33^{\prime} 04^{\prime \prime} ; 48^{\circ} 43^{\prime} 20^{\prime \prime}$ \\
\hline & 16 & Serra da Jaguatirica** & $24^{\circ} 33^{\prime} 50^{\prime \prime} ; 48^{\circ} 41^{\prime} 15^{\prime \prime}$ & $24^{\circ} 33^{\prime} 52^{\prime \prime} ; 48^{\circ} 41^{\prime} 14^{\prime \prime}$ \\
\hline & 17 & Trilha da Onça Parda & $24^{\circ} 31^{\prime} 06^{\prime \prime} ; 48^{\circ} 40^{\prime} 19^{\prime \prime}$ & $24^{\circ} 30^{\prime} 53^{\prime \prime} ; 48^{\circ} 39^{\prime} 51^{\prime \prime}$ \\
\hline & 18 & Santana & $24^{\circ} 32^{\prime} 00^{\prime \prime} ; 48^{\circ} 42^{\prime} 07^{\prime \prime}$ & $24^{\circ} 32^{\prime} 05^{\prime \prime} ; 48^{\circ} 42^{\prime} 08^{\prime \prime}$ \\
\hline & 19 & Betari & $24^{\circ} 31^{\prime} 59^{\prime \prime} ; 48^{\circ} 42^{\prime} 04^{\prime \prime}$ & $24^{\circ} 31^{\prime} 49^{\prime \prime} ; 48^{\circ} 42^{\prime} 19^{\prime \prime}$ \\
\hline \multirow[t]{3}{*}{ Ouro Grosso } & 20 & Trilha do Camargo & $24^{\circ} 32^{\prime} 39^{\prime \prime} ; 48^{\circ} 39^{\prime} 17^{\prime \prime}$ & $24^{\circ} 31^{\prime} 41^{\prime \prime} ; 48^{\circ} 38^{\prime} 38^{\prime \prime}$ \\
\hline & 21 & Lapias & $24^{\circ} 32^{\prime} 42^{\prime \prime} ; 48^{\circ} 40^{\prime} 51^{\prime \prime}$ & $24^{\circ} 32^{\prime} 41^{\prime \prime} ; 48^{\circ} 40^{\prime} 49^{\prime \prime}$ \\
\hline & 22 & Garrafão da Ouro Grosso & $24^{\circ} 32^{\prime} 42^{\prime \prime} ; 48^{\circ} 40^{\prime} 51^{\prime \prime}$ & $24^{\circ} 32^{\prime} 23^{\prime \prime} ; 48^{\circ} 40^{\prime} 28^{\prime \prime}$ \\
\hline
\end{tabular}

*Fim do trecho percorrido na trilha; **Entorno do Parque.

Fungos do Brasil (Forzza et al. 2010), ou ainda dos volumes da Flora Fanerogâmica do Estado de São Paulo (Wanderley et al. 2001, 2002, 2003, 2005, 2007, 2009), do banco de dados do Missouri Botanical Garden (Tropicos 2010) e do catálogo mundial de espécies conhecidas (Bisby et al. 2010).

Com base na lista contendo os dados primários e secundários foram destacadas as espécies ameaçadas e exóticas registradas no interior do Parque. As listas oficiais das espécies vegetais ameaçadas de extinção utilizadas para consulta foram: a) Lista oficial de espécies ameaçadas de extinção no estado de São Paulo (Mamede et al. 2007); b) Lista oficial das espécies da flora brasileira ameaçada de extinção (Brasil 2008); c) Lista vermelha de espécies ameaçadas de extinção globalmente (International Union for Conservation of Nature 2008). Foram consideradas como espécies exóticas aquelas de ocorrência fora dos limites geográficos historicamente reconhecidos (Ziller 2001). Já como espécies-problema foram consideradas as espécies nativas e/ou exóticas que formassem populações fora de seu sistema normal ou fora de seu tamanho desejável (Moreira \& Piovezan 2005). A primeira situação refere-se às populações que, mesmo em seu estado normal e estável, não são desejáveis num determinado local e exigem manejo contínuo, situação frequente entre as espécies exóticas que invadem áreas naturais. Já a segunda situação trata da necessidade de controle de uma população que apresenta uma explosão em densidade ou biomassa e, portanto, se encontra fora de sua estabilidade natural. Em sua maior parte, as espécies nativas causam problemas desse tipo e a ação de manejo necessária é temporária, pois visa apenas restabelecer o estado normal dessa população.

As espécies com potencial invasor foram identificadas com base na lista do Instituto Hórus (Instituto 2011). Para avaliar a situação da invasão foram utilizadas as seguintes classes (Zalba 2005):
1 - presente: encontrada em ambiente natural, porém ainda sem descendência ou dispersão aparente; 2 - estabelecida: quando está se reproduzindo localmente, com descendência; 3 - invasora: quando se expande a partir do ponto inicial e está em processo de dispersão.

\section{Resultados}

\section{Fitofisionomias existentes no PETAR}

No PETAR predomina a Floresta Ombrófila, da qual cerca de $65 \%$ (23.218,37 ha) estão representados pela Floresta Ombrófila Densa e 13,3\% (4.774,57 ha) por áreas de Floresta Ombrófila Aberta com bambu. Aproximadamente 17\% (6.112,24 ha) são ocupados por vegetação secundária e o restante da área, por outros tipos de cobertura, como campo antrópico, afloramentos de rocha, uso antrópico, entre outros (Figuras 2 e 3, Tabela 2).

De acordo com o sistema de classificação da vegetação de Veloso et al. (1991), a separação entre as formações se dá de acordo com uma combinação entre os limites altitudinais e a latitude do local. No PETAR, onde a latitude do extremo norte é de $24^{\circ} \mathrm{S}$, a Floresta Ombrófila está representada pelas formações Alto-montana (em cotas altitudinais superiores a $1.000 \mathrm{~m}$ ), Montana (entre 400 e $1.000 \mathrm{~m}$ ) e Submontana (entre 30 e $400 \mathrm{~m}$ ), além da formação Aluvial, que ocorre ao longo dos cursos d'água (Figura 2, Tabela 2).

Embora a presença de Floresta Ombrófila Densa Alto-montana $(0,1 \%)$ tenha sido identificada pelo mapeamento considerando as cotas altitudinais definidas por Veloso et al. (1991), não foi possível realizar o levantamento em nenhum trecho dessa formação, devido às dificuldades de acesso. A Floresta Ombrófila Densa Montana é a formação florestal predominante no Parque $(78,2 \%)$ e a Floresta 


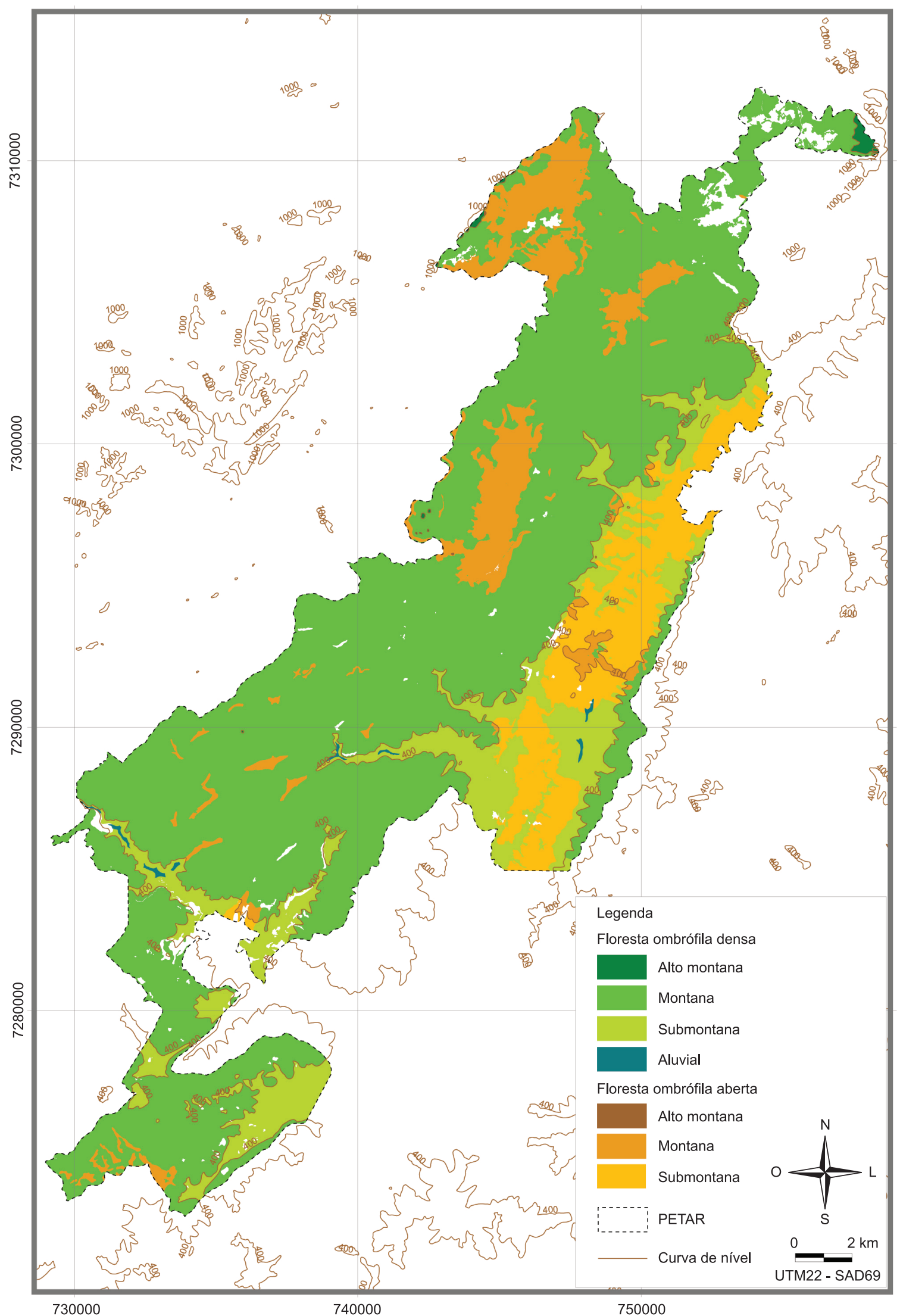

Figura 2. Tipos vegetacionais presentes no Parque Estadual Turístico do Alto Ribeira, estado de São Paulo, de acordo com Veloso et al. (1991).

Figure 2. Vegetation types that occur in the Alto Ribeira Touristic State Park, São Paulo State, Brazil, according to Veloso et al. (1991). 


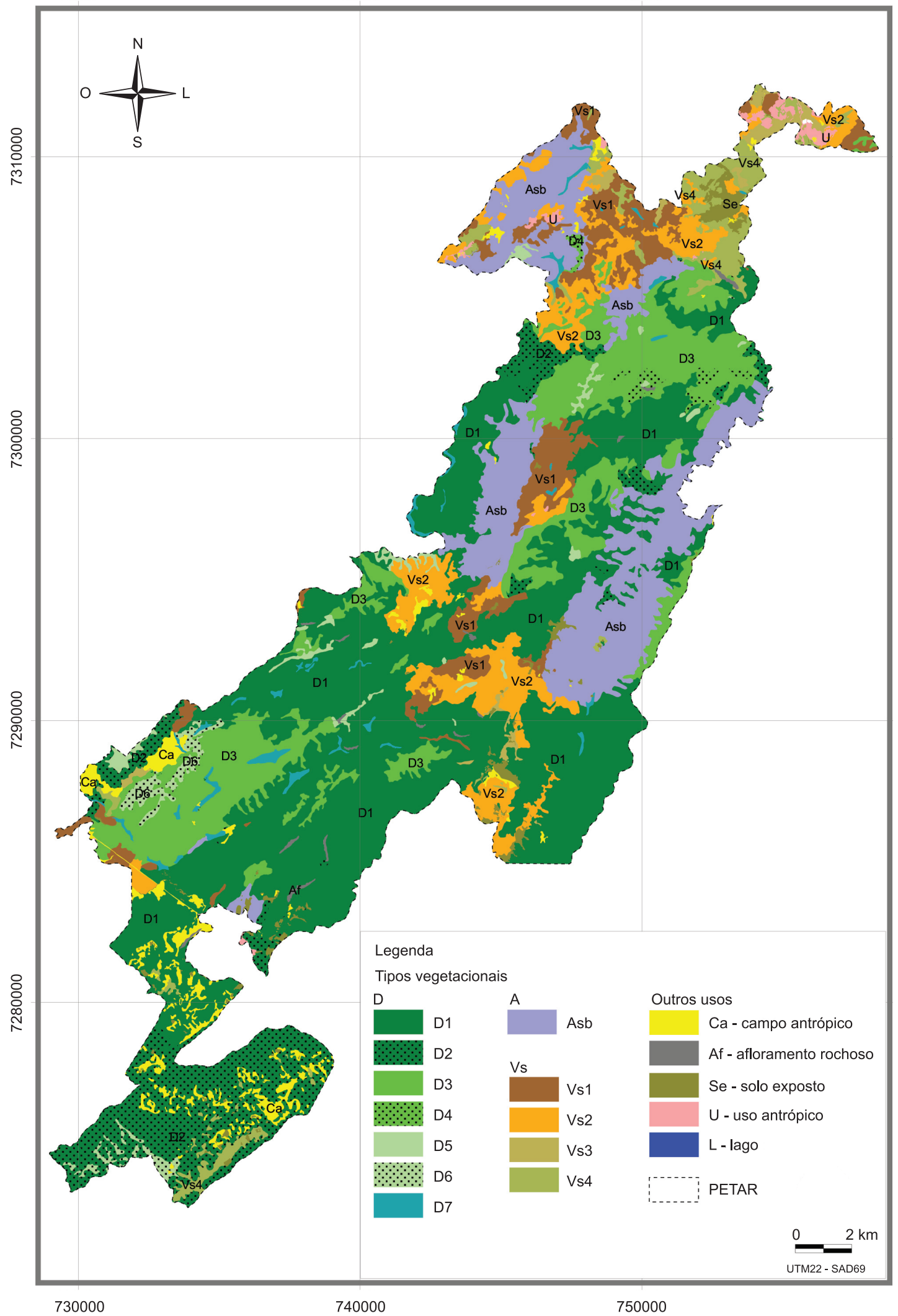

Figura 3. Mapa detalhado da vegetação do Parque Estadual Turístico do Alto Ribeira, estado de São Paulo. Os códigos da legenda correspondem aos da Tabela 2. Figure 3. Detailed map of the vegetation in the Alto Ribeira Touristic State Park, São Paulo State, Brazil. Legend codes are the same as Table 2. 
Tabela 2. Fitofisionomias mapeadas no Parque Estadual Turístico do Alto Ribeira, estado de São Paulo.

Table 2. Phytophysiognomies mapped in the Alto Ribeira Touristic State Park, São Paulo State, Brazil.

\begin{tabular}{|c|c|c|c|c|c|c|c|c|c|}
\hline \multirow[t]{2}{*}{ Código } & \multirow[t]{2}{*}{ Porte } & \multirow[t]{2}{*}{ Cobertura } & \multirow[t]{2}{*}{ Observações } & \multicolumn{4}{|c|}{ Área (ha) } & \multicolumn{2}{|c|}{ Área total } \\
\hline & & & & & & & & (ha) & $(\%)$ \\
\hline \multicolumn{4}{|c|}{ Floresta Ombrófila Densa } & Altomontana & Montana & Submontana & Aluvial & & \\
\hline D1 & alto & dossel fechado & - & 4,52 & 9878,70 & 3307,67 & - & 13190,89 & 36,8 \\
\hline D2 & alto & dossel fechado & $\begin{array}{c}\text { Algumas alterações } \\
\text { antrópicas }\end{array}$ & - & 2512,20 & 780,92 & - & 3448,26 & 9,6 \\
\hline D3 & médio & dossel fechado & $\begin{array}{l}\text { Situa-se nos topos } \\
\text { dos interflúvios }\end{array}$ & 16,07 & 4867,90 & 361,81 & - & 5245,78 & 14,6 \\
\hline D4 & médio & dossel aberto & $\begin{array}{l}\text { Algumas alterações } \\
\text { antrópicas; topos } \\
\text { dos interflúvios }\end{array}$ & - & 172,67 & 42,47 & - & 215,14 & 0,6 \\
\hline D5 & baixo & dossel fechado & $\begin{array}{l}\text { Situa-se sobre } \\
\text { solos rasos, nos } \\
\text { topos em cristas }\end{array}$ & - & 352,20 & 4,43 & - & 356,63 & 1,0 \\
\hline D6 & baixo & dossel fechado & - & - & 377,35 & & - & 377,35 & 1,1 \\
\hline D7 & médio a alto & dossel aberto & $\begin{array}{c}\text { Situa-se nas } \\
\text { planícies fluviais } \\
\text { restritas } \\
\end{array}$ & - & - & - & 384,32 & 384,32 & 1,1 \\
\hline \multicolumn{10}{|c|}{ Floresta Ombrófila Aberta com bambu } \\
\hline Asb & alto & dossel aberto & $\begin{array}{l}\text { Fortemente alterado } \\
\text { em função da } \\
\text { presença abundante } \\
\text { de bambus }\end{array}$ & 1,33 & 2647,18 & 2126,06 & - & 4774,57 & 13,3 \\
\hline \multicolumn{10}{|c|}{ Vegetação secundária } \\
\hline Vs1 & médio a alto & dossel fechado & - & 46,69 & 1959,60 & 90,02 & - & 2096,31 & 5,8 \\
\hline Vs2 & médio a alto & dossel aberto & Forte alteração & 17,06 & 2061,10 & 576,13 & - & 2654,29 & 7,4 \\
\hline Vs3 & baixo & dossel fechado & - & - & 258,87 & 56,74 & - & 315,60 & 0,9 \\
\hline Vs4 & baixo & dossel aberto & Forte alteração & 0,39 & 926,78 & 118,85 & - & 1046,04 & 2,9 \\
\hline
\end{tabular}

Ombrófila Densa Submontana (19,4\%) ocupa sobretudo as áreas de fundo de vales dos grandes rios, como o Betari, Iporanga e Pilões (Figura 2). As áreas de Floresta Ombrófila Densa Aluvial (1,7\%) correspondem a áreas de inundação temporária situadas nas planícies fluviais.

Grande parte das áreas de Floresta Ombrófila Densa Submontana e Aluvial já sofreu corte raso e, portanto, foi classificada como vegetação secundária (Figura 3 - Vs) ou reenquadrada na categoria de Floresta Ombrófila Aberta com bambu (Asb). Foram mapeados como capoeirão (Veloso et al. 1991) os trechos de vegetação de porte arbóreo médio a alto, com estrutura de dossel fechado (Vs7) ou aberto (Vs8), em torno de $15 \mathrm{~m}$ de altura. Os trechos denominados de capoeira (Veloso et al. 1991) apresentaram vegetação de porte arbóreo mais baixo (cerca de $5 \mathrm{~m}$ ), com dossel aberto (Vs9) ou fechado (Vs10).

Apesar do predomínio da Floresta Ombrófila, trechos de Floresta Estacional Semidecidual estão presentes em encraves sobre os afloramentos de calcário e lápies. Apesar de reconhecida em campo, esta fitofisionomia não foi mapeada devido à ausência de imagens em escala ou período favoráveis para detectar a deciduidade do dossel e de informações sobre a localização precisa dos afloramentos de calcário e lápies.

No detalhamento, foram identificados e mapeados 12 tipos de vegetação natural, subdivididos de acordo com o porte e a densidade da cobertura florestal (Figura 3; Tabela 2). Os trechos florestais mais conservados de Floresta Ombrófila Densa Montana, caracterizados como vegetação de porte arbóreo alto, com estrutura de dossel fechado (Figura 3 - D1), compreendem aproximadamente 37\% da área vegetada do Parque. Trechos com esta mesma fisionomia, mas onde foi possível detectar alguma alteração de caráter antrópico, foram diferenciados pela presença de dossel aberto (D2). As florestas de porte médio, presentes próximas aos topos de morros, também foram separadas entre aquelas de dossel fechado (D3) ou aberto (D4). Foram identificadas ainda áreas com dossel fechado e árvores de porte baixo, ocorrendo parte nas cristas da serras (D5) ou nas demais regiões do Parque (D6), mas neste caso devido a escorregamentos naturais ou influência da ação humana.

\section{Composição florística}

Foram registradas 680 espécies de plantas nativas (Tabela 3), pertencentes a 357 gêneros e 120 famílias. As famílias mais ricas em espécies foram Myrtaceae (65 espécies), Fabaceae (46), Melastomataceae (39), Rubiaceae (35) e Asteraceae (31). Do total de espécies, 518 foram provenientes de dados secundários e 312 dos levantamentos de campo. O número de espécies comuns entre dados primários e secundários foi de 150, sendo que 162 espécies amostradas em campo (23,8\%) foram novas citações para o Parque.

Entre as espécies listadas para o PETAR, 40 estão presentes em uma ou mais listas de espécies ameaçadas de extinção (Tabela 4), das quais cinco são consideradas presumivelmente extintas, 21 ameaçadas de extinção (presentes na lista nacional ou pertencentes às categorias criticamente em perigo, em perigo ou vulneráveis), 11 com baixo risco de extinção (dependentes de conservação, quase ameaçadas ou com risco mínimo) e três com dados insuficientes para a sua categorização. As cinco espécies presumivelmente extintas de acordo com a lista de espécies ameaçadas no Estado de São Paulo são 
Tabela 3. Espécies de plantas nativas registradas no Parque Estadual Turístico do Alto Ribeira, estado de São Paulo. SPSF - Número do voucher depositado no Herbário do Instituto Florestal. Fonte de informação: P - Dados primários; S - Dados secundários. Forma de vida: árvore (Av); arbusto (Ab); subarbusto $(\mathrm{Sb})$; palmeira $(\mathrm{Pa})$; bambu $(\mathrm{Ba})$; feto arborescente $(\mathrm{Fa})$; erva terrestre ou aquática (Ev); trepadeira (Tr); epífita (Ep); hemiepífita (He). Os códigos da trilha correspondem aos da Tabela 1, onde constam as respectivas coordenadas geográficas.

Table 3. Native plant species recorded in the Alto Ribeira Touristic State Park, São Paulo State, Brazil. SPSF - Record number of the voucher specimens at the Forest Institute Herbarium. Information source: P - Primary data; S - Secondary data. Life form: tree (Av); shrub (Ab); subshrub (Sb); palm (Pa); bamboo (Ba); tree fern (Fa); terrestrial or aquatic herb (Ev); vine (Tr); epiphyte (Ep); hemiepiphyte (He). Trail codes correspond to those at Table 1, with the respective geographic coordinates.

\begin{tabular}{|c|c|c|c|c|c|c|}
\hline \multirow[t]{2}{*}{ Família } & \multirow[t]{2}{*}{ Espécie } & \multirow{2}{*}{$\begin{array}{l}\text { Forma } \\
\text { de vida }\end{array}$} & \multirow[t]{2}{*}{ SPSF } & \multicolumn{2}{|c|}{ FI } & \multirow[t]{2}{*}{ Trilha } \\
\hline & & & & $\mathbf{P}$ & $\mathbf{S}$ & \\
\hline Acanthaceae & Aphelandra chamissoniana Nees & $\mathrm{Sb}$ & & & $\bullet$ & \\
\hline Acanthaceae & Hygrophila costata Nees & Ev & & & $\bullet$ & \\
\hline Acanthaceae & Justicia carnea Lindl. & $\mathrm{Sb}$ & & $\bullet$ & $\bullet$ & $17,18,22$ \\
\hline Acanthaceae & Mendoncia velloziana Mart. & $\operatorname{Tr}$ & & & $\bullet$ & \\
\hline Acanthaceae & Ruellia brevifolia (Pohl) C.Ezcurra & $\mathrm{Sb}$ & & & $\bullet$ & \\
\hline Alismataceae & Echinodorus grandiflorus (Cham. \& Schltdl.) Micheli & Ev & & & $\bullet$ & \\
\hline Amaranthaceae & Celosia grandifolia Moq. & Ev & & & $\bullet$ & \\
\hline Amaranthaceae & Iresine diffusa Humb. \& Bonpl. ex Willd. & Ev & & & $\bullet$ & \\
\hline Alstroemeriaceae & Alstroemeria cunha Vell. & Ev & & & $\bullet$ & \\
\hline Amaryllidaceae & Hippeastrum aulicum Herb. & Ev & & & $\bullet$ & \\
\hline Anacardiaceae & Lithrea molleoides (Vell.) Engl. & Av & & & $\bullet$ & \\
\hline Anacardiaceae & Schinus terebinthifolius Raddi & $\mathrm{Av}$ & & $\bullet$ & & $4,5,8,11,14$ \\
\hline Anemiaceae & Anemia phyllitidis (L.) Sw. & Ev & & & $\bullet$ & \\
\hline Anemiaceae & Anemia raddiana Link & Ev & & & $\bullet$ & \\
\hline Annonaceae & Annona cacans Warm. & Av & & $\bullet$ & & 12 \\
\hline Annonaceae & Annona dolabripetala Raddi & Av & 43163,43166 & $\bullet$ & $\bullet$ & $1,2,4,7,8,9,11,14$ \\
\hline Annonaceae & Annona emarginata (Schltdl.) H.Rainer & Av & 43168,43165 & $\bullet$ & $\bullet$ & $8,10,11,12,19,22$ \\
\hline Annonaceae & Annona rugulosa (Schltdl.) H.Rainer & Av & & & $\bullet$ & \\
\hline Annonaceae & Annona sylvatica A. St.-Hil. & Av & 43167 & $\bullet$ & $\bullet$ & $1,5,7$ \\
\hline Annonaceae & Guatteria australis A. St.-Hil. & $\mathrm{Av}$ & & $\bullet$ & $\bullet$ & $1,4,8,9$ \\
\hline Annonaceae & Xylopia brasiliensis Spreng. & $\mathrm{Av}$ & & $\bullet$ & & 16,19 \\
\hline Apocynaceae & Aspidosperma cylindrocarpon Müll. Arg. & Av & & & $\bullet$ & \\
\hline Apocynaceae & Aspidosperma olivaceum Müll. Arg. & Av & 43171 & $\bullet$ & & 4,19 \\
\hline Apocynaceae & Aspidosperma polyneuron Müll. Arg. & Av & & & $\bullet$ & \\
\hline Apocynaceae & Aspidosperma tomentosum Mart. & Av & & $\bullet$ & & 19 \\
\hline Apocynaceae & Ditassa burchellii Hook. \& Arn. & $\operatorname{Tr}$ & & & $\bullet$ & \\
\hline Apocynaceae & Ditassa congesta E. Fourn. & $\operatorname{Tr}$ & & & $\bullet$ & \\
\hline Apocynaceae & Forsteronia refracta Müll. Arg. & $\operatorname{Tr}$ & & & $\bullet$ & \\
\hline Apocynaceae & Malouetia cestroides (Nees ex Mart.) Müll.Arg. & $\operatorname{Tr}$ & & $\bullet$ & $\bullet$ & $7,8,11,19$ \\
\hline Apocynaceae & Mandevilla pentlandiana (A. DC.) Woodson & $\operatorname{Tr}$ & & & $\bullet$ & \\
\hline Apocynaceae & Orthosia urceolata E. Fourn. & $\operatorname{Tr}$ & & & $\bullet$ & \\
\hline Apocynaceae & Oxypetalum pachyglossum Decne. & $\operatorname{Tr}$ & & & $\bullet$ & \\
\hline Apocynaceae & Rauvolfia sellowii Müll. Arg. & $\mathrm{Av}$ & 43170 & $\bullet$ & & 8,11 \\
\hline Apocynaceae & Tabernaemontana catharinensis A. DC. & $\mathrm{Av}$ & & & $\bullet$ & \\
\hline Apocynaceae & Tabernaemontana hystrix Steud. & $\mathrm{Av}$ & 43169 & $\bullet$ & & 1 \\
\hline Apocynaceae & Tabernaemontana laeta Mart. & $\mathrm{Av}$ & & $\bullet$ & & $7,8,9,11$ \\
\hline Aquifoliaceae & Ilex dumosa Reissek & $\mathrm{Av}$ & & & $\bullet$ & \\
\hline Aquifoliaceae & Ilex paraguariensis A. St.-Hil. & Av & $\begin{array}{c}43172,43173 \\
43174\end{array}$ & $\bullet$ & $\bullet$ & $4,5,14$ \\
\hline Aquifoliaceae & Ilex theezans Mart. ex Reissek & $\mathrm{Av}$ & & & $\bullet$ & \\
\hline Araceae & Anthurium sellowianum Kunth & Ep & & & $\bullet$ & \\
\hline Araceae & Philodendron glaziovii Hook. f. & $\mathrm{He}$ & & & $\bullet$ & \\
\hline Araceae & Philodendron loefgrenii Engl. & $\mathrm{He}$ & & & $\bullet$ & \\
\hline
\end{tabular}

*COELHO, R. L. G. , SOUZA, V. C. \& FERRUCCI, M. S. 2012 (no prelo). Matayba obovata, a new species of Matayba sect. Matayba (Sapindaceae) from Brazil. Brittonia (Bronx, N.Y.). 
Tabela 3. Continuação...

\begin{tabular}{|c|c|c|c|c|c|c|}
\hline \multirow[t]{2}{*}{ Família } & \multirow[t]{2}{*}{ Espécie } & \multirow{2}{*}{$\begin{array}{r}\text { Forma } \\
\text { de vida }\end{array}$} & \multirow[t]{2}{*}{ SPSF } & \multicolumn{2}{|c|}{ FI } & \multirow[t]{2}{*}{ Trilha } \\
\hline & & & & $\mathbf{P}$ & $\mathbf{S}$ & \\
\hline Araceae & Philodendron obliquifolium Engl. & $\mathrm{He}$ & & & $\bullet$ & \\
\hline Araceae & Philodendron propinquum Schott & $\mathrm{He}$ & & & $\bullet$ & \\
\hline Araliaceae & Oreopanax fulvus Marchal & $\mathrm{He}$ & 43175 & $\bullet$ & $\bullet$ & $\begin{array}{l}6,8,9,11,12,13 \\
14,16,20,21,22\end{array}$ \\
\hline Araliaceae & Schefflera angustissima (Marchal) Frodin & Av & & $\bullet$ & & $8,9,14,17$ \\
\hline Araliaceae & Schefflera calva (Cham.) Frodin \& Fiaschi & $\mathrm{Av}$ & & $\bullet$ & & $3,4,5,20$ \\
\hline Araliaceae & $\begin{array}{l}\text { Schefflera morototoni (Aubl.) Maguire, Steyerm. \& } \\
\text { Frodin }\end{array}$ & $\mathrm{Av}$ & & & $\bullet$ & \\
\hline Arecaceae & Bactris setosa Mart. & $\mathrm{Pa}$ & & $\bullet$ & & $4,5,10,17$ \\
\hline Arecaceae & Euterpe edulis Mart. & $\mathrm{Pa}$ & & $\bullet$ & $\bullet$ & $\begin{array}{c}1,2,3,5,6,7,8,9 \\
10,11,12,13,18 \\
19,20,21,22\end{array}$ \\
\hline Arecaceae & Geonoma elegans Mart. & $\mathrm{Pa}$ & & $\bullet$ & & $2,3,8,9,11,17,20$ \\
\hline Arecaceae & Geonoma gamiova Barb. Rodr. & $\mathrm{Pa}$ & & $\bullet$ & & $4,5,8,12$ \\
\hline Arecaceae & Geonoma schottiana Mart. & $\mathrm{Pa}$ & & $\bullet$ & & 2,4 \\
\hline Arecaceae & Syagrus romanzoffiana (Cham.) Glassman & $\mathrm{Pa}$ & & $\bullet$ & $\bullet$ & $\begin{array}{l}4,5,7,10,12,13,14 \\
16,17,18,20,21,22\end{array}$ \\
\hline Asteraceae & Achyrocline satureioides (Lam.) DC. & Ev & & & $\bullet$ & \\
\hline Asteraceae & Adenostemma brasilianum (Pers.) Cass. & Ev & & & $\bullet$ & \\
\hline Asteraceae & Baccharis retusa DC. & $\mathrm{Ab}$ & & & $\bullet$ & \\
\hline Asteraceae & Baccharis lateralis Baker & $\mathrm{Ab}$ & 43176,43179 & $\bullet$ & & 4,5 \\
\hline Asteraceae & Baccharis montana DC. & $\mathrm{Ab}$ & 43180 & $\bullet$ & & 4,5 \\
\hline Asteraceae & Baccharis spicata (Lam.) Baill. & $\mathrm{Ab}$ & & & $\bullet$ & \\
\hline Asteraceae & Bidens pilosa $\mathrm{L}$. & Ev & & & $\bullet$ & \\
\hline Asteraceae & Calea parvifolia (DC.) Baker & $\mathrm{Ab}$ & & & $\bullet$ & \\
\hline Asteraceae & $\begin{array}{l}\text { Chromolaena maximilianii (Schrad. ex DC.) R.M.King } \\
\& \text { H.Rob. }\end{array}$ & $\mathrm{Ab}$ & & & $\bullet$ & \\
\hline Asteraceae & Chromolaena squalida (DC.) R.M.King \& H.Rob. & $\mathrm{Ab}$ & & & $\bullet$ & \\
\hline Asteraceae & Critoniopsis quinqueflora (Less.) H.Rob. & $\mathrm{Ab}$ & 43183 & $\bullet$ & & 4 \\
\hline Asteraceae & Eclipta prostrata (L.) L. & Ev & & & $\bullet$ & \\
\hline Asteraceae & Elephantopus mollis Kunth & Ev & & & $\bullet$ & \\
\hline Asteraceae & Grazielia serrata (Spreng.) R.M.King \& H.Rob. & $\mathrm{Ab}$ & & & $\bullet$ & \\
\hline Asteraceae & Hebeclinium macrophyllum (L.) DC. & $\mathrm{Ab}$ & & & $\bullet$ & \\
\hline Asteraceae & Lepidaploa canescens (Kunth) H.Rob. & $\mathrm{Ab}$ & & & $\bullet$ & \\
\hline Asteraceae & Mikania sessilifolia DC. & $\operatorname{Tr}$ & & & $\bullet$ & \\
\hline Asteraceae & Piptocarpha axillaris (Less.) Baker & Av & & & $\bullet$ & \\
\hline Asteraceae & Piptocarpha macropoda (DC.) Baker & Av & 43178 & $\bullet$ & & $3,4,5$ \\
\hline Asteraceae & Piptocarpha rotundifolia (Less.) Baker & Av & & & $\bullet$ & \\
\hline Asteraceae & Piptocarpha sellowii (Sch. Bip.) Baker & $\operatorname{Tr}$ & & & $\bullet$ & \\
\hline Asteraceae & $\begin{array}{l}\text { Raulinoreitzia leptophlebia (B.L. Rob.) R.M. King } \\
\text { \& H. Rob. }\end{array}$ & Av & & & $\bullet$ & \\
\hline Asteraceae & $\begin{array}{l}\text { Symphyopappus itatiayensis (Hieron.) R.M. King \& } \\
\text { H. Rob. }\end{array}$ & $\mathrm{Av}$ & & & $\bullet$ & \\
\hline Asteraceae & Urolepis hecatantha (DC.) R.M. King \& H. Rob. & Ev & & & $\bullet$ & \\
\hline Asteraceae & Verbesina glabrata Hook. \& Arn. & $\mathrm{Ab}$ & & & $\bullet$ & \\
\hline Asteraceae & Vernonanthura crassa (Vell.) H. Rob. & $\mathrm{Ab}$ & & & $\bullet$ & \\
\hline Asteraceae & Vernonanthura divaricata (Spreng.) H.Rob. & Av & 43177 & $\bullet$ & & $4,5,8,9,10,13,17$ \\
\hline Asteraceae & Vernonanthura petiolaris (DC.) H. Rob. & Av & & & $\bullet$ & \\
\hline Asteraceae & Vernonanthura phosphorica (Vell.) H.Rob. & $\mathrm{Ab}$ & & & $\bullet$ & \\
\hline Asteraceae & Vernonanthura puberula (Less.) H.Rob. & $\mathrm{Av}$ & 43181,43182 & $\bullet$ & & $7,11,13$ \\
\hline
\end{tabular}

*COELHO, R. L. G. , SOUZA, V. C. \& FERRUCCI, M. S. 2012 (no prelo). Matayba obovata, a new species of Matayba sect. Matayba (Sapindaceae) from Brazil. Brittonia (Bronx, N.Y.). 
Tabela 3. Continuação...

\begin{tabular}{|c|c|c|c|c|c|c|}
\hline \multirow[t]{2}{*}{ Família } & \multirow[t]{2}{*}{ Espécie } & \multirow{2}{*}{$\begin{array}{l}\text { Forma } \\
\text { de vida }\end{array}$} & \multirow[t]{2}{*}{ SPSF } & \multicolumn{2}{|c|}{ FI } & \multirow[t]{2}{*}{ Trilha } \\
\hline & & & & $\mathbf{P}$ & $\mathbf{S}$ & \\
\hline Asteraceae & Vittetia orbiculata (DC.) R.M.King \& H.Rob. & $\mathrm{Ab}$ & & & $\bullet$ & \\
\hline Begoniaceae & Begonia bidentata Raddi & $\mathrm{Ev}$ & & & $\bullet$ & \\
\hline Begoniaceae & Begonia bradei Irmsch. & Ev & & & $\bullet$ & \\
\hline Begoniaceae & Begonia capanemae Brade & Ev & & & $\bullet$ & \\
\hline Begoniaceae & Begonia convolvulacea (Klotzsch) A. DC. & Ev & & & $\bullet$ & \\
\hline Begoniaceae & Begonia cucullata Willd. & Ev & & & $\bullet$ & \\
\hline Begoniaceae & Begonia fischeri Schrank & Ev & & & $\bullet$ & \\
\hline Begoniaceae & Begonia hirtella Link & Ev & & & $\bullet$ & \\
\hline Begoniaceae & Begonia hoehneana Irmsch. & Ev & & & $\bullet$ & \\
\hline Begoniaceae & Begonia incisoserrata A. DC. & Ev & & & $\bullet$ & \\
\hline Begoniaceae & Begonia juliana Loefgr. ex Irmsch. & Ev & & & $\bullet$ & \\
\hline Begoniaceae & Begonia paranaensis Brade & Ev & & & $\bullet$ & \\
\hline Begoniaceae & Begonia toledoana Handro & Ev & & & $\bullet$ & \\
\hline Berberidaceae & Berberis laurina Billb. & Av & & & $\bullet$ & \\
\hline Bignoniaceae & Jacaranda micrantha Cham. & $\mathrm{Av}$ & & $\bullet$ & $\bullet$ & $\begin{array}{c}1,3,4,5,8 \\
11,14,20,22\end{array}$ \\
\hline Bignoniaceae & Jacaranda puberula Cham. & Av & & & $\bullet$ & \\
\hline Bignoniaceae & Amphilophium crucigerum (L.) L.G.Lohmann & $\operatorname{Tr}$ & & & $\bullet$ & \\
\hline Bignoniaceae & Handroantus albus (Cham.) Mattos & Av & & $\bullet$ & & 4 \\
\hline Boraginaceae & Cordia ecalyculata Vell. & Av & & $\bullet$ & & 5 \\
\hline Boraginaceae & Cordia sellowiana Cham. & Av & & $\bullet$ & $\bullet$ & 19,22 \\
\hline Boraginaceae & Cordia trichotoma (Vell.) Arráb. ex Steud. & Av & & $\bullet$ & $\bullet$ & 1 \\
\hline Boraginaceae & Heliotropium transalpinum Vell. & $\mathrm{Ab}$ & & & $\bullet$ & \\
\hline Boraginaceae & Tournefortia aff. rubicunda Salzm. ex A.DC. & $\operatorname{Tr}$ & & & $\bullet$ & \\
\hline Bromeliaceae & Aechmea apocalyptica Reitz & Ep & & & $\bullet$ & \\
\hline Bromeliaceae & Aechmea cylindrata Lindm. & Ep & & & $\bullet$ & \\
\hline Bromeliaceae & Aechmea gracilis Lindm. & Ep & & & $\bullet$ & \\
\hline Bromeliaceae & Billbergia zebrina (Herb.) Lindl. & Ep & & & $\bullet$ & \\
\hline Bromeliaceae & Neoregelia marmorata (Baker) L.B.Sm. & Ep & & & $\bullet$ & \\
\hline Bromeliaceae & Nidularium jonesianum Leme & Ep & & & $\bullet$ & \\
\hline Bromeliaceae & Tillandsia geminiflora Brongn. & Ep & & & $\bullet$ & \\
\hline Bromeliaceae & Tillandsia linearis Vell. & Ep & & & $\bullet$ & \\
\hline Bromeliaceae & Vriesea carinata Wawra & Ep & & & $\bullet$ & \\
\hline Bromeliaceae & Vriesea ensiformes (Vell.) Beer & Ep & & & $\bullet$ & \\
\hline Bromeliaceae & Vriesea friburgensis Mez & Ep & & & $\bullet$ & \\
\hline Bromeliaceae & Vriesea incurvata Gaudich. & Ep & & & $\bullet$ & \\
\hline Bromeliaceae & Vriesea psittacina (Hook.) Lindl. & Ep & & & $\bullet$ & \\
\hline Burseraceae & Protium heptaphyllum (Aubl.) Marchand & Av & & & $\bullet$ & \\
\hline Burseraceae & Protium widgrenii Engl. & Av & & $\bullet$ & & 3,20 \\
\hline Cactaceae & Rhipsalis puniceodiscus G. Lindb. & Ep & & & $\bullet$ & \\
\hline Cactaceae & Rhipsalis teres (Vell.) Steud. & Ep & & & $\bullet$ & \\
\hline Campanulaceae & Hippobroma longiflora (L.) G. Don & Ev & & & $\bullet$ & \\
\hline Campanulaceae & Lobelia hassleri Zahlbr. & Ev & & & $\bullet$ & \\
\hline Campanulaceae & Siphocampylus duploserratus Pohl & Ev & & & $\bullet$ & \\
\hline Campanulaceae & Siphocampylus sulfureus E. Wimm. & Ev & & & $\bullet$ & \\
\hline Canellaceae & Cinnamodendron dinisii Schwacke & $\mathrm{Av}$ & & $\bullet$ & $\bullet$ & $2,3,7,8,12,22$ \\
\hline Cannabaceae & Trema micrantha (L.) Blume & $\mathrm{Av}$ & & $\bullet$ & $\bullet$ & $\begin{array}{c}1,2,3,10 \\
11,12,14,19\end{array}$ \\
\hline Cannaceae & Canna indica $\mathrm{L}$. & Ev & & $\bullet$ & $\bullet$ & 1 \\
\hline
\end{tabular}

*COELHO, R. L. G. , SOUZA, V. C. \& FERRUCCI, M. S. 2012 (no prelo). Matayba obovata, a new species of Matayba sect. Matayba (Sapindaceae) from Brazil. Brittonia (Bronx, N.Y.). 
Tabela 3. Continuação...

\begin{tabular}{|c|c|c|c|c|c|c|}
\hline \multirow[t]{2}{*}{ Família } & \multirow[t]{2}{*}{ Espécie } & \multirow{2}{*}{$\begin{array}{r}\text { Forma } \\
\text { de vida }\end{array}$} & \multirow[t]{2}{*}{ SPSF } & \multicolumn{2}{|c|}{ FI } & \multirow[t]{2}{*}{ Trilha } \\
\hline & & & & $\mathbf{P}$ & $\mathbf{S}$ & \\
\hline Cardiopteridaceae & Citronella gongonha (Mart.) R.A. Howard & Av & & & $\bullet$ & \\
\hline Cardiopteridaceae & Citronella paniculata (Mart.) R.A. Howard & Av & 43208 & $\bullet$ & $\bullet$ & $\begin{array}{l}2,3,4,5,7,8,9,10 \\
11,12,13,14,16,19\end{array}$ \\
\hline Caricaceae & Jacaratia heptaphylla (Vell.) A. DC. & Av & & $\bullet$ & & 20 \\
\hline Celastraceae & Maytenus aquifolia Mart. & Av & & $\bullet$ & & $2,7,20,21$ \\
\hline Celastraceae & Maytenus cestrifolia Reissek & Av & 43184,43186 & $\bullet$ & & $2,3,17,18$ \\
\hline Celastraceae & Maytenus evonymoides Reissek & Av & 43185,43187 & $\bullet$ & $\bullet$ & $8,9,17$ \\
\hline Celastraceae & Maytenus gonoclada Mart. & Av & & & $\bullet$ & \\
\hline Celastraceae & Maytenus sp. & Av & & $\bullet$ & & 12 \\
\hline Chloranthaceae & Hedyosmum brasiliense Miq. & Av & 43189 & $\bullet$ & $\bullet$ & $7,8,11,13$ \\
\hline Chrysobalanaceae & Hirtella gracilipes (Hook. f.) Prance & Av & & $\bullet$ & & 1 \\
\hline Chrysobalanaceae & Hirtella hebeclada Moric. ex DC. & Av & 43188 & $\bullet$ & $\bullet$ & 3,8 \\
\hline Clethraceae & Clethra scabra Pers. & $\mathrm{Av}$ & & $\bullet$ & $\bullet$ & $\begin{array}{c}1,3,4,5,6,9,10,11 \\
13,14\end{array}$ \\
\hline Clusiaceae & Clusia criuva Cambess. & Av & 43190 & $\bullet$ & $\bullet$ & 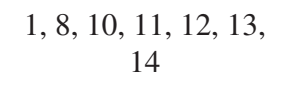 \\
\hline Clusiaceae & Garcinia gardneriana (Planch. \& Triana) Zappi & Av & & $\bullet$ & $\bullet$ & $\begin{array}{c}4,8,9,10,11,12 \\
13,17,19,22\end{array}$ \\
\hline Combretaceae & Combretum fruticosum (Loefl.) Stuntz & $\operatorname{Tr}$ & & & $\bullet$ & \\
\hline Commelinaceae & Dichorisandra thyrsiflora J.C. Mikan & Ev & & & $\bullet$ & \\
\hline Commelinaceae & Gibasis geniculata (Jacq.) Rohweder & $\mathrm{Ev}$ & & & $\bullet$ & \\
\hline Convolvulaceae & Ipomoea aristolochiifolia G.Don & $\operatorname{Tr}$ & & & $\bullet$ & \\
\hline Convolvulaceae & Ipomoea nil (L.) Roth & $\operatorname{Tr}$ & & & $\bullet$ & \\
\hline Convolvulaceae & Ipomoea purpurea (L.) Roth. & $\operatorname{Tr}$ & & & $\bullet$ & \\
\hline Cunoniaceae & Lamanonia ternata Vell. & Av & 43191 & $\bullet$ & & $4,5,8,14$ \\
\hline Cunoniaceae & Weinmannia paulliniifolia Pohl ex Ser. & $\mathrm{Av}$ & 43192 & $\bullet$ & & $4,5,14$ \\
\hline Cyatheaceae & Alsophila setosa Kaulf. & $\mathrm{Fa}$ & & $\bullet$ & $\bullet$ & 17 \\
\hline Cyatheaceae & Alsophila sternbergii (Sternb.) D.S. Conant & $\mathrm{Fa}$ & & $\bullet$ & & $2,8,9,10,11,12,22$ \\
\hline Cyatheaceae & Cyathea atrovirens (Langsd. \& Fisch.) Domin & $\mathrm{Fa}$ & & $\bullet$ & & $1,3,4,5,11,12$ \\
\hline Cyatheaceae & Cyathea corcovadensis (Raddi) Domin & $\mathrm{Fa}$ & & $\bullet$ & $\bullet$ & $3,11,17,19$ \\
\hline Cyatheaceae & Cyathea delgadii Sternb. & $\mathrm{Fa}$ & & $\bullet$ & $\bullet$ & $\begin{array}{c}4,5,8,9,10, \\
11,13,17,18,20\end{array}$ \\
\hline Cyatheaceae & Cyathea hirsuta C. Presl & $\mathrm{Fa}$ & & & $\bullet$ & \\
\hline Cyatheaceae & Cyathea phalerata Mart. & $\mathrm{Fa}$ & & & $\bullet$ & \\
\hline Cyperaceae & Cyperus laxus Lam. & $\mathrm{Ev}$ & & & $\bullet$ & \\
\hline Cyperaceae & Eleocharis debilis Kunth & $\mathrm{Ev}$ & & & $\bullet$ & \\
\hline Cyperaceae & Eleocharis glaucovirens Boeckeler & Ev & & & $\bullet$ & \\
\hline Cyperaceae & Eleocharis maculosa (Vahl) Roem. \& Schult. & Ev & & & $\bullet$ & \\
\hline Cyperaceae & Eleocharis montana (Kunth) Roem. \& Schult. & Ev & & & $\bullet$ & \\
\hline Cyperaceae & Hypolytrum schraderianum Nees & Ev & & & $\bullet$ & \\
\hline Cyperaceae & Pleurostachys gaudichaudii Brongn. & Ev & & & $\bullet$ & \\
\hline Cyperaceae & Rhynchospora brasiliensis Boeckeler & Ev & & & $\bullet$ & \\
\hline Cyperaceae & Rhynchospora breviuscula H. Pfeiff. & Ev & & & $\bullet$ & \\
\hline Cyperaceae & Rhynchospora pubera (Vahl) Boeckeler & $\mathrm{Ev}$ & & & $\bullet$ & \\
\hline Cyperaceae & Schoenoplectus californicus (C.A.Mey.) Soják & Ev & 43647 & $\bullet$ & & 11 \\
\hline Cyperaceae & Scleria panicoides Kunth & Ev & & & $\bullet$ & \\
\hline Cyperaceae & Scleria melaleuca Rchb. ex Schltdl. \& Cham. & $\mathrm{Ev}$ & & & $\bullet$ & \\
\hline Cyperaceae & Scleria virgata (Nees) Steud. & Ev & & & $\bullet$ & \\
\hline Dilleniaceae & Davilla rugosa Poir. & $\operatorname{Tr}$ & & & $\bullet$ & \\
\hline
\end{tabular}

*COELHO, R. L. G. , SOUZA, V. C. \& FERRUCCI, M. S. 2012 (no prelo). Matayba obovata, a new species of Matayba sect. Matayba (Sapindaceae) from Brazil. Brittonia (Bronx, N.Y.). 
Tabela 3. Continuação...

\begin{tabular}{|c|c|c|c|c|c|c|}
\hline \multirow[t]{2}{*}{ Família } & \multirow[t]{2}{*}{ Espécie } & \multirow{2}{*}{$\begin{array}{l}\text { Forma } \\
\text { de vida }\end{array}$} & \multirow[t]{2}{*}{ SPSF } & \multicolumn{2}{|c|}{ FI } & \multirow[t]{2}{*}{ Trilha } \\
\hline & & & & $\mathbf{P}$ & $\mathbf{S}$ & \\
\hline Dioscoreaceae & Dioscorea laxiflora Mart. ex Griseb. & $\operatorname{Tr}$ & & & $\bullet$ & \\
\hline Droseraceae & Drosera communis A. St.-Hil. & Ev & & & $\bullet$ & \\
\hline Dryopteridaceae & Olfersia cervina (L.) Kunze & Ev & & & $\bullet$ & \\
\hline Elaeocarpaceae & Sloanea guianensis (Aubl.) Benth. & Av & & $\bullet$ & $\bullet$ & $\begin{array}{l}8,12,17,18 \\
19,20,21,22\end{array}$ \\
\hline Elaeocarpaceae & Sloanea hirsuta (Schott) Planch. ex Benth. & Av & $\begin{array}{c}43193,43194 \\
43195\end{array}$ & $\bullet$ & $\bullet$ & $\begin{array}{l}2,3,8,9,10,11, \\
12,15,17,19,22\end{array}$ \\
\hline Elaeocarpaceae & Sloanea lasiocoma K. Schum. & Av & & $\bullet$ & & 11 \\
\hline Ericaceae & Gaylussacia brasiliensis (Spreng.) Meisn. & $\mathrm{Ab}$ & & & $\bullet$ & \\
\hline Eriocaulaceae & Actinocephalus polyanthus (Bong.) Sano & & & & $\bullet$ & \\
\hline Euphorbiaceae & Acalypha gracilis Spreng. & $\mathrm{Ab}$ & 43196 & $\bullet$ & $\bullet$ & 7,11 \\
\hline Euphorbiaceae & Alchornea glandulosa Poepp. & Ev & & $\bullet$ & & $1,4,5,12,13,19,22$ \\
\hline Euphorbiaceae & Alchornea sidifolia Müll. Arg. & Av & 43198 & $\bullet$ & $\bullet$ & $4,5,14$ \\
\hline Euphorbiaceae & Alchornea triplinervia (Spreng.) Müll. Arg. & Av & & $\bullet$ & $\bullet$ & $\begin{array}{c}1,2,3,4,5,7,8,9 \\
10,11,12,13,14,17 \\
18,19,20,21,22\end{array}$ \\
\hline Euphorbiaceae & Aparisthmium cordatum (A.Juss.) Baill. & Av & & $\bullet$ & $\bullet$ & 8,19 \\
\hline Euphorbiaceae & Bernardia pulchella (Baill.) Müll. Arg. & Av & & & $\bullet$ & \\
\hline Euphorbiaceae & Croton calonervosus G.L.Webster & Ev & & & $\bullet$ & \\
\hline Euphorbiaceae & Croton grandivelum Baill. & Av & & & $\bullet$ & \\
\hline Euphorbiaceae & Croton lundianus (Didr.) Müll. Arg. & Ev & & & $\bullet$ & \\
\hline Euphorbiaceae & Croton macrobothrys Baill. & $\mathrm{Av}$ & & $\bullet$ & & $\begin{array}{l}1,2,3,5,7,8,9 \\
10,11,12,13,17\end{array}$ \\
\hline Euphorbiaceae & Croton triqueter Lam. & Ev & & & $\bullet$ & \\
\hline Euphorbiaceae & Croton urucurana Baill. & Av & & & $\bullet$ & \\
\hline Euphorbiaceae & Dalechampia triphylla Lam. & $\operatorname{Tr}$ & & & $\bullet$ & \\
\hline Euphorbiaceae & Jatropha curcas L. & Av & & & $\bullet$ & \\
\hline Euphorbiaceae & Manihot cf. grahamii Hook. & Av & 43197 & $\bullet$ & & $10,11,12$ \\
\hline Euphorbiaceae & Pera glabrata (Schott) Poepp. ex Baill. & Av & & $\bullet$ & $\bullet$ & 1 \\
\hline Euphorbiaceae & Sapium glandulosum (L.) Morong & Av & 43199 & $\bullet$ & $\bullet$ & $\begin{array}{c}4,5,7,8,9 \\
10,12,14,17\end{array}$ \\
\hline Euphorbiaceae & Sebastiania brasiliensis Spreng. & Av & & $\bullet$ & & $11,18,19,22$ \\
\hline Euphorbiaceae & Tetrorchidium rubrivenium Poepp. & Av & & $\bullet$ & $\bullet$ & $\begin{array}{c}1,5,7,8,9,10,11 \\
12,13,14,17,19,22\end{array}$ \\
\hline $\begin{array}{l}\text { Fabaceae } \\
\text { (Caesalpinioideae) }\end{array}$ & Copaifera trapezifolia Hayne & Av & & $\bullet$ & & $3,4,5,8,15$ \\
\hline $\begin{array}{l}\text { Fabaceae } \\
\text { (Caesalpinioideae) }\end{array}$ & Holocalyx balansae Micheli & Av & & $\bullet$ & & 21 \\
\hline $\begin{array}{l}\text { Fabaceae } \\
\text { (Caesalpinioideae) }\end{array}$ & Hymenaea courbaril L. & Av & & $\bullet$ & $\bullet$ & 2,20 \\
\hline $\begin{array}{l}\text { Fabaceae } \\
\text { (Caesalpinioideae) }\end{array}$ & Schizolobium parahyba (Vell.) S.F. Blake & $\mathrm{Av}$ & & $\bullet$ & $\bullet$ & $\begin{array}{c}3,8,11,15 \\
19,20,22\end{array}$ \\
\hline $\begin{array}{l}\text { Fabaceae } \\
\text { (Caesalpinioideae) }\end{array}$ & Senna cernua (Balb.) H.S.Irwin \& Barneby & $\mathrm{Ab}$ & & & $\bullet$ & \\
\hline $\begin{array}{l}\text { Fabaceae } \\
\text { (Caesalpinioideae) }\end{array}$ & Senna multijuga (Rich.) H.S.Irwin \& Barneby & Av & & $\bullet$ & $\bullet$ & $\begin{array}{l}1,4,5,7,8,9,10 \\
11,13,14,17,20\end{array}$ \\
\hline $\begin{array}{l}\text { Fabaceae } \\
\text { (Caesalpinioideae) }\end{array}$ & Senna occidentalis (L.) Link & $\mathrm{Ab}$ & & & $\bullet$ & \\
\hline $\begin{array}{l}\text { Fabaceae } \\
\text { (Caesalpinioideae) }\end{array}$ & $\begin{array}{l}\text { Senna pendula (Humb.\& Bonpl.ex Willd.) H.S.Irwin } \\
\text { \& Barneby }\end{array}$ & $\mathrm{Ab}$ & & & $\bullet$ & \\
\hline
\end{tabular}


Tabela 3. Continuação...

\begin{tabular}{|c|c|c|c|c|c|c|}
\hline \multirow[t]{2}{*}{ Família } & \multirow[t]{2}{*}{ Espécie } & \multirow{2}{*}{$\begin{array}{r}\text { Forma } \\
\text { de vida }\end{array}$} & \multirow[t]{2}{*}{ SPSF } & \multicolumn{2}{|c|}{ FI } & \multirow[t]{2}{*}{ Trilha } \\
\hline & & & & $\mathbf{P}$ & $\mathbf{S}$ & \\
\hline $\begin{array}{l}\text { Fabaceae } \\
\text { (Caesalpinioideae) }\end{array}$ & Tachigali denudata (Vogel) Oliveira-Filho & $\mathrm{Av}$ & & $\bullet$ & & 20 \\
\hline $\begin{array}{l}\text { Fabaceae } \\
\text { (Cercideae) }\end{array}$ & Bauhinia forficata Link & $\mathrm{Av}$ & 43200 & $\bullet$ & $\bullet$ & $1,2,9,11,12,13$ \\
\hline $\begin{array}{l}\text { Fabaceae } \\
\text { (Faboideae) }\end{array}$ & Andira anthelmia (Vell.) Benth. & Av & 43202 & $\bullet$ & $\bullet$ & $1,3,4,5,8,9,10,14$ \\
\hline $\begin{array}{l}\text { Fabaceae } \\
\text { (Faboideae) }\end{array}$ & Centrolobium robustum (Vell.) Mart. ex Benth. & Av & & $\bullet$ & & 7,11 \\
\hline $\begin{array}{l}\text { Fabaceae } \\
\text { (Faboideae) }\end{array}$ & Centrolobium tomentosum Guillem. ex Benth. & Av & & $\bullet$ & & 20 \\
\hline $\begin{array}{l}\text { Fabaceae } \\
\text { (Faboideae) }\end{array}$ & Dahlstedtia pinnata (Benth.) Malme & $\mathrm{Av}$ & 43203 & $\bullet$ & & $\begin{array}{c}2,3,5,8,9,11,12 \\
13,17,18,19 \\
20,21,22\end{array}$ \\
\hline $\begin{array}{l}\text { Fabaceae } \\
\text { (Faboideae) }\end{array}$ & Dalbergia frutescens (Vell.) Britton & Av & & & $\bullet$ & \\
\hline $\begin{array}{l}\text { Fabaceae } \\
\text { (Faboideae) }\end{array}$ & Desmodium affine Schltdl. & $\mathrm{Ev}$ & & & $\bullet$ & \\
\hline $\begin{array}{l}\text { Fabaceae } \\
\text { (Faboideae) }\end{array}$ & Erythrina speciosa Andrews & Av & & $\bullet$ & & 1 \\
\hline $\begin{array}{l}\text { Fabaceae } \\
\text { (Faboideae) }\end{array}$ & Hymenolobium janeirense Kuhlm. & Av & & $\bullet$ & & 20 \\
\hline $\begin{array}{l}\text { Fabaceae } \\
\text { (Faboideae) }\end{array}$ & $\begin{array}{l}\text { Lonchocarpus cultratus (Vell.) A.M.G. Azevedo \& } \\
\text { H.C. Lima }\end{array}$ & $\mathrm{Av}$ & & & $\bullet$ & \\
\hline $\begin{array}{l}\text { Fabaceae } \\
\text { (Faboideae) }\end{array}$ & Lonchocarpus muehlbergianus Hassl. & Av & & & $\bullet$ & \\
\hline $\begin{array}{l}\text { Fabaceae } \\
\text { (Faboideae) }\end{array}$ & Lonchocarpus subglaucescens Mart. ex Benth. & Av & & $\bullet$ & & $1,9,11,14,22$ \\
\hline $\begin{array}{l}\text { Fabaceae } \\
\text { (Faboideae) }\end{array}$ & Machaerium hirtum (Vell.) Stellfeld & $\mathrm{Av}$ & & $\bullet$ & $\bullet$ & 1,8 \\
\hline $\begin{array}{l}\text { Fabaceae } \\
\text { (Faboideae) }\end{array}$ & Machaerium nyctitans (Vell.) Benth. & Av & & $\bullet$ & $\bullet$ & $\begin{array}{l}3,5,7,9,10 \\
11,12,14,19\end{array}$ \\
\hline $\begin{array}{l}\text { Fabaceae } \\
\text { (Faboideae) }\end{array}$ & Machaerium punctatum (Poir.) Pers. & Av & & & $\bullet$ & \\
\hline $\begin{array}{l}\text { Fabaceae } \\
\text { (Faboideae) }\end{array}$ & Machaerium scleroxylon Tul. & Av & & $\bullet$ & & $1,12,16,22$ \\
\hline $\begin{array}{l}\text { Fabaceae } \\
\text { (Faboideae) }\end{array}$ & Machaerium stipitatum (DC.) Vogel & Av & & $\bullet$ & $\bullet$ & $\begin{array}{c}1,7,11,12 \\
18,19,22\end{array}$ \\
\hline $\begin{array}{l}\text { Fabaceae } \\
\text { (Faboideae) }\end{array}$ & Myrocarpus frondosus Allemão & $\mathrm{Av}$ & & $\bullet$ & $\bullet$ & 8,11 \\
\hline $\begin{array}{l}\text { Fabaceae } \\
\text { (Faboideae) }\end{array}$ & Ormosia arborea (Vell.) Harms & $\mathrm{Av}$ & & $\bullet$ & $\bullet$ & $3,11,21$ \\
\hline $\begin{array}{l}\text { Fabaceae } \\
\text { (Faboideae) }\end{array}$ & Platymiscium floribundum Vogel & Av & & $\bullet$ & $\bullet$ & $8,9,10,12,13,22$ \\
\hline $\begin{array}{l}\text { Fabaceae } \\
\text { (Faboideae) }\end{array}$ & Pterocarpus rohrii Vahl & $\mathrm{Av}$ & 43201 & $\bullet$ & $\bullet$ & $\begin{array}{c}2,5,12,13 \\
14,15,17\end{array}$ \\
\hline $\begin{array}{l}\text { Fabaceae } \\
\text { (Faboideae) }\end{array}$ & Swartzia acutifolia Vogel & Av & & & $\bullet$ & \\
\hline $\begin{array}{l}\text { Fabaceae } \\
\text { (Faboideae) }\end{array}$ & Zollernia ilicifolia (Brongn.) Vogel & Av & & $\bullet$ & & 9,11 \\
\hline $\begin{array}{l}\text { Fabaceae } \\
\text { (Mimosoideae) }\end{array}$ & Abarema langsdorffii (Benth.) Barneby \& J.W. Grimes & $\mathrm{Av}$ & & $\bullet$ & $\bullet$ & $16,20,22$ \\
\hline $\begin{array}{l}\text { Fabaceae } \\
\text { (Mimosoideae) }\end{array}$ & Anadenanthera colubrina (Vell.) Brenan & $\mathrm{Av}$ & & $\bullet$ & & 20 \\
\hline
\end{tabular}

*COELHO, R. L. G. , SOUZA, V. C. \& FERRUCCI, M. S. 2012 (no prelo). Matayba obovata, a new species of Matayba sect. Matayba (Sapindaceae) from Brazil. Brittonia (Bronx, N.Y.). 
Tabela 3. Continuação...

\begin{tabular}{|c|c|c|c|c|c|c|}
\hline \multirow[t]{2}{*}{ Família } & \multirow[t]{2}{*}{ Espécie } & \multirow{2}{*}{$\begin{array}{l}\text { Forma } \\
\text { de vida }\end{array}$} & \multirow[t]{2}{*}{ SPSF } & \multicolumn{2}{|c|}{ FI } & \multirow[t]{2}{*}{ Trilha } \\
\hline & & & & $\mathbf{P}$ & $\mathbf{S}$ & \\
\hline $\begin{array}{l}\text { Fabaceae } \\
\text { (Mimosoideae) }\end{array}$ & Inga barbata Benth. & $\mathrm{Av}$ & 43205 & $\bullet$ & & 14 \\
\hline $\begin{array}{l}\text { Fabaceae } \\
\text { (Mimosoideae) }\end{array}$ & Inga edulis Mart. & $\mathrm{Av}$ & & $\bullet$ & & 20 \\
\hline $\begin{array}{l}\text { Fabaceae } \\
\text { (Mimosoideae) }\end{array}$ & Inga marginata Willd. & $\mathrm{Av}$ & 43206,43207 & $\bullet$ & $\bullet$ & $\begin{array}{c}1,2,6,7,8,10 \\
11,12,13,14,17 \\
18,19,21,22\end{array}$ \\
\hline $\begin{array}{l}\text { Fabaceae } \\
\text { (Mimosoideae) }\end{array}$ & Inga sessilis (Vell.) Mart. & $\mathrm{Av}$ & 43204 & $\bullet$ & & $\begin{array}{c}1,3,4,5,8,9,10 \\
11,12,13,14,17 \\
18,19,22\end{array}$ \\
\hline $\begin{array}{l}\text { Fabaceae } \\
\text { (Mimosoideae) }\end{array}$ & Mimosa aff. bocainae Barneby & $\mathrm{Ab}$ & & & $\bullet$ & \\
\hline $\begin{array}{l}\text { Fabaceae } \\
\text { (Mimosoideae) }\end{array}$ & Mimosa furfuracea Benth. & $\mathrm{Ab}$ & & & $\bullet$ & \\
\hline $\begin{array}{l}\text { Fabaceae } \\
\text { (Mimosoideae) }\end{array}$ & Mimosa paranapiacabae Barneby & $\mathrm{Ab}$ & & & $\bullet$ & \\
\hline $\begin{array}{l}\text { Fabaceae } \\
\text { (Mimosoideae) }\end{array}$ & Mimosa scabrella Benth. & $\mathrm{Av}$ & & & $\bullet$ & \\
\hline $\begin{array}{l}\text { Fabaceae } \\
\text { (Mimosoideae) }\end{array}$ & Piptadenia gonoacantha (Mart.) J.F. Macbr. & $\mathrm{Av}$ & & $\bullet$ & $\bullet$ & $\begin{array}{l}1,2,3,7,8,9,11 \\
12,13,19,20\end{array}$ \\
\hline $\begin{array}{l}\text { Fabaceae } \\
\text { (Mimosoideae) }\end{array}$ & Piptadenia paniculata Benth. & $\mathrm{Av}$ & & $\bullet$ & $\bullet$ & $\begin{array}{l}6,7,8,9,10 \\
12,17,19,21\end{array}$ \\
\hline $\begin{array}{l}\text { Fabaceae } \\
\text { (Mimosoideae) }\end{array}$ & $\begin{array}{l}\text { Pseudopiptadenia warmingii (Benth.) G.P. Lewis \& } \\
\text { M.P. Lima }\end{array}$ & Av & & $\bullet$ & & 17,20 \\
\hline $\begin{array}{l}\text { Fabaceae } \\
\text { (Mimosoideae) }\end{array}$ & Senegalia lacerans (Benth.) Seigler \& Ebinger & $\operatorname{Tr}$ & & & $\bullet$ & \\
\hline Gesneriaceae & Nematanthus fritschii Hoehne & Ep & & & $\bullet$ & \\
\hline Gesneriaceae & Nematanthus striatus (Handro) Chautems & Ep & & & $\bullet$ & \\
\hline Gesneriaceae & Nematanthus tessmannii (Hoehne) Chautems & Ep & & & $\bullet$ & \\
\hline Gesneriaceae & Sinningia calcaria (Malme) Chautems & Ep & & & $\bullet$ & \\
\hline Gleicheniaceae & Dicranopteris flexuosa (Schrad.) Underw. & Ev & & $\bullet$ & & $1,4,11$ \\
\hline Heliconiaceae & Heliconia farinosa Raddi & Ev & & $\bullet$ & & 1 \\
\hline Humiriaceae & Humiriastrum dentatum (Casar.) Cuatrec. & Av & & $\bullet$ & & 13 \\
\hline Humiriaceae & Vantanea compacta (Schnizl.) Cuatrec. & Av & & $\bullet$ & & 4 \\
\hline Hymenophyllaceae & Trichomanes elegans Rich. & Ev & & & $\bullet$ & \\
\hline Hypericaceae & Hypericum brasiliense Choisy & Ev & & & $\bullet$ & \\
\hline Hypoxidaceae & Hypoxis decumbens $\mathrm{L}$. & Ev & & & $\bullet$ & \\
\hline Iridaceae & Sisyrinchium restioides Spreng. & Ev & & & $\bullet$ & \\
\hline Iridaceae & Sisyrinchium vaginatum Spreng. & Ev & & & $\bullet$ & \\
\hline Iridaceae & Trimezia martinicensis (Jacq.) Herb. & Ev & & & $\bullet$ & \\
\hline Lacistemataceae & Lacistema hasslerianum Chodat & Av & 43209 & $\bullet$ & & 22 \\
\hline Lamiaceae & Aegiphila integrifolia (Jacq.) Moldenke & Av & 43333 & $\bullet$ & $\bullet$ & $7,8,9,10,11,12,14$ \\
\hline Lamiaceae & Hyptis mutabilis (Rich.) Briq. & $\mathrm{Ab}$ & & & $\bullet$ & \\
\hline Lamiaceae & Hyptis sidifolia (L'Hér.) Briq. & $\mathrm{Ev}$ & & & $\bullet$ & \\
\hline Lamiaceae & Marsypianthes chamaedrys (Vahl) Kuntze & $\mathrm{Ev}$ & & & $\bullet$ & \\
\hline Lamiaceae & Ocimum campechianum Mill. & Ev & & & $\bullet$ & \\
\hline Lamiaceae & Ocimum carnosum (Spreng.) Link \& Otto ex Benth. & Ev & & & $\bullet$ & \\
\hline Lamiaceae & Salvia melissaeflora Benth. & Ev & & & $\bullet$ & \\
\hline Lamiaceae & Vitex megapotamica (Spreng.) Moldenke & $\mathrm{Av}$ & & & $\bullet$ & \\
\hline Lamiaceae & Vitex polygama Cham. & Av & & & $\bullet$ & \\
\hline Lauraceae & Beilschmiedia emarginata (Meisn.) Kosterm. & Av & & $\bullet$ & $\bullet$ & 4 \\
\hline
\end{tabular}

*COELHO, R. L. G. , SOUZA, V. C. \& FERRUCCI, M. S. 2012 (no prelo). Matayba obovata, a new species of Matayba sect. Matayba (Sapindaceae) from Brazil. Brittonia (Bronx, N.Y.). 
Tabela 3. Continuação...

\begin{tabular}{|c|c|c|c|c|c|c|}
\hline \multirow[t]{2}{*}{ Família } & \multirow[t]{2}{*}{ Espécie } & \multirow{2}{*}{$\begin{array}{l}\text { Forma } \\
\text { de vida }\end{array}$} & \multirow[t]{2}{*}{ SPSF } & \multicolumn{2}{|c|}{ FI } & \multirow[t]{2}{*}{ Trilha } \\
\hline & & & & $\mathbf{P}$ & $\mathbf{S}$ & \\
\hline Lauraceae & Cinnamomum sellowianum (Nees \& Mart.) Kosterm. & Av & & & $\bullet$ & \\
\hline Lauraceae & Cinnamomum triplinerve (Ruiz \& Pav.) Kosterm. & Av & & $\bullet$ & & 14 \\
\hline Lauraceae & Cryptocarya mandioccana Meisn. & Av & & $\bullet$ & $\bullet$ & $8,9,13,20$ \\
\hline Lauraceae & Endlicheria paniculata (Spreng.) J.F. Macbr. & $\mathrm{Av}$ & $\begin{array}{c}43212,43216 \\
43220\end{array}$ & $\bullet$ & $\bullet$ & $\begin{array}{c}2,3,4,5,9,11 \\
14,17,19,22\end{array}$ \\
\hline Lauraceae & Licaria armeniaca (Nees) Kosterm. & Av & & $\bullet$ & & 19 \\
\hline Lauraceae & Nectandra debilis $\mathrm{Mez}$ & Av & & $\bullet$ & & 1,2 \\
\hline Lauraceae & Nectandra lanceolata Nees & Av & & & $\bullet$ & \\
\hline Lauraceae & Nectandra leucantha Nees & Av & 43222 & $\bullet$ & $\bullet$ & 19 \\
\hline Lauraceae & Nectandra megapotamica (Spreng.) Mez & Av & 43219 & $\bullet$ & $\bullet$ & $13,14,21,22$ \\
\hline Lauraceae & Nectandra membranacea (Sw.) Griseb. & $\mathrm{Av}$ & 43221 & $\bullet$ & $\bullet$ & $\begin{array}{c}1,2,3,4,5,7 \\
8,9,10,11,12 \\
13,18,19,20,22\end{array}$ \\
\hline Lauraceae & Nectandra oppositifolia Nees & Av & & $\bullet$ & $\bullet$ & $1,3,8,9,10,11,12$ \\
\hline Lauraceae & Nectandra paranaensis Coe-Teix. & Av & 43214 & $\bullet$ & & 4 \\
\hline Lauraceae & Ocotea aciphylla (Nees \& Mart.) Mez & Av & 43213 & $\bullet$ & & 4 \\
\hline Lauraceae & Ocotea dispersa (Nees \& Mart.) Mez & Av & & & $\bullet$ & \\
\hline Lauraceae & Ocotea elegans $\mathrm{Mez}$ & Av & & $\bullet$ & $\bullet$ & 4 \\
\hline Lauraceae & Ocotea glaziovii $\mathrm{Mez}$ & $\mathrm{Av}$ & & $\bullet$ & $\bullet$ & 5 \\
\hline Lauraceae & Ocotea odorifera (Vell.) Rohwer & $\mathrm{Av}$ & & $\bullet$ & & 3,4 \\
\hline Lauraceae & Ocotea puberula (Rich.) Nees & Av & $\begin{array}{l}43210,43215 \\
43218\end{array}$ & $\bullet$ & & $\begin{array}{c}1,2,5,7,9 \\
10,11,12,14\end{array}$ \\
\hline Lauraceae & Ocotea teleiandra (Meisn.) Mez & $\mathrm{Av}$ & 43211,43217 & $\bullet$ & & $\begin{array}{c}2,3,4,5,9,11 \\
12,18,20,22\end{array}$ \\
\hline Lauraceae & Ocotea sp. & Av & & $\bullet$ & & 11,12 \\
\hline Lauraceae & Persea venosa Nees \& Mart. & $\mathrm{Av}$ & & & $\bullet$ & \\
\hline Lauraceae & Persea willdenovii Kosterm. & Av & & & $\bullet$ & \\
\hline Lauraceae & $\begin{array}{l}\text { Rhodostemonodaphne macrocalyx (Meisn.) Rohwer } \\
\text { ex Madriñán }\end{array}$ & $\mathrm{Av}$ & & & $\bullet$ & \\
\hline Lecythidaceae & Cariniana estrellensis (Raddi) Kuntze & Av & & $\bullet$ & $\bullet$ & $3,7,15,17,18,19$ \\
\hline Loganiaceae & Spigelia beyrichiana Cham. \& Schltdl. & Ev & & & $\bullet$ & \\
\hline Lomariopsidaceae & Nephrolepis cordifolia (L.) C. Presl & Ev & & & $\bullet$ & \\
\hline Lycopodiaceae & Huperzia reflexa (Lam.) Trevis. & Ev & & & $\bullet$ & \\
\hline Lycopodiaceae & Lycopodiella cernua (L.) Pic. Serm. & Ev & & & $\bullet$ & \\
\hline Lycopodiaceae & Lycopodiella pendulina (Hook.) B. Øllg. & Ev & & & $\bullet$ & \\
\hline Lycopodiaceae & Lycopodium clavatum $\mathrm{L}$. & Ev & & & $\bullet$ & \\
\hline Lygodiaceae & Lygodium volubile $\mathrm{Sw}$. & Ev & & & $\bullet$ & \\
\hline Lythraceae & Heimia myrtifolia Cham. \& Schltdl. & $\mathrm{Ab}$ & & & $\bullet$ & \\
\hline Lythraceae & Lafoensia vandelliana Cham. \& Schltdl. & Av & & & $\bullet$ & \\
\hline Magnoliaceae & Magnolia ovata (A.St.-Hil.) Spreng. & $\mathrm{Av}$ & & $\bullet$ & $\bullet$ & $\begin{array}{c}3,7,8,9 \\
10,12,14,15\end{array}$ \\
\hline Malpighiaceae & Bunchosia fluminensis Juss. & Av & & & $\bullet$ & \\
\hline Malpighiaceae & Bunchosia pallescens Skottsb. & $\mathrm{Av}$ & 43223 & $\bullet$ & & 7 \\
\hline Malpighiaceae & Byrsonima ligustrifolia A.Juss. & Av & & & $\bullet$ & \\
\hline Malpighiaceae & Heteropterys intermedia (A.Juss.) Griseb. & $\mathrm{Ab}$ & & & $\bullet$ & \\
\hline Malpighiaceae & Stigmaphyllon puberulum Griseb. & $\operatorname{Tr}$ & & & $\bullet$ & \\
\hline Malpighiaceae & Stigmaphyllon tomentosum A. Juss. & $\operatorname{Tr}$ & & & $\bullet$ & \\
\hline Malpighiaceae & Tetrapterys mollis Griseb. & $\operatorname{Tr}$ & & & $\bullet$ & \\
\hline Malpighiaceae & Tetrapterys phlomoides (Spreng.) Nied. & $\operatorname{Tr}$ & & & $\bullet$ & \\
\hline
\end{tabular}

*COELHO, R. L. G. , SOUZA, V. C. \& FERRUCCI, M. S. 2012 (no prelo). Matayba obovata, a new species of Matayba sect. Matayba (Sapindaceae) from Brazil. Brittonia (Bronx, N.Y.). 
Tabela 3. Continuação...

\begin{tabular}{|c|c|c|c|c|c|c|}
\hline \multirow[t]{2}{*}{ Família } & \multirow[t]{2}{*}{ Espécie } & \multirow{2}{*}{$\begin{array}{l}\text { Forma } \\
\text { de vida }\end{array}$} & \multirow[t]{2}{*}{ SPSF } & \multicolumn{2}{|c|}{ FI } & \multirow[t]{2}{*}{ Trilha } \\
\hline & & & & $\mathbf{P}$ & $\mathbf{S}$ & \\
\hline Malvaceae & Abutilon macrocarpum Guillem. \& Perr. & $\mathrm{Ab}$ & & & $\bullet$ & \\
\hline Malvaceae & Guazuma ulmifolia Lam. & Av & & $\bullet$ & & 11,13 \\
\hline Malvaceae & Luehea divaricata Mart. \& Zucc. & Av & 43332 & $\bullet$ & $\bullet$ & 5,7 \\
\hline Malvaceae & Melochia pyramidata $\mathrm{L}$. & Ev & & & $\bullet$ & \\
\hline Malvaceae & Pavonia communis A. St.-Hil. & $\mathrm{Ab}$ & & & $\bullet$ & \\
\hline Malvaceae & Pavonia nemoralis A. St.-Hil. & $\mathrm{Ab}$ & & & $\bullet$ & \\
\hline Malvaceae & Pavonia schiedeana Steud. & Ev & & & $\bullet$ & \\
\hline Malvaceae & Pseudobombax grandiflorum (Cav.) A. Robyns & $\mathrm{Av}$ & & $\bullet$ & & 22 \\
\hline Malvaceae & $\begin{array}{l}\text { Spirotheca rivieri var. passifloroides (Cuatrec.) P.E. } \\
\text { Gibbs \& W.S. Alverson }\end{array}$ & $\mathrm{He}$ & & $\bullet$ & $\bullet$ & $\begin{array}{l}5,11,12,13 \\
17,19,22\end{array}$ \\
\hline Malvaceae & Triumfetta semitriloba Jacq. & $\mathrm{Ab}$ & & & $\bullet$ & \\
\hline Malvaceae & Abutilon rufinerve A. St.-Hil. & $\mathrm{Ab}$ & 43224 & $\bullet$ & & $7,9,10,11,12$ \\
\hline Marantaceae & Calathea communis Wanderley \& S. Vieira & Ev & & & $\bullet$ & \\
\hline Marantaceae & Stromanthe papillosa Petersen & Ev & & $\bullet$ & & 11 \\
\hline Marattiaceae & Danaea geniculata Raddi & Ev & & & $\bullet$ & \\
\hline Marcgraviaceae & Schwartzia brasiliensis (Choisy) Bedell ex Gir.-Cañas & $\mathrm{Ab}$ & & & $\bullet$ & \\
\hline Melastomataceae & Aciotis paludosa (Mart. ex DC.) Triana & $\mathrm{Ev}$ & & & $\bullet$ & \\
\hline Melastomataceae & Bertolonia mosenii Cogn. & Ev & & & $\bullet$ & \\
\hline Melastomataceae & Clidemia hirta (L.) D. Don & $\mathrm{Ab}$ & & & $\bullet$ & \\
\hline Melastomataceae & Leandra acutiflora (Naudin) Cogn. & $\mathrm{Av}$ & 43229,43231 & $\bullet$ & & 5,11 \\
\hline Melastomataceae & Leandra australis (Cham.) Cogn. & $\mathrm{Av}$ & 43232 & $\bullet$ & $\bullet$ & 11 \\
\hline Melastomataceae & Leandra dasytricha (A. Gray) Cogn. & $\mathrm{Av}$ & & & $\bullet$ & \\
\hline Melastomataceae & Leandra echinata Cogn. & $\mathrm{Av}$ & 43226 & $\bullet$ & $\bullet$ & 3,5 \\
\hline Melastomataceae & Leandra melastomoides Raddi & $\mathrm{Av}$ & & & $\bullet$ & \\
\hline Melastomataceae & Leandra mosenii Cogn. & Av & 43236 & $\bullet$ & $\bullet$ & $\begin{array}{c}1,2,3,4,7,8 \\
10,11,12,17,18\end{array}$ \\
\hline Melastomataceae & Leandra pilonensis Wurdack & $\mathrm{Av}$ & & & $\bullet$ & \\
\hline Melastomataceae & Leandra purpurascens (DC.) Cogn. & $\mathrm{Av}$ & & & $\bullet$ & \\
\hline Melastomataceae & Leandra regnellii (Triana) Cogn. & $\mathrm{Av}$ & 43233,43245 & $\bullet$ & & $11,12,19$ \\
\hline Melastomataceae & Leandra reversa (DC.) Cogn. & $\mathrm{Av}$ & & & $\bullet$ & \\
\hline Melastomataceae & Leandra cf. xanthocoma (Naudin) Cogn. & $\mathrm{Ab}$ & & & $\bullet$ & \\
\hline Melastomataceae & Miconia cabussu Hoehne & $\mathrm{Av}$ & & $\bullet$ & $\bullet$ & $\begin{array}{c}1,3,4,7,8,9 \\
10,11,13,14,17\end{array}$ \\
\hline Melastomataceae & Miconia cinerascens Miq. & $\mathrm{Av}$ & & & $\bullet$ & \\
\hline Melastomataceae & Miconia cinnamomifolia (DC.) Naudin & $\mathrm{Av}$ & 43237 & $\bullet$ & $\bullet$ & 8 \\
\hline Melastomataceae & Miconia cubatanensis Hoehne & $\mathrm{Av}$ & & $\bullet$ & & 3 \\
\hline Melastomataceae & Miconia discolor DC. & $\mathrm{Av}$ & 43244 & $\bullet$ & & 22 \\
\hline Melastomataceae & Miconia doriana Cogn. & $\mathrm{Av}$ & & $\bullet$ & & 5 \\
\hline Melastomataceae & Miconia fasciculata Gardner & $\mathrm{Av}$ & 43240 & $\bullet$ & $\bullet$ & 9 \\
\hline Melastomataceae & Miconia hyemalis A. St.-Hil. \& Naudin & $\mathrm{Av}$ & 43230 & $\bullet$ & $\bullet$ & 5 \\
\hline Melastomataceae & Miconia ibaguensis (Bonpl.) Triana & $\mathrm{Av}$ & 43243 & $\bullet$ & $\bullet$ & 22 \\
\hline Melastomataceae & Miconia latecrenata (DC.) Naudin & $\mathrm{Av}$ & 43225 & $\bullet$ & $\bullet$ & 1,7 \\
\hline Melastomataceae & Miconia ligustroides (DC.) Naudin & $\mathrm{Av}$ & 43241 & $\bullet$ & & 7,13 \\
\hline Melastomataceae & Miconia paucidens DC. & $\mathrm{Av}$ & & & $\bullet$ & \\
\hline Melastomataceae & Miconia petropolitana Cogn. & $\mathrm{Av}$ & 43235 & $\bullet$ & & $8,9,10,11$ \\
\hline Melastomataceae & Miconia pusilliflora (DC.) Naudin & $\mathrm{Av}$ & 43228 & $\bullet$ & $\bullet$ & $3,4,5$ \\
\hline Melastomataceae & Miconia racemifera (DC.) Triana & Av & & & $\bullet$ & \\
\hline Melastomataceae & Miconia sellowiana Naudin & Av & & & $\bullet$ & \\
\hline Melastomataceae & Miconia tristis Spring & Av & 43234 & $\bullet$ & $\bullet$ & 11,22 \\
\hline
\end{tabular}

*COELHO, R. L. G. , SOUZA, V. C. \& FERRUCCI, M. S. 2012 (no prelo). Matayba obovata, a new species of Matayba sect. Matayba (Sapindaceae) from Brazil. Brittonia (Bronx, N.Y.). 
Tabela 3. Continuação...

\begin{tabular}{|c|c|c|c|c|c|c|}
\hline \multirow[t]{2}{*}{ Família } & \multirow[t]{2}{*}{ Espécie } & \multirow{2}{*}{$\begin{array}{l}\text { Forma } \\
\text { de vida }\end{array}$} & \multirow[t]{2}{*}{ SPSF } & \multicolumn{2}{|c|}{ FI } & \multirow[t]{2}{*}{ Trilha } \\
\hline & & & & $\mathbf{P}$ & $\mathbf{S}$ & \\
\hline Melastomataceae & Ossaea amygdaloides (DC.) Triana & $\mathrm{Ab}$ & 43242 & $\bullet$ & & 22 \\
\hline Melastomataceae & Ossaea sanguinea Cogn. & $\mathrm{Ab}$ & & & $\bullet$ & \\
\hline Melastomataceae & Pleiochiton blepharodes (DC.) Reginato et al. & Ep & & & $\bullet$ & \\
\hline Melastomataceae & Tibouchina clinopodifolia (DC.) Cogn. & $\mathrm{Av}$ & & & $\bullet$ & \\
\hline Melastomataceae & Tibouchina fothergillae (Schrank \& Mart. ex DC.) Cogn. & $\mathrm{Av}$ & & & $\bullet$ & \\
\hline Melastomataceae & Tibouchina pulchra Cogn. & $\mathrm{Av}$ & 43227,43238 & $\bullet$ & $\bullet$ & $\begin{array}{c}1,2,3,4,5,7,8,9 \\
10,11,12,13,17\end{array}$ \\
\hline Melastomataceae & Tibouchina sellowiana Cogn. & $\mathrm{Av}$ & 43239 & $\bullet$ & $\bullet$ & 14 \\
\hline Melastomataceae & Trembleya parviflora (D. Don) Cogn. & $\mathrm{Ab}$ & & & $\bullet$ & \\
\hline Meliaceae & Cabralea canjerana (Vell.) Mart. & $\mathrm{Av}$ & & $\bullet$ & $\bullet$ & $\begin{array}{c}1,2,3,4,5,6,7,8 \\
9,10,11,12,13,17 \\
18,19,20,21,22\end{array}$ \\
\hline Meliaceae & Cedrela fissilis Vell. & Av & & $\bullet$ & $\bullet$ & $\begin{array}{l}1,4,5,6,7,8,10,11 \\
12,13,16,19,22\end{array}$ \\
\hline Meliaceae & Guarea macrophylla Vahl & Av & 43247 & $\bullet$ & $\bullet$ & $\begin{array}{l}2,3,7,8,9,10,11 \\
12,13,17,18,21,22\end{array}$ \\
\hline Meliaceae & Trichilia claussenii C. DC. & Av & & $\bullet$ & & $11,12,16,18,21,22$ \\
\hline Meliaceae & Trichilia lepidota Mart. & $\mathrm{Av}$ & & & $\bullet$ & \\
\hline Meliaceae & Trichilia pallens C. DC. & Av & $\begin{array}{l}43246,43248 \\
43249,43250\end{array}$ & $\bullet$ & $\bullet$ & $\begin{array}{l}2,9,11,12 \\
13,18,21,22\end{array}$ \\
\hline Monimiaceae & Mollinedia clavigera Tul. & $\mathrm{Av}$ & & & $\bullet$ & \\
\hline Monimiaceae & Mollinedia elegans Tul. & $\mathrm{Av}$ & 43252 & $\bullet$ & & 3,5 \\
\hline Monimiaceae & Mollinedia oligantha Perkins & $\mathrm{Av}$ & & $\bullet$ & & 9 \\
\hline Monimiaceae & Mollinedia schottiana (Spreng.) Perkins & Av & $\begin{array}{l}43251,43254 \\
43256\end{array}$ & $\bullet$ & $\bullet$ & $2,3,8,9,11,17$ \\
\hline Monimiaceae & Mollinedia cf. triflora (Spreng.) Tul. & Av & 43255 & $\bullet$ & & $7,8,11$ \\
\hline Monimiaceae & Mollinedia uleana Perkins & $\mathrm{Av}$ & 43253,43257 & $\bullet$ & $\bullet$ & $3,4,17,18,19,22$ \\
\hline Moraceae & Brosimum guianense (Aubl.) Huber & $\mathrm{Av}$ & & & $\bullet$ & \\
\hline Moraceae & Dorstenia hirta Desv. & Ev & 43268 & $\bullet$ & $\bullet$ & 22 \\
\hline Moraceae & Ficus citrifolia Mill. & $\mathrm{He}$ & & & $\bullet$ & \\
\hline Moraceae & Ficus enormis Mart. ex Miq. & $\mathrm{He}$ & & $\bullet$ & $\bullet$ & 19 \\
\hline Moraceae & Ficus guaranitica Chodat & $\mathrm{He}$ & & $\bullet$ & & $1,5,6$ \\
\hline Moraceae & Ficus insipida Willd. & $\mathrm{He}$ & 43263,43267 & $\bullet$ & $\bullet$ & $\begin{array}{l}4,8,9,10,11,12,13 \\
18,19,20,21,22\end{array}$ \\
\hline Moraceae & Ficus luschnathiana (Miq.) Miq. & $\mathrm{He}$ & 43264 & $\bullet$ & & $7,9,11,12$ \\
\hline Moraceae & Ficus pertusa L. f. & $\mathrm{He}$ & 43265 & $\bullet$ & $\bullet$ & $6,10,11,12$ \\
\hline Moraceae & Maclura tinctoria (L.) D. Don ex Steud. & Av & & $\bullet$ & $\bullet$ & $7,19,21$ \\
\hline Moraceae & $\begin{array}{l}\text { Sorocea bonplandii (Baill.) W.C. Burger, Lanj. \& } \\
\text { Wess. Boer }\end{array}$ & Av & 43258,43266 & $\bullet$ & $\bullet$ & $\begin{array}{l}2,3,4,5,7,8,9 \\
11,15,18,19,21\end{array}$ \\
\hline Myristicaceae & Virola bicuhyba (Schott ex Spreng.) Warb. & Av & & $\bullet$ & $\bullet$ & $\begin{array}{l}1,2,3,8,9,11 \\
17,18,19,20,22\end{array}$ \\
\hline Myrtaceae & Calyptranthes concinna DC. & $\mathrm{Av}$ & & & $\bullet$ & \\
\hline Myrtaceae & Calyptranthes lanceolata $\mathrm{O}$. Berg & Av & & $\bullet$ & & 3 \\
\hline Myrtaceae & Calyptranthes lucida Mart. ex DC. & $\mathrm{Av}$ & & & $\bullet$ & \\
\hline Myrtaceae & Calyptranthes aff. strigipes O.Berg & $\mathrm{Av}$ & & $\bullet$ & & 12 \\
\hline Myrtaceae & Campomanesia guaviroba (DC.) Kiaersk. & $\mathrm{Av}$ & 43661 & $\bullet$ & & $1,2,3,4,5,12,14$ \\
\hline Myrtaceae & Campomanesia neriiflora (O. Berg) Nied. & $\mathrm{Av}$ & 43654,43671 & $\bullet$ & $\bullet$ & $\begin{array}{c}2,7,8,9,10,11 \\
12,13,14,16,17 \\
18,19,20,21,22\end{array}$ \\
\hline Myrtaceae & Eugenia acutata Miq. & $\mathrm{Av}$ & & & $\bullet$ & \\
\hline
\end{tabular}

*COELHO, R. L. G. , SOUZA, V. C. \& FERRUCCI, M. S. 2012 (no prelo). Matayba obovata, a new species of Matayba sect. Matayba (Sapindaceae) from Brazil. Brittonia (Bronx, N.Y.). 
Tabela 3. Continuação...

\begin{tabular}{|c|c|c|c|c|c|c|}
\hline \multirow[t]{2}{*}{ Família } & \multirow[t]{2}{*}{ Espécie } & \multirow{2}{*}{$\begin{array}{r}\text { Forma } \\
\text { de vida }\end{array}$} & \multirow[t]{2}{*}{ SPSF } & \multicolumn{2}{|c|}{ FI } & \multirow[t]{2}{*}{ Trilha } \\
\hline & & & & $\mathbf{P}$ & $\mathbf{S}$ & \\
\hline Myrtaceae & Eugenia bimarginata DC. & $\mathrm{Av}$ & & & $\bullet$ & \\
\hline Myrtaceae & Eugenia cerasiflora Miq. & $\mathrm{Av}$ & & & $\bullet$ & \\
\hline Myrtaceae & Eugenia cuprea (O.Berg) Nied. & $\mathrm{Av}$ & & $\bullet$ & $\bullet$ & $2,11,12,18,21$ \\
\hline Myrtaceae & Eugenia florida DC. & Av & & & $\bullet$ & \\
\hline Myrtaceae & Eugenia hiemalis Cambess. & $\mathrm{Av}$ & & & $\bullet$ & \\
\hline Myrtaceae & Eugenia melanogyna (D. Legrand) Sobral & Av & 43663,43668 & $\bullet$ & $\bullet$ & 9,17 \\
\hline Myrtaceae & Eugenia mosenii (Kausel) Sobral & $\mathrm{Av}$ & & $\bullet$ & $\bullet$ & $3,4,5,17$ \\
\hline Myrtaceae & Eugenia multicostata D. Legrand & Av & & $\bullet$ & & $8,11,15,17$ \\
\hline Myrtaceae & Eugenia neoaustralis Sobral & Av & & $\bullet$ & & $2,4,8,9$ \\
\hline Myrtaceae & Eugenia cf. neoverrucosa Sobral & Av & & $\bullet$ & & $\begin{array}{l}2,4,5,11,12 \\
13,17,19,22\end{array}$ \\
\hline Myrtaceae & Eugenia oblongata $\mathrm{O}$. Berg & Av & & $\bullet$ & & $7,8,9,10,17,19$ \\
\hline Myrtaceae & Eugenia pruinosa D. Legrand & $\mathrm{Av}$ & & $\bullet$ & & 19 \\
\hline Myrtaceae & Eugenia pyriformis Cambess. & $\mathrm{Av}$ & & & $\bullet$ & \\
\hline Myrtaceae & Eugenia subavenia $\mathrm{O}$. Berg & $\mathrm{Av}$ & & $\bullet$ & & 8 \\
\hline Myrtaceae & Eugenia suffrutescens Nied. & $\mathrm{Av}$ & & & $\bullet$ & \\
\hline Myrtaceae & Eugenia supraaxillaris Spring & $\mathrm{Av}$ & & $\bullet$ & & 8 \\
\hline Myrtaceae & Eugenia verticillata (Vell.) Angely & $\mathrm{Av}$ & & & $\bullet$ & \\
\hline Myrtaceae & Eugenia sp.1 & Av & 43665 & $\bullet$ & & 12 \\
\hline Myrtaceae & Eugenia sp.2 & $\mathrm{Av}$ & & $\bullet$ & & 17 \\
\hline Myrtaceae & Eugenia sp.3 & $\mathrm{Av}$ & & $\bullet$ & & 21,22 \\
\hline Myrtaceae & Eugenia sp.4 & $\mathrm{Av}$ & & $\bullet$ & & 22 \\
\hline Myrtaceae & Eugenia sp.5 & Av & & $\bullet$ & & 22 \\
\hline Myrtaceae & Eugenia sp.6 & Av & & $\bullet$ & & 22 \\
\hline Myrtaceae & Eugenia sp.7 & $\mathrm{Av}$ & & $\bullet$ & & 2 \\
\hline Myrtaceae & Marlierea eugenioides (Cambess.) D. Legrand & Av & & & $\bullet$ & \\
\hline Myrtaceae & $\begin{array}{l}\text { Marlierea eugeniopsoides (D. Legrand \& Kausel) } \\
\text { D. Legrand }\end{array}$ & $\mathrm{Av}$ & 43672 & $\bullet$ & $\bullet$ & 19 \\
\hline Myrtaceae & Marlierea excoriata Mart. & $\mathrm{Av}$ & & $\bullet$ & $\bullet$ & 8,10 \\
\hline Myrtaceae & Marlierea aff. excoriata Mart. & Av & & $\bullet$ & & 11 \\
\hline Myrtaceae & Marlierea racemosa (Vell.) Kiaersk. & Av & $\begin{array}{l}43649,43655 \\
43656,43662\end{array}$ & $\bullet$ & & $3,8,9,11,14$ \\
\hline Myrtaceae & Marlierea reitzii D. Legrand & Av & & & $\bullet$ & \\
\hline Myrtaceae & Marlierea tomentosa Cambess. & $\mathrm{Av}$ & 43658,43670 & $\bullet$ & $\bullet$ & $8,11,13,19,22$ \\
\hline Myrtaceae & Myrceugenia campestris (DC.) D. Legrand \& Kausel & Av & 43650 & $\bullet$ & & 4,5 \\
\hline Myrtaceae & $\begin{array}{l}\text { Myrceugenia miersiana (Gardner) D. Legrand \& } \\
\text { Kausel }\end{array}$ & Av & & $\bullet$ & & $3,4,11,17,18$ \\
\hline Myrtaceae & Myrceugenia myrcioides (Cambess.) O. Berg & Av & 43648,43659 & $\bullet$ & $\bullet$ & $2,3,14$ \\
\hline Myrtaceae & Myrceugenia reitzii D. Legrand \& Kausel & $\mathrm{Av}$ & 43652,43666 & $\bullet$ & $\bullet$ & $11,17,18,19$ \\
\hline Myrtaceae & Myrceugenia sp. & $\mathrm{Av}$ & & $\bullet$ & & 5 \\
\hline Myrtaceae & Myrcia anacardiifolia Gardner & Av & & $\bullet$ & $\bullet$ & 22 \\
\hline Myrtaceae & Myrcia fallax (Rich.) DC. & Av & & & $\bullet$ & \\
\hline Myrtaceae & Myrcia formosiana DC. & Av & & & $\bullet$ & \\
\hline Myrtaceae & Myrcia grandiflora (O.Berg) Nied. & Av & & & $\bullet$ & \\
\hline Myrtaceae & Myrcia hatschbachii D. Legrand & Av & $\begin{array}{l}43651,43657, \\
43664\end{array}$ & $\bullet$ & & $5,8,12$ \\
\hline Myrtaceae & Myrcia laruotteana Cambess. & Av & & & $\bullet$ & \\
\hline Myrtaceae & Myrcia palustris DC. & Av & & & $\bullet$ & \\
\hline Myrtaceae & Myrcia pubipetala Miq. & $\mathrm{Av}$ & & & $\bullet$ & \\
\hline
\end{tabular}

*COELHO, R. L. G. , SOUZA, V. C. \& FERRUCCI, M. S. 2012 (no prelo). Matayba obovata, a new species of Matayba sect. Matayba (Sapindaceae) from Brazil. Brittonia (Bronx, N.Y.). 
Tabela 3. Continuação...

\begin{tabular}{|c|c|c|c|c|c|c|}
\hline \multirow[t]{2}{*}{ Família } & \multirow[t]{2}{*}{ Espécie } & \multirow{2}{*}{$\begin{array}{l}\text { Forma } \\
\text { de vida }\end{array}$} & \multirow[t]{2}{*}{ SPSF } & \multicolumn{2}{|c|}{ FI } & \multirow[t]{2}{*}{ Trilha } \\
\hline & & & & $\mathbf{P}$ & $\mathbf{S}$ & \\
\hline Myrtaceae & Myrcia pulchra (O.Berg) Kiaersk. & Av & & & $\bullet$ & \\
\hline Myrtaceae & Myrcia rufula Miq. & Av & 43660,43669 & $\bullet$ & $\bullet$ & $1,4,5,9,12,14$ \\
\hline Myrtaceae & Myrcia aff. rufula Miq. & Av & & $\bullet$ & & 17 \\
\hline Myrtaceae & Myrcia spectabilis DC. & Av & & $\bullet$ & & $3,8,9,10,13$ \\
\hline Myrtaceae & Myrcia tenuivenosa Kiaersk. & Av & & $\bullet$ & $\bullet$ & 12 \\
\hline Myrtaceae & Myrcia tijucensis Kiaersk. & Av & & $\bullet$ & $\bullet$ & 19 \\
\hline Myrtaceae & Myrcia sp. & Av & & $\bullet$ & & 2 \\
\hline Myrtaceae & Myrcia sp.1 & Av & & $\bullet$ & & 17 \\
\hline Myrtaceae & Myrcia sp.2 & $\mathrm{Av}$ & & $\bullet$ & & 19,21 \\
\hline Myrtaceae & Myrciaria cf. floribunda (H.West ex Willd.) O.Berg & Av & & $\bullet$ & & $\begin{array}{c}2,3,7,8,9,11 \\
12,14,21,22\end{array}$ \\
\hline Myrtaceae & Plinia cauliflora (Mart.) Kausel & Av & & $\bullet$ & & 13 \\
\hline Myrtaceae & Psidium cattleianum Sabine & Av & 43653 & $\bullet$ & $\bullet$ & $\begin{array}{c}1,3,4,7,8,9 \\
11,13,15,17\end{array}$ \\
\hline Myrtaceae & Psidium sp. & Av & 43667 & $\bullet$ & & 17,19 \\
\hline Myrtaceae & Indeterminada & Av & & $\bullet$ & & 11 \\
\hline Nyctaginaceae & Guapira opposita (Vell.) Reitz & Av & $\begin{array}{c}43273,43274 \\
43275,43276\end{array}$ & $\bullet$ & $\bullet$ & $\begin{array}{c}2,4,5,7,8,11,12, \\
13,17,18,19,21,22\end{array}$ \\
\hline Ochnaceae & Quiina glaziovii Engl. & $\mathrm{Av}$ & & $\bullet$ & $\bullet$ & $\begin{array}{l}3,8,9,11,12 \\
13,19,20,22\end{array}$ \\
\hline Olacaceae & Heisteria silvianii Schwacke & Av & & $\bullet$ & $\bullet$ & $3,8,17$ \\
\hline Olacaceae & Tetrastylidium grandifolium (Baill.) Sleumer & Av & 43277 & $\bullet$ & & 11,20 \\
\hline Oleaceae & Chionanthus filiformis (Vell.) P.S. Green & Av & & $\bullet$ & & $4,11,12,22$ \\
\hline Onagraceae & Fuchsia regia (Vell.) Munz & $\operatorname{Tr}$ & & & $\bullet$ & \\
\hline Onagraceae & Ludwigia octovalvis (Jacq.) P.H. Raven & $\mathrm{Sb}$ & & & $\bullet$ & \\
\hline Onagraceae & Ludwigia sericea (Cambess.) H. Hara & $\mathrm{Sb}$ & & & $\bullet$ & \\
\hline Orchidaceae & Bifrenaria harrisoniae (Hook.) Rchb.f. & Ep & & & $\bullet$ & \\
\hline Orchidaceae & Capanemia australis (Kraenzl.) Schltr. & Ep & & & $\bullet$ & \\
\hline Orchidaceae & Cleistes libonii (Rchb.f.) Schltr. & Ev & & & $\bullet$ & \\
\hline Orchidaceae & Cranichis candida (Barb. Rodr.) Cogn. & Ep & & & $\bullet$ & \\
\hline Orchidaceae & Epidendrum secundum Jacq. & Ep & & & $\bullet$ & \\
\hline Orchidaceae & Habenaria parviflora Lindl. & Ev & & & $\bullet$ & \\
\hline Orchidaceae & Liparis nervosa (Thunb.) Lindl. & Ep & & & $\bullet$ & \\
\hline Orchidaceae & Maxillaria picta Hook. & Ep & & & $\bullet$ & \\
\hline Orchidaceae & Oncidium hookerii Rolfe & Ep & & & $\bullet$ & \\
\hline Orchidaceae & Phymatidium delicatulum Lindl. & Ep & & & $\bullet$ & \\
\hline Orchidaceae & Prosthechea fausta (Rchb.f. ex Cogn.) W.E.Higgins & Ep & & & $\bullet$ & \\
\hline Orchidaceae & Specklinia aff. grobyi (Batem. ex Lindl.) F.Barros & Ep & & & $\bullet$ & \\
\hline Orchidaceae & Zygostastes multiflora (Rolfe) Schltr. & Ep & & & $\bullet$ & \\
\hline Osmundaceae & Osmundastrum cinnamomeum (L.) C.Presl & Ep & & & $\bullet$ & \\
\hline Passifloraceae & Passiflora capsularis L. & $\operatorname{Tr}$ & & & $\bullet$ & \\
\hline Passifloraceae & Passiflora jileki Wawra & $\operatorname{Tr}$ & & & $\bullet$ & \\
\hline Passifloraceae & Passiflora misera Kunth & $\operatorname{Tr}$ & & & $\bullet$ & \\
\hline Passifloraceae & Passiflora organensis Gardner & $\operatorname{Tr}$ & & & $\bullet$ & \\
\hline Phyllanthaceae & Hieronyma alchorneoides Allemão & $\mathrm{Av}$ & 43278 & $\bullet$ & $\bullet$ & $\begin{array}{l}1,2,3,4,5,7,8 \\
9,10,11,12,13 \\
17,19,20,21,22\end{array}$ \\
\hline Phyllanthaceae & Margaritaria nobilis L. f. & Av & & & $\bullet$ & \\
\hline Phyllanthaceae & Phyllanthus avicularis Müll. Arg. & $\mathrm{Ab}$ & & & $\bullet$ & \\
\hline
\end{tabular}


Tabela 3. Continuação...

\begin{tabular}{|c|c|c|c|c|c|c|}
\hline \multirow[t]{2}{*}{ Família } & \multirow[t]{2}{*}{ Espécie } & \multirow{2}{*}{$\begin{array}{l}\text { Forma } \\
\text { de vida }\end{array}$} & \multirow[t]{2}{*}{ SPSF } & \multicolumn{2}{|c|}{ FI } & \multirow[t]{2}{*}{ Trilha } \\
\hline & & & & $\mathbf{P}$ & $\mathbf{S}$ & \\
\hline Phytolaccaceae & Gallesia integrifolia (Spreng.) Harms & $\mathrm{Av}$ & & $\bullet$ & & $18,21,22$ \\
\hline Phytolaccaceae & Phytolacca dioica $\mathrm{L}$. & $\mathrm{Av}$ & 43279 & $\bullet$ & $\bullet$ & $\begin{array}{c}2,8,12,13,14 \\
17,20,21,22\end{array}$ \\
\hline Phytolaccaceae & Phytolacca thyrsiflora Fenzl ex J.A. Schmidt & Ev & & & $\bullet$ & \\
\hline Phytolaccaceae & Seguieria langsdorffii Moq. & $\mathrm{Av}$ & & $\bullet$ & & 1,22 \\
\hline Piperaceae & Manekia obtusa (Miq.) T. Arias, Callejas \& Bornst. & $\mathrm{Sb}$ & & & $\bullet$ & \\
\hline Piperaceae & Peperomia catharinae Miq. & Ep & & & $\bullet$ & \\
\hline Piperaceae & Peperomia corcovadensis Gardner & Ep & & & $\bullet$ & \\
\hline Piperaceae & Peperomia emarginella (Sw.) C. DC. & Ep & & & $\bullet$ & \\
\hline Piperaceae & Peperomia martiana Miq. & Ep & & & $\bullet$ & \\
\hline Piperaceae & Peperomia rubricaulis (Nees) A. Dietr. & Ep & & & $\bullet$ & \\
\hline Piperaceae & Peperomia tetraphylla (G. Forst.) Hook. \& Arn. & Ep & & & $\bullet$ & \\
\hline Piperaceae & Peperomia urocarpa Fisch. \& C.A. Mey. & Ep & & & $\bullet$ & \\
\hline Piperaceae & Piper aduncum L. & $\mathrm{Ab}$ & 43285 & $\bullet$ & $\bullet$ & $\begin{array}{c}3,4,5,6,7,8,9,10 \\
11,12,18,19,22\end{array}$ \\
\hline Piperaceae & Piper arboreum Aubl. & $\mathrm{Ab}$ & & & $\bullet$ & \\
\hline Piperaceae & Piper caldense C. DC. & $\mathrm{Ab}$ & 43280,43281 & $\bullet$ & & 2,17 \\
\hline Piperaceae & Piper cernuum Vell. & $\mathrm{Ab}$ & 43282 & $\bullet$ & $\bullet$ & $\begin{array}{l}2,3,4,8,10 \\
13,17,19,22\end{array}$ \\
\hline Piperaceae & Piper crassinervium Kunth & $\mathrm{Ab}$ & & & $\bullet$ & \\
\hline Piperaceae & Piper diospyrifolium Kunth & $\mathrm{Ab}$ & & & $\bullet$ & \\
\hline Piperaceae & Piper gaudichaudianum Kunth & $\mathrm{Ab}$ & 43283,43287 & $\bullet$ & $\bullet$ & 2,17 \\
\hline Piperaceae & Piper lepturum Kunth & $\mathrm{Ab}$ & & & $\bullet$ & \\
\hline Piperaceae & Piper lhotzkyanum Kunth & $\mathrm{Ab}$ & 43286 & $\bullet$ & & $7,10,11$ \\
\hline Piperaceae & Piper cf. mosenii C. DC. & $\mathrm{Ab}$ & & & $\bullet$ & \\
\hline Piperaceae & Piper xylosteoides (Kunth) Steud. & $\mathrm{Ab}$ & 43284 & $\bullet$ & & 3 \\
\hline Plantaginaceae & Mecardonia procumbens (Mill.) Small & Ev & & & $\bullet$ & \\
\hline Plantaginaceae & Scoparia dulcis $\mathrm{L}$. & Ev & & & $\bullet$ & \\
\hline Plantaginaceae & Scoparia elliptica Cham. & Ev & & & $\bullet$ & \\
\hline Plantaginaceae & Scoparia montevidensis (Spreng.) R.E. Fr. & Ev & & & $\bullet$ & \\
\hline Plantaginaceae & Stemodia trifoliata (Link) Rchb. & $\mathrm{Ev}$ & & & $\bullet$ & \\
\hline Plantaginaceae & Stemodia verticillata (Mill.) Hassl. & $\mathrm{Ev}$ & & & $\bullet$ & \\
\hline Poaceae & Andropogon bicornis $\mathrm{L}$. & $\mathrm{Ev}$ & & $\bullet$ & & 1 \\
\hline Poaceae & Chusquea sp. & $\mathrm{Ba}$ & & $\bullet$ & & 5 \\
\hline Poaceae & Guadua tagoara (Nees) Kunth & $\mathrm{Ba}$ & 43288 & $\bullet$ & & $1,2,3,10$ \\
\hline Poaceae & Ichnanthus pallens (Sw.) Munro ex Benth. & Ev & & & $\bullet$ & \\
\hline Poaceae & Lasiacis sorghoidea (Desv. ex Ham.) Hitchc. \& Chase & $\mathrm{Ev}$ & & & $\bullet$ & \\
\hline Poaceae & Leptochloa fusca subsp. uninervia (J. Presl) N. Snow & Ev & & & $\bullet$ & \\
\hline Poaceae & Merostachys cf. abadiana Send. & $\mathrm{Ba}$ & 43289 & $\bullet$ & & $3,4,5,8,11$ \\
\hline Poaceae & Merostachys cf. skvortzovii Send. & $\mathrm{Ba}$ & 43290 & $\bullet$ & & 19 \\
\hline Poaceae & cf. Merostachys sp. & $\mathrm{Ba}$ & & $\bullet$ & & 4 \\
\hline Poaceae & Olyra latifolia L. & Ev & & & $\bullet$ & \\
\hline Poaceae & Oplismenus hirtellus (L.) P. Beauv. & Ev & & & $\bullet$ & \\
\hline Poaceae & Panicum pilosum $\mathrm{Sw}$. & Ev & & & $\bullet$ & \\
\hline Poaceae & Steinchisma laxa (Sw.) Zuloaga & Ev & & & $\bullet$ & \\
\hline Podocarpaceae & Podocarpus sellowii Klotzsch ex Endl. & Av & & & $\bullet$ & \\
\hline Polygalaceae & Polygala lancifolia A. St.-Hil. \& Moq. & Ev & & & $\bullet$ & \\
\hline Polygalaceae & Polygala laureola A. St.-Hil. \& Moq. & Ev & & & $\bullet$ & \\
\hline Polygalaceae & Polygala paniculata $\mathrm{L}$. & Ev & & & $\bullet$ & \\
\hline
\end{tabular}

*COELHO, R. L. G., SOUZA, V. C. \& FERRUCCI, M. S. 2012 (no prelo). Matayba obovata, a new species of Matayba sect. Matayba (Sapindaceae) from Brazil. Brittonia (Bronx, N.Y.). 
Tabela 3. Continuação...

\begin{tabular}{|c|c|c|c|c|c|c|}
\hline \multirow[t]{2}{*}{ Família } & \multirow[t]{2}{*}{ Espécie } & \multirow{2}{*}{$\begin{array}{l}\text { Forma } \\
\text { de vida }\end{array}$} & \multirow[t]{2}{*}{ SPSF } & \multicolumn{2}{|c|}{ FI } & \multirow[t]{2}{*}{ Trilha } \\
\hline & & & & $\mathbf{P}$ & $\mathbf{S}$ & \\
\hline Polygonaceae & Coccoloba mollis Casar. & $\mathrm{Av}$ & & $\bullet$ & & $3,4,5$ \\
\hline Polygonaceae & Polygonum punctatum Elliott & Ev & & & $\bullet$ & \\
\hline Polygonaceae & Ruprechtia laxiflora Meisn. & $\mathrm{Av}$ & & $\bullet$ & & $\begin{array}{c}2,8,11,12 \\
16,17,21\end{array}$ \\
\hline Pontederiaceae & Heteranthera reniformis Ruiz \& Pav. & Ev & & & $\bullet$ & \\
\hline Primulaceae & Anagallis barbata (P. Taylor) Kupicha & Ev & & & $\bullet$ & \\
\hline Primulaceae & Anagallis filiformis Cham. \& Schltdl. & Ev & & & $\bullet$ & \\
\hline Primulaceae & Ardisia guianensis (Aubl.) Mez & Av & 43269 & $\bullet$ & $\bullet$ & 11,12 \\
\hline Primulaceae & Rapanea lancifolia (Mart.) Mez & Av & & & $\bullet$ & \\
\hline Primulaceae & Rapanea ferruginea (Ruiz \& Pav.) Mez & $\mathrm{Av}$ & 43270 & $\bullet$ & $\bullet$ & $\begin{array}{l}1,2,3,4,5,7,8,9 \\
10,11,13,14,19,21\end{array}$ \\
\hline Primulaceae & Rapanea gardneriana (A. DC.) Mez & Av & 43271 & $\bullet$ & $\bullet$ & 4,5 \\
\hline Primulaceae & Rapanea hermogenesii Jung-Mend. \& Bernacci & Av & & $\bullet$ & $\bullet$ & 12 \\
\hline Primulaceae & Rapanea umbellata (Mart.) Mez & Av & 43272 & $\bullet$ & $\bullet$ & $4,11,13,14$ \\
\hline Proteaceae & $\begin{array}{l}\text { Roupala montana var. brasiliensis (Klotzsch) } \\
\text { K.S.Edwards }\end{array}$ & Av & & $\bullet$ & $\bullet$ & 14,20 \\
\hline Psilotaceae & Psilotum nudum (L.) P. Beauv. & Ev & & & $\bullet$ & \\
\hline Ranunculaceae & Clematis dioica $\mathrm{L}$. & $\operatorname{Tr}$ & & & $\bullet$ & \\
\hline Rhamnaceae & Gouania latifolia Reissek & $\operatorname{Tr}$ & & & $\bullet$ & \\
\hline Rhamnaceae & Rhamnus sphaerosperma $\mathrm{Sw}$. & $\mathrm{Av}$ & & $\bullet$ & $\bullet$ & 14 \\
\hline Rosaceae & Acaena eupatoria Cham. \& Schltdl. & Ev & & & $\bullet$ & \\
\hline Rosaceae & Prunus myrtifolia (L.) Urb. & Av & & $\bullet$ & $\bullet$ & $1,3,4,5,8,11,14$ \\
\hline Rosaceae & Rubus rosifolius $\mathrm{Sm}$. & $\mathrm{Ab}$ & & & $\bullet$ & \\
\hline Rubiaceae & Alseis floribunda Schott & Av & & $\bullet$ & $\bullet$ & $12,17,18,19,22$ \\
\hline Rubiaceae & Amaioua intermedia Mart. ex Schult. \& Schult.f. & Av & & $\bullet$ & & $3,8,11$ \\
\hline Rubiaceae & Bathysa australis (A.St.-Hil.) K.Schum. & $\mathrm{Av}$ & 43297 & $\bullet$ & $\bullet$ & $\begin{array}{c}1,2,3,4,5,7,8,9 \\
10,11,12,13,17 \\
18,19,20,21,22\end{array}$ \\
\hline Rubiaceae & Borreria alata (Aubl.) DC. & $\mathrm{Ev}$ & & & $\bullet$ & \\
\hline Rubiaceae & Borreria suaveolens $\mathrm{G}$. Mey. & $\mathrm{Ev}$ & & & $\bullet$ & \\
\hline Rubiaceae & Borreria verticillata (L.) G.Mey. & Ev & & & $\bullet$ & \\
\hline Rubiaceae & Chomelia brasiliana A. Rich. & Av & & $\bullet$ & & 22 \\
\hline Rubiaceae & Coccocypselum guianense (Aubl.) K. Schum. & Ev & & & $\bullet$ & \\
\hline Rubiaceae & Coccocypselum lanceolatum (Ruiz \& Pav.) Pers. & Ev & & & $\bullet$ & \\
\hline Rubiaceae & Cordiera concolor (Cham.) Kuntze & Av & & & $\bullet$ & \\
\hline Rubiaceae & $\begin{array}{l}\text { Cordiera myrciifolia (K.Schum.) C.H.Perss. \& } \\
\text { Delprete }\end{array}$ & $\mathrm{Av}$ & & & $\bullet$ & \\
\hline Rubiaceae & Faramea sp. & $\mathrm{Av}$ & 43300 & $\bullet$ & & 19 \\
\hline Rubiaceae & Galianthe pseudopeciolata E.L.Cabral & $\mathrm{Ab}$ & & & $\bullet$ & \\
\hline Rubiaceae & Galium hypocarpium (L.) Endl. ex Griseb. & Ev & & & $\bullet$ & \\
\hline Rubiaceae & Manettia gracilis Cham. \& Schltdl. & $\operatorname{Tr}$ & & & $\bullet$ & \\
\hline Rubiaceae & Manettia pubescens Cham. \& Schltdl. & $\operatorname{Tr}$ & & & $\bullet$ & \\
\hline Rubiaceae & Palicourea marcgravii A. St.-Hil. & Av & & & $\bullet$ & \\
\hline Rubiaceae & Posoqueria acutifolia Mart. & $\mathrm{Av}$ & & & $\bullet$ & \\
\hline Rubiaceae & Posoqueria latifolia (Rudge) Schult. & Av & & $\bullet$ & $\bullet$ & 11 \\
\hline Rubiaceae & Psychotria cf. brachypoda (Müll. Arg.) Britton & Av & 43299 & $\bullet$ & & 8,22 \\
\hline Rubiaceae & Psychotria carthagenensis Jacq. & $\mathrm{Av}$ & 43295,43298 & $\bullet$ & $\bullet$ & $\begin{array}{l}2,3,8,11,12 \\
17,18,19,22\end{array}$ \\
\hline Rubiaceae & Psychotria deflexa DC. & $\mathrm{Av}$ & & & $\bullet$ & \\
\hline
\end{tabular}

*COELHO, R. L. G. , SOUZA, V. C. \& FERRUCCI, M. S. 2012 (no prelo). Matayba obovata, a new species of Matayba sect. Matayba (Sapindaceae) from Brazil. Brittonia (Bronx, N.Y.). 
Tabela 3. Continuação...

\begin{tabular}{|c|c|c|c|c|c|c|}
\hline \multirow[t]{2}{*}{ Família } & \multirow[t]{2}{*}{ Espécie } & \multirow{2}{*}{$\begin{array}{l}\text { Forma } \\
\text { de vida }\end{array}$} & \multirow[t]{2}{*}{ SPSF } & \multicolumn{2}{|c|}{ FI } & \multirow[t]{2}{*}{ Trilha } \\
\hline & & & & $\mathbf{P}$ & $\mathbf{S}$ & \\
\hline Rubiaceae & Psychotria paniculata (Aubl.) Raeusch. & Av & & & $\bullet$ & \\
\hline Rubiaceae & Psychotria forsteronioides Müll. Arg. & Av & & & $\bullet$ & \\
\hline Rubiaceae & Psychotria laciniata Vell. & $\mathrm{Av}$ & & & $\bullet$ & \\
\hline Rubiaceae & Psychotria leiocarpa Cham. \& Schltdl. & Av & & & $\bullet$ & \\
\hline Rubiaceae & Psychotria longipes Müll. Arg. & Av & & $\bullet$ & & 5 \\
\hline Rubiaceae & Psychotria forsteronioides Müll. Arg. & Av & & & $\bullet$ & \\
\hline Rubiaceae & Psychotria mapoureoides DC. & Av & & & $\bullet$ & \\
\hline Rubiaceae & Psychotria suterella Müll. Arg. & $\mathrm{Av}$ & 43291 & $\bullet$ & $\bullet$ & $\begin{array}{l}1,3,4,5,7,8,9 \\
11,12,14,17,19\end{array}$ \\
\hline Rubiaceae & Psychotria tenerior (Cham.) Müll. Arg. & $\mathrm{Av}$ & & & $\bullet$ & \\
\hline Rubiaceae & Randia armata (Sw.) DC. & $\mathrm{Ab}$ & 43294 & $\bullet$ & & 11 \\
\hline Rubiaceae & Rudgea jasminoides (Cham.) Müll. Arg. & $\mathrm{Av}$ & 43292,43293 & $\bullet$ & $\bullet$ & $3,4,8,9,12,17,19$ \\
\hline Rubiaceae & Rudgea sessilis (Vell.) Müll.Arg. & $\mathrm{Av}$ & & & $\bullet$ & \\
\hline Rubiaceae & Simira pikia (K. Schum.) Steyerm. & $\mathrm{Av}$ & 43296 & $\bullet$ & & 12 \\
\hline Rutaceae & Esenbeckia febrifuga (A. St.-Hil.) A. Juss. ex Mart. & $\mathrm{Av}$ & & & $\bullet$ & \\
\hline Rutaceae & Esenbeckia grandiflora Mart. & $\mathrm{Av}$ & & & - & \\
\hline Rutaceae & Zanthoxylum rhoifolium Lam. & $\mathrm{Av}$ & & $\bullet$ & $\bullet$ & $1,3,5,8,10,20$ \\
\hline Sabiaceae & Meliosma sellowii Urb. & $\mathrm{Av}$ & 43301,43302 & $\bullet$ & $\bullet$ & $8,20,22$ \\
\hline Saccolomataceae & Saccoloma elegans Kaulf. & Ev & & & $\bullet$ & \\
\hline Salicaceae & Abatia angeliana M.H.Alford & $\mathrm{Ab}$ & & & $\bullet$ & \\
\hline Salicaceae & Banara tomentosa Clos. & $\mathrm{Ab}$ & & & $\bullet$ & \\
\hline Salicaceae & Casearia decandra Jacq. & Av & 43306 & $\bullet$ & $\bullet$ & $1,4,8,9,10,12,17$ \\
\hline Salicaceae & Casearia lasiophylla Eichler & Av & & & $\bullet$ & \\
\hline Salicaceae & Casearia obliqua Spreng. & $\mathrm{Av}$ & & $\bullet$ & $\bullet$ & 4,5 \\
\hline Salicaceae & Casearia sylvestris $\mathrm{Sw}$. & Av & 43303,43305 & $\bullet$ & $\bullet$ & $\begin{array}{l}1,2,3,4,5,6,7,8,9 \\
10,11,12,13,14,17\end{array}$ \\
\hline Salicaceae & Prockia crucis P. Browne ex L. & $\mathrm{Av}$ & 43304 & $\bullet$ & $\bullet$ & $2,7,8,11,12,20$ \\
\hline Sapindaceae & Allophylus edulis (A.St.-Hil. et al.) Hieron. ex Niederl. & $\mathrm{Av}$ & 43312 & $\bullet$ & $\bullet$ & $\begin{array}{l}1,2,6,7,8,9,10 \\
11,12,13,16,17 \\
18,19,20,21,22\end{array}$ \\
\hline Sapindaceae & Allophylus petiolulatus Radlk. & $\mathrm{Av}$ & 43307 & $\bullet$ & & $3,10,19$ \\
\hline Sapindaceae & Allophylus semidentatus (Miq.) Radlk. & $\mathrm{Av}$ & 43308 & $\bullet$ & & 11 \\
\hline Sapindaceae & Cupania oblongifolia Mart. & $\mathrm{Av}$ & 43309,43311 & $\bullet$ & $\bullet$ & $\begin{array}{l}1,3,4,5,7,8,9,11 \\
13,14,16,17,18,19\end{array}$ \\
\hline Sapindaceae & Cupania vernalis Cambess. & $\mathrm{Av}$ & & $\bullet$ & $\bullet$ & 14 \\
\hline Sapindaceae & Matayba elaegnoides Radlk. & $\mathrm{Av}$ & & & $\bullet$ & \\
\hline Sapindaceae & Matayba guianensis Aubl. & Av & 43310 & $\bullet$ & $\bullet$ & $\begin{array}{l}1,2,3,4,5,7,8 \\
10,13,14,20\end{array}$ \\
\hline Sapindaceae & Matayba obovata sp. nov.* & $\mathrm{Av}$ & & $\bullet$ & $\bullet$ & $8,9,13,14,17$ \\
\hline Sapindaceae & Serjania glabrata Kunth & $\operatorname{Tr}$ & & & $\bullet$ & \\
\hline Sapotaceae & $\begin{array}{l}\text { Chrysophyllum gonocarpum (Mart. \& Eichler ex } \\
\text { Miq.) Engl. }\end{array}$ & $\mathrm{Av}$ & 43828 & $\bullet$ & & 12,22 \\
\hline Sapotaceae & Chrysophyllum inornatum Mart. & Av & 43313,43314 & $\bullet$ & $\bullet$ & $\begin{array}{c}3,7,8,9,10,11 \\
12,13,17,18,19 \\
20,21,22\end{array}$ \\
\hline Sapotaceae & Chrysophyllum viride Mart. \& Eichler & $\mathrm{Av}$ & & $\bullet$ & & $\begin{array}{l}2,3,4,9,12 \\
13,17,18,20\end{array}$ \\
\hline Sapotaceae & Ecclinusa ramiflora Mart. & $\mathrm{Av}$ & & & $\bullet$ & \\
\hline Sapotaceae & Pouteria bullata (S. Moore) Baehni & $\mathrm{Av}$ & & $\bullet$ & & $4,5,8,11$ \\
\hline Sapotaceae & Pouteria caimito (Ruiz \& Pav.) Radlk. & Av & & $\bullet$ & & $8,9,12,16$ \\
\hline
\end{tabular}

*COELHO, R. L. G. , SOUZA, V. C. \& FERRUCCI, M. S. 2012 (no prelo). Matayba obovata, a new species of Matayba sect. Matayba (Sapindaceae) from Brazil. Brittonia (Bronx, N.Y.). 
Tabela 3. Continuação...

\begin{tabular}{|c|c|c|c|c|c|c|}
\hline \multirow[t]{2}{*}{ Família } & \multirow[t]{2}{*}{ Espécie } & \multirow{2}{*}{$\begin{array}{l}\text { Forma } \\
\text { de vida }\end{array}$} & \multirow[t]{2}{*}{ SPSF } & \multicolumn{2}{|c|}{ FI } & \multirow[t]{2}{*}{ Trilha } \\
\hline & & & & $\mathbf{P}$ & $\mathbf{S}$ & \\
\hline Sapotaceae & Pouteria gardneri (Mart. \& Miq.) Baehni & Av & & $\bullet$ & & 22 \\
\hline Sapotaceae & Pouteria psammophila (Mart.) Radlk. & Av & & $\bullet$ & $\bullet$ & $2,5,11,15,22$ \\
\hline Sapotaceae & Pouteria venosa (Mart.) Baehni & Av & & & $\bullet$ & \\
\hline Selaginellaceae & Selaginella flexuosa Spring & Ev & & & $\bullet$ & \\
\hline Selaginellaceae & Selaginella sulcata (Desv. ex Poir.) Spring & Ev & & & $\bullet$ & \\
\hline Smilacaceae & Smilax cognata Kunth & $\operatorname{Tr}$ & & & $\bullet$ & \\
\hline Solanaceae & Athenaea picta (Mart.) Sendtn. & Av & & & $\bullet$ & \\
\hline Solanaceae & Aureliana fasciculata (Vell.) Sendtn. & $\mathrm{Av}$ & $\begin{array}{c}43317,43320 \\
43321\end{array}$ & $\bullet$ & $\bullet$ & $2,3,4,5,9$ \\
\hline Solanaceae & Aureliana wettsteiniana (Witasek) Hunz. & Av & & & $\bullet$ & \\
\hline Solanaceae & Brunfelsia pauciflora (Cham. \& Schltdl.) Benth. & $\mathrm{Ab}$ & & $\bullet$ & & 20,22 \\
\hline Solanaceae & Brunfelsia aff. pauciflora (Cham. \& Schltdl.) Benth. & $\mathrm{Ab}$ & & & $\bullet$ & \\
\hline Solanaceae & Brunfelsia uniflora (Pohl) D. Don & $\mathrm{Ab}$ & & $\bullet$ & & 5 \\
\hline Solanaceae & Capsicum baccatum $\mathrm{L}$. & $\mathrm{Ab}$ & & & $\bullet$ & \\
\hline Solanaceae & Cestrum bracteatum Link \& Otto & Av & & & $\bullet$ & \\
\hline Solanaceae & Cestrum mariquitense Kunth & $\mathrm{Ab}$ & 43319 & $\bullet$ & & 2 \\
\hline Solanaceae & Dyssochroma longipes (Sendtn.) Miers & Ep & & & $\bullet$ & \\
\hline Solanaceae & Solandra grandiflora $\mathrm{Sw}$. & $\mathrm{He}$ & 43318 & $\bullet$ & & 2 \\
\hline Solanaceae & Solanum campaniforme Roem. \& Schult. & $\mathrm{Ab}$ & 43322,43327 & $\bullet$ & & $8,10,11,18$ \\
\hline Solanaceae & Solanum cinnamomeum Sendtn. & Av & & $\bullet$ & & 4,5 \\
\hline Solanaceae & Solanum flaccidum Vell. & Ev & & & $\bullet$ & \\
\hline Solanaceae & Solanum granulosoleprosum Dunal & Av & & $\bullet$ & & 1 \\
\hline Solanaceae & Solanum hirtellum (Spreng.) Hassl. & $\mathrm{Ab}$ & & & $\bullet$ & \\
\hline Solanaceae & Solanum intermedium Sendtn. & $\mathrm{Ab}$ & & & $\bullet$ & \\
\hline Solanaceae & Solanum lacerdae Dusén & $\mathrm{Ab}$ & & & $\bullet$ & \\
\hline Solanaceae & Solanum mauritianum Scop. & Av & & & $\bullet$ & \\
\hline Solanaceae & Solanum pseudoquina A. St.-Hil. & $\mathrm{Av}$ & & $\bullet$ & & $1,2,22$ \\
\hline Solanaceae & Solanum sanctae-catharinae Dunal & Av & $\begin{array}{c}43315,43316 \\
43325\end{array}$ & $\bullet$ & & $1,2,5,7,13$ \\
\hline Solanaceae & Solanum swartzianum Roem. \& Schult. & $\mathrm{Av}$ & 43323 & $\bullet$ & $\bullet$ & 4,14 \\
\hline Solanaceae & Solanum variabile Mart. & $\mathrm{Ab}$ & 43324 & $\bullet$ & & 10 \\
\hline Styracaceae & Styrax acuminatus Pohl & Av & & & $\bullet$ & \\
\hline Styracaceae & Styrax leprosus Hook. \& Arn. & $\mathrm{Av}$ & & & $\bullet$ & \\
\hline Symplocaceae & Symplocos celastrinea Mart. & $\mathrm{Av}$ & 43328,43329 & $\bullet$ & $\bullet$ & $5,7,21$ \\
\hline Symplocaceae & Symplocos estrellensis Casar. & Av & & $\bullet$ & & 9,11 \\
\hline Symplocaceae & Symplocos kleinii A.Bida & Av & & & $\bullet$ & \\
\hline Symplocaceae & Symplocos laxiflora Benth. & Av & & & $\bullet$ & \\
\hline Symplocaceae & Symplocos tenuifolia Brand & Av & & & $\bullet$ & \\
\hline Symplocaceae & Symplocos tetrandra Mart. & Av & & & $\bullet$ & \\
\hline Symplocaceae & Symplocos uniflora (Pohl) Benth. & Av & & & $\bullet$ & \\
\hline Theaceae & Laplacea fructicosa (Schrad.) Kobuski & Av & 43330 & $\bullet$ & $\bullet$ & 4 \\
\hline Thelypteridaceae & Thelypteris opposita (Vahl) Ching & Ev & & & $\bullet$ & \\
\hline Thymelaeaceae & Daphnopsis fasciculata (Meisn.) Nevling & $\mathrm{Av}$ & 43331 & $\bullet$ & & $4,5,11$ \\
\hline Urticaceae & Boehmeria caudata $\mathrm{Sw}$. & $\mathrm{Ab}$ & & $\bullet$ & $\bullet$ & $\begin{array}{c}1,2,3,4,7,8 \\
9,10,11,12,19\end{array}$ \\
\hline Urticaceae & Cecropia glaziovi Snethl. & $\mathrm{Av}$ & & $\bullet$ & $\bullet$ & $\begin{array}{c}1,2,3,4,6,8 \\
10,11,12,13,14 \\
17,18,19,21,22\end{array}$ \\
\hline Urticaceae & Cecropia pachystachya Trécul & Av & & & $\bullet$ & \\
\hline
\end{tabular}

*COELHO, R. L. G. , SOUZA, V. C. \& FERRUCCI, M. S. 2012 (no prelo). Matayba obovata, a new species of Matayba sect. Matayba (Sapindaceae) from Brazil. Brittonia (Bronx, N.Y.). 
Tabela 3. Continuação...

\begin{tabular}{|c|c|c|c|c|c|c|}
\hline \multirow[t]{2}{*}{ Família } & \multirow[t]{2}{*}{ Espécie } & \multirow{2}{*}{$\begin{array}{r}\text { Forma } \\
\text { de vida }\end{array}$} & \multirow[t]{2}{*}{ SPSF } & \multicolumn{2}{|c|}{ FI } & \multirow[t]{2}{*}{ Trilha } \\
\hline & & & & $\mathbf{P}$ & $\mathbf{S}$ & \\
\hline Urticaceae & Coussapoa microcarpa (Schott) Rizzini & $\mathrm{He}$ & & $\bullet$ & $\bullet$ & $1,3,6,12,13,19$ \\
\hline Urticaceae & Myriocarpa stipitata Benth. & $\mathrm{Ab}$ & & $\bullet$ & & $\begin{array}{c}2,7,8,12,13 \\
18,19,21,22\end{array}$ \\
\hline Urticaceae & Pilea grossecrenata Miq. & Ev & & & $\bullet$ & \\
\hline Urticaceae & Pourouma guianensis Aubl. & $\mathrm{Av}$ & & & $\bullet$ & \\
\hline Urticaceae & Urera baccifera (L.) Gaudich. ex Wedd. & Av & & $\bullet$ & $\bullet$ & $2,9,10,11,12,21$ \\
\hline Verbenaceae & Aloysia virgata (Ruiz \& Pav.) Juss. & $\mathrm{Av}$ & & $\bullet$ & & 12 \\
\hline Verbenaceae & Citharexylum myrianthum Cham. & Av & & $\bullet$ & $\bullet$ & $6,7,8,10,11,12$ \\
\hline Verbenaceae & Citharexylum solanaceum Cham. & Av & & & $\bullet$ & \\
\hline Verbenaceae & Lantana trifolia $\mathrm{L}$. & $\mathrm{Ab}$ & & & $\bullet$ & \\
\hline Verbenaceae & Lippia alba (Mill.) N.E. Br. & $\mathrm{Ab}$ & & & $\bullet$ & \\
\hline Verbenaceae & Verbena bonariensis L. & $\mathrm{Ab}$ & & & $\bullet$ & \\
\hline Verbenaceae & Verbena litoralis Kunth & $\mathrm{Ab}$ & & & $\bullet$ & \\
\hline Verbenaceae & Verbena montevidensis Spreng. & $\mathrm{Ab}$ & & & $\bullet$ & \\
\hline Vitaceae & Cissus verticillata (L.) Nicolson \& C.E. Jarvis & $\operatorname{Tr}$ & & & $\bullet$ & \\
\hline Vitaceae & Cissus sulcicaulis (Baker) Planch. & $\operatorname{Tr}$ & & & $\bullet$ & \\
\hline Vochysiaceae & Qualea glaziovii Warm. & Av & & & $\bullet$ & \\
\hline Vochysiaceae & Vochysia bifalcata Warm. & Av & & $\bullet$ & $\bullet$ & 8 \\
\hline Woodsiaceae & Diplazium ambiguum Raddi & Ev & & & $\bullet$ & \\
\hline Woodsiaceae & Diplazium cristatum (Desr.) Alston & Ev & & & $\bullet$ & \\
\hline Woodsiaceae & Diplazium lindbergii (Mett.) Christ & Ev & & & $\bullet$ & \\
\hline Woodsiaceae & Diplazium plantaginifolium (L.) Urb. & Ev & & & $\bullet$ & \\
\hline Zingiberaceae & Alpinia zerumbet (Pers.) B.L. Burtt \& R.M. Sm. & Ev & & & $\bullet$ & \\
\hline
\end{tabular}

*COELHO, R. L. G. , SOUZA, V. C. \& FERRUCCI, M. S. 2012 (no prelo). Matayba obovata, a new species of Matayba sect. Matayba (Sapindaceae) from Brazil. Brittonia (Bronx, N.Y.).

Tabela 4. Espécies vegetais ameaçadas presentes no Parque Estadual Turístico do Alto Ribeira, estado de São Paulo, e suas respectivas categorias de ameaça de acordo com as listas oficiais de espécies ameaçadas no estado de São Paulo (SMA), no Brasil (MMA) e no mundo (IUCN). Categorias: EX - Presumivelmente extinta, CR - Em perigo crítico, EN - Em perigo, VU - Vulnerável, LR/cd - Dependente de conservação, LR/NT - Quase ameaçada, LR/lc - De risco mínimo. $\mathrm{Na}$ lista nacional (MMA) constam apenas duas categorias: Ameaçada (X) ou Deficiente de dados (DD). Fonte de informação: $\mathrm{P}$ - Dados primários; $\mathrm{S}$ - Dados secundários.

Table 4. Threatened plant species recorded in the Alto Ribeira Touristic State Park, São Paulo State, Brazil, and reported by the official red lists of São Paulo State (SMA), Brazil (MMA) and Worldwide (IUCN). Categories of threat: EX - Extinct in the wild, CR - Critically endangered, EN - Endangered, VU - Vulnerable, LR/cd - Lower risk/conservation dependent, LR/nt - Lower risk/almost threatened, LR/lc - Lower risk/least concern. The National red list (MMA) contains only two categories: threatened (X) or Data deficient (DD). Information source: P - Primary data; S - Secondary data.

\begin{tabular}{|c|c|c|c|c|c|c|c|}
\hline \multirow[t]{2}{*}{ Família } & \multirow[t]{2}{*}{ Espécie } & \multirow[t]{2}{*}{ Nome popular } & \multicolumn{3}{|c|}{ Lista } & \multicolumn{2}{|c|}{ Fonte } \\
\hline & & & SMA & MMA & IUCN & $\mathbf{P}$ & $\mathbf{S}$ \\
\hline Apocynaceae & Aspidosperma polyneuron Müll. Arg. & peroba-rosa & & & $\mathrm{EN}$ & & $\bullet$ \\
\hline Aquifoliaceae & Ilex paraguariensis A. St.-Hil. & erva-mate & & & $\mathrm{LR} / \mathrm{nt}$ & $\bullet$ & $\bullet$ \\
\hline Arecaceae & Euterpe edulis Mart. & palmito-juçara & VU & $\mathrm{X}$ & & $\bullet$ & $\bullet$ \\
\hline Asteraceae & $\begin{array}{l}\text { Raulinoreitzia leptophlebia (B.L. Rob.) } \\
\text { R.M. King \& H. Rob. }\end{array}$ & & VU & & & & $\bullet$ \\
\hline Begoniaceae & Begonia toledoana Handro & & VU & & & & $\bullet$ \\
\hline Bromeliaceae & Aechmea apocalyptica Reitz & & & $\mathrm{X}$ & & & $\bullet$ \\
\hline Bromeliaceae & Aechmea gracilis Lindm. & & VU & DD & & & $\bullet$ \\
\hline Bromeliaceae & Nidularium jonesianum Leme & & EX & & & & $\bullet$ \\
\hline Bromeliaceae & Tillandsia linearis Vell. & & EX & & & & $\bullet$ \\
\hline Bromeliaceae & Vriesea psittacina (Hook.) Lindl. & & & DD & & & $\bullet$ \\
\hline $\begin{array}{l}\text { Fabaceae } \\
\text { (Caesalpinioideae) }\end{array}$ & $\begin{array}{l}\text { Tachigali denudata (Vogel) Oliveira- } \\
\text { Filho }\end{array}$ & passuaré & & & $\mathrm{LR} / \mathrm{nt}$ & $\bullet$ & \\
\hline
\end{tabular}


Tabela 4. Continuação...

\begin{tabular}{|c|c|c|c|c|c|c|c|}
\hline \multirow[t]{2}{*}{ Família } & \multirow[t]{2}{*}{ Espécie } & \multirow[t]{2}{*}{ Nome popular } & \multicolumn{3}{|c|}{ Lista } & \multicolumn{2}{|c|}{ Fonte } \\
\hline & & & SMA & MMA & IUCN & $\mathbf{P}$ & $\mathbf{S}$ \\
\hline Fabaceae (Faboideae) & Myrocarpus frondosus Allemão & cabreúva & & & $\mathrm{DD}$ & $\bullet$ & $\bullet$ \\
\hline Heliconiaceae & Heliconia farinosa Raddi & & & $\mathrm{X}$ & & $\bullet$ & \\
\hline Lauraceae & Nectandra debilis $\mathrm{Mez}$ & & $\mathrm{EN}$ & & CR & $\bullet$ & \\
\hline Lauraceae & Nectandra paranaensis Coe-Teix. & & EN & & VU & $\bullet$ & \\
\hline Lauraceae & Ocotea aciphylla (Nees \& Mart.) Mez & & & & $\mathrm{LR} / \mathrm{lc}$ & $\bullet$ & \\
\hline Lauraceae & Ocotea odorifera (Vell.) Rohwer & canela-batalha & & $\mathrm{X}$ & & $\bullet$ & \\
\hline Lauraceae & Ocotea puberula (Rich.) Nees & & & & $\mathrm{LR} / \mathrm{lc}$ & $\bullet$ & \\
\hline Malpighiaceae & Bunchosia pallescens Skottsb. & & EX & & & $\bullet$ & \\
\hline Meliaceae & Cedrela fissilis Vell. & cedro & & & $\mathrm{EN}$ & $\bullet$ & $\bullet$ \\
\hline Meliaceae & Trichilia pallens $\mathrm{C}$. DC. & & & & $\mathrm{LR} / \mathrm{nt}$ & $\bullet$ & $\bullet$ \\
\hline Myrtaceae & $\begin{array}{l}\text { Campomanesia neriiflora }(\mathrm{O} \text {. Berg) } \\
\text { Nied. }\end{array}$ & gauviroba & & & VU & $\bullet$ & $\bullet$ \\
\hline Myrtaceae & Eugenia neoaustralis Sobral & & & & $\mathrm{EN}$ & $\bullet$ & \\
\hline Myrtaceae & $\begin{array}{l}\text { Myrceugenia campestris (DC.) D. } \\
\text { Legrand \& Kausel }\end{array}$ & & & & VU & $\bullet$ & \\
\hline Myrtaceae & $\begin{array}{l}\text { Myrceugenia miersiana (Gardner) D. } \\
\text { Legrand \& Kausel }\end{array}$ & & & & $\mathrm{LR} / \mathrm{nt}$ & $\bullet$ & \\
\hline Myrtaceae & $\begin{array}{l}\text { Myrceugenia myrcioides(Cambess.) } \\
\text { O. Berg }\end{array}$ & & & & $\mathrm{LR} / \mathrm{nt}$ & $\bullet$ & $\bullet$ \\
\hline Myrtaceae & Myrcia grandiflora (O. Berg) Nied. & & & & VU & & $\bullet$ \\
\hline Myrtaceae & Myrcia tijucensis Kiaersk. & & VU & & & $\bullet$ & $\bullet$ \\
\hline Oleaceae & $\begin{array}{l}\text { Chionanthus filiformis (Vell.) P.S. } \\
\text { Green }\end{array}$ & & & & $\mathrm{LR} / \mathrm{nt}$ & $\bullet$ & \\
\hline Piperaceae & Peperomia emarginella (Sw.) C. DC. & & EX & & & & $\bullet$ \\
\hline Podocarpaceae & Podocarpus sellowii Klotzsch ex Endl. & podocarpo & & & $\mathrm{DD}$ & & $\bullet$ \\
\hline Primulaceae & Anagallis barbata (P. Taylor) Kupicha & & VU & & & & $\bullet$ \\
\hline Rubiaceae & $\begin{array}{l}\text { Galianthe pseudopeciolata E.L. } \\
\text { Cabral }\end{array}$ & & EX & & & & $\bullet$ \\
\hline Salicaceae & Casearia lasiophylla Eichler & guaçatonga & & & $\mathrm{DD}$ & & $\bullet$ \\
\hline Sapindaceae & Allophylus semidentatus (Miq.) Radlk. & & VU & & & $\bullet$ & \\
\hline Sapotaceae & Chrysophyllum inornatum Mart. & aleixo & & & $\mathrm{LR} / \mathrm{cd}$ & $\bullet$ & $\bullet$ \\
\hline Sapotaceae & Chrysophyllum viride Mart. \& Eichler & $\begin{array}{l}\text { massaranduba, } \\
\text { bujuero }\end{array}$ & & & $\mathrm{LR} / \mathrm{nt}$ & $\bullet$ & \\
\hline Sapotaceae & Pouteria bullata (S. Moore) Baehni & & & & VU & $\bullet$ & \\
\hline Sapotaceae & Pouteria psammophila (Mart.) Radlk. & & & & $\mathrm{EN}$ & $\bullet$ & $\bullet$ \\
\hline Solanaceae & Aureliana fasciculata (Vell.) Sendtn. & & & & $\mathrm{LR} / \mathrm{cd}$ & $\bullet$ & $\bullet$ \\
\hline
\end{tabular}

Tabela 5. Espécies exóticas registradas no Parque Estadual Turístico do Alto Ribeira, estado de São Paulo. FO - Forma de ocorrência; SI - Situação da invasão; Fonte de informação (P - dados primários, S - dados secundários). *espécie nativa no Brasil, mas exótica no domínio da Floresta Ombrófila Densa na Serra de Paranapiacaba.

Table 5. Exotic species recorded in the Alto Ribeira Touristic State Park, São Paulo State, Brazil. FO - Type of occurrence; SI - Invasion category; Fonte - Information source (P - Primary data; S - Secondary data). *species that are native to Brazil, but not to the Ombrophilous Dense Forest Domain at Paranapiacaba Range.

\begin{tabular}{|c|c|c|c|c|c|}
\hline Família & Espécie & Nome popular & FO & SI & Fonte \\
\hline Acanthaceae & Thunbergia fragrans Roxb. & tumbérgia & - & - & S \\
\hline Anacardiaceae & Mangifera indica $\mathrm{L}$. & mangueira & Adulto isolado & Presente & $\mathrm{P}$ \\
\hline Araucariaceae & Araucaria angustifolia (Bertol.) Kuntze * & araucária & Adulto isolado & Presente & $\mathrm{P}$ \\
\hline Asparagaceae & Yucca gigantea Lem. & Iuca-elefante & População de adultos & Presente & $\mathrm{P}$ \\
\hline Asteraceae & Tithonia diversifolia (Hemsl.) A. Gray & $\begin{array}{c}\text { titônia, } \\
\text { margaridão-amarelo }\end{array}$ & - & - & $\mathrm{S}$ \\
\hline
\end{tabular}


Tabela 5. Continuação...

\begin{tabular}{|c|c|c|c|c|c|}
\hline Família & Espécie & Nome popular & FO & SI & Fonte \\
\hline Balsaminaceae & Impatiens walleriana Hook. f. & maria-sem-vergonha, beijo & População de adultos & Invasora & $\mathrm{P}$ \\
\hline Commelinaceae & Tradescantia zebrina Heynh. & zebrina & População de adultos & Invasora & $\mathrm{P}$ \\
\hline Cucurbitaceae & Momordica charantia L. & melão-de-são-caetano & - & - & S \\
\hline Cucurbitaceae & Sechium edule (Jacq.) Sw. & chuchu & População de adultos & Invasora & $\mathrm{P}$ \\
\hline Cupressaceae & Thuja sp. & tuia & Adulto isolado & Presente & $\mathrm{P}$ \\
\hline Cyperaceae & Cyperus rotundus $\mathrm{L}$. & tiririca & População de adultos & Invasora & $\mathrm{P}$ \\
\hline $\begin{array}{l}\text { Fabaceae } \\
\text { (Mimosoideae) }\end{array}$ & Calliandra brevipes Benth. & cabelo-de-anjo & População de adultos & Presente & $\mathrm{P}$ \\
\hline Iridaceae & $\begin{array}{l}\text { Crocosmia x crocosmiiflora (Lemoine) } \\
\text { N.E. Br. }\end{array}$ & palminha & População de adultos & Invasora & $\mathrm{P}$ \\
\hline Lamiaceae & Leonotis nepetifolia (L.) R. Br. & cordão-de-frade & - & - & $\mathrm{S}$ \\
\hline Lauraceae & Persea americana Mill. & abacateiro & Adulto isolado & Estabelecida & $\mathrm{P}$ \\
\hline Malvaceae & Ceiba speciosa (A. St.-Hil.) Ravenna & paineira & Adulto isolado & Presente & $\mathrm{P}$ \\
\hline Malvaceae & Dombeya wallichii (Lindl.) K. Schum. & dombéia & População de adultos & Presente & $\mathrm{P}$ \\
\hline Malvaceae & Hibiscus rosa-sinensis L. & hibisco & População de adultos & Presente & $\mathrm{P}$ \\
\hline Melastomataceae & Tibouchina clavata (Pers.) Wurdack & orelha-de-urso & População de adultos & Presente & $\mathrm{P}$ \\
\hline Moraceae & Morus nigra $\mathrm{L}$. & amoreira & Adulto isolado & Estabelecida & $\mathrm{P}$ \\
\hline Muntingiaceae & Muntingia calabura $\mathrm{L}$. & calabura & Adulto isolado & Estabelecida & $\mathrm{P}$ \\
\hline Musaceae & Musa paradisiaca $\mathrm{L}$. & bananeira & Adulto isolado & Estabelecida & $\mathrm{P}$ \\
\hline Musaceae & Musa rosacea Jacq. & banana-flor & População de adultos & Invasora & $\mathrm{P}$ \\
\hline Myrtaceae & Eucalyptus grandis W. Hill ex Maiden & eucalipto & Adulto isolado & Estabelecida & $\mathrm{P}$ \\
\hline Myrtaceae & Psidium guajava $\mathrm{L}$. & goiabeira & Adulto isolado & Estabelecida & $\mathrm{P}$ \\
\hline Myrtaceae & Syzygium jambos (L.) Alston & jambo & Adulto isolado & Estabelecida & $\mathrm{P}, \mathrm{S}$ \\
\hline Oleaceae & Ligustrum lucidum W.T. Aiton & alfeneiro-do-japão & Adulto isolado & Presente & $\mathrm{P}$ \\
\hline Pinaceae & Pinus bahamensis Griseb. & pinus & Adulto isolado & Estabelecida & $\mathrm{P}$ \\
\hline Pinaceae & Pinus hondurensis Sénécl. & pinus & Adulto isolado & Estabelecida & $\mathrm{P}$ \\
\hline Poaceae & $\begin{array}{l}\text { Bambusa vulgaris Schrad. ex J.C. } \\
\text { Wendl. }\end{array}$ & $\begin{array}{l}\text { bambu-amarelo-e-verde, } \\
\text { bambu-brasil }\end{array}$ & População de adultos & Estabelecida & $\mathrm{P}$ \\
\hline Poaceae & Coix lacryma-jobi $\mathrm{L}$. & lágrima-de-Nossa-Senhora & - & - & $\mathrm{S}$ \\
\hline Poaceae & Paspalum notatum Flüggé & grama-batatais & População de adultos & Invasora & $\mathrm{P}$ \\
\hline Poaceae & Pennisetum purpureum Schumach. & capim-napier & População de adultos & Invasora & $\mathrm{P}$ \\
\hline Poaceae & $\begin{array}{l}\text { Phyllostachys cf. aurea Rivière \& C. } \\
\text { Rivière }\end{array}$ & bambu-vara-de-pescar & População de adultos & Estabelecida & $\mathrm{P}$ \\
\hline Poaceae & $\begin{array}{l}\text { Urochloa cf. brizantha (Hochst. ex } \\
\text { A. Rich.) }\end{array}$ & braquiária & População de adultos & Invasora & $\mathrm{P}$ \\
\hline Rhamnaceae & Hovenia dulcis Thunb. & uva-japonesa & Adulto isolado & Invasora & $\mathrm{P}$ \\
\hline Rosaceae & Eriobotrya japonica (Thunb.) Lindl. & nespereira & Adulto isolado & Invasora & $\mathrm{P}$ \\
\hline Rutaceae & $\begin{array}{l}\text { Citrus } x \text { aurantiifolia (Christm.) } \\
\text { Swingle }\end{array}$ & $\operatorname{lima}$ & Adulto isolado & Estabelecida & $\mathrm{P}$ \\
\hline Rutaceae & Citrus x aurantium $\mathrm{L}$. & laranjeira & Adulto isolado & Estabelecida & $\mathrm{P}$ \\
\hline Rutaceae & Citrus x limon (L.) Osbeck & limão-rosa & Adulto isolado & Estabelecida & $\mathrm{P}$ \\
\hline Rutaceae & Citrus reticulata Blanco & mexerica & Adulto isolado & Estabelecida & $\mathrm{P}$ \\
\hline Solanaceae & $\begin{array}{l}\text { Brugmansia suaveolens (Willd.) } \\
\text { Bercht. \& J.Presl }\end{array}$ & trombeteira & Adulto isolado & Invasora & $\mathrm{P}$ \\
\hline Typhaceae & Typha domingensis Pers. & taboa & População de adultos & Invasora & $\mathrm{P}$ \\
\hline Zingiberaceae & Hedychium coronarium J. Koenig & lírio-do-brejo, napoleão & População de adultos & Invasora & $\mathrm{P}, \mathrm{S}$ \\
\hline
\end{tabular}


as epífitas Nidularium jonesianum Leme (sem data, exsicata no JBRJ), Tillandsia linearis Vell. (coletada em 1997, exsicata ESA 37554), Peperomia emarginella (Sw.) C. DC. (coletada em 2003, JBRJ 429428) e Galianthe pseudopeciolata E.L.Cabral. (coletada em 1997, exsicatas ESA 37726, FUEL 21661 e IAC 36420), além do arbusto Bunchosia pallescens Skottsb (dado primário, SPSF 43223).

Foram registradas 44 espécies consideradas exóticas (Tabela 5), a maior parte (39 espécies) durante o levantamento de campo, sendo apenas sete espécies provenientes de dados secundários. Parte das espécies (22) foi observada ocorrendo como árvores isoladas ao longo de estradas e ao redor de moradias; já as espécies herbáceas e arbustivas tenderam a ocorrer de forma agrupada. Analisando-se a situação de invasão, 10 espécies foram consideradas "presentes", 15 "estabelecidas" e 14 "invasoras". Todas as espécies invasoras, a espécie nativa Dicranopteris flexuosa (Schrad.) Underw. e o bambu nativo Guadua tagoara (Nees) Kunth foram classificadas como espécies-problema.

\section{Discussão}

\section{Fitofisionomias existentes no PETAR}

A Floresta Ombrófila Densa, formação mais característica do Parque, é uma floresta perenifólia que ocorre em clima de elevadas temperaturas e alta precipitação, bem distribuída durante o ano (Veloso et al. 1991). Situa-se em toda a Província Costeira do Estado de São Paulo, com penetrações em direção ao Planalto Atlântico, onde se encontra com a Floresta Estacional. Assim, o Planalto Atlântico é uma área de ecótono entre duas formações distintas (a Floresta Estacional e a Floresta Ombrófila), o que dificulta o traçado de limites. Este avanço da Floresta Ombrófila para o interior em direção ao Planalto Atlântico parece ocorrer apenas em algumas condições fisiográficas específicas de elevadas altitudes, onde a entrada de espécies ombrófilas é facilitada pela ausência de estação seca e elevada umidade relativa do ar, mas onde há uma pressão de seleção para espécies tolerantes ao clima frio, resistentes a geadas e adaptadas à baixa luminosidade ocasionada pela neblina constante (Ivanauskas et al. 2000).

Um pequeno trecho do PETAR situa-se sobre o Planalto Atlântico, na região do Planalto da Guapiara. Esse Planalto contém um dos principais ecótonos vegetacionais do estado de São Paulo, pois ali se dá o contato entre a Floresta Estacional Semidecidual típica do interior, a Floresta Ombrófila Densa da região costeira e o limite norte da distribuição contínua do domínio da Floresta Ombrófila Mista proveniente da bacia do Paraná. Há relatos de antigos funcionários de que a Floresta Ombrófila Mista ocupava grande parte da região de Planalto no interior do Parque, mas a exploração madeireira de sua espécie típica (Araucaria angustifolia - araucária) foi tão intensa que atualmente remanescentes significativos desta formação são encontrados apenas na zona limítrofe do Parque. No interior do PETAR foram observadas poucas árvores de araucária, que foram plantadas por funcionários ou moradores, não mais em área de Planalto e sim sobre a Serrania Costeira, caracterizando-a, assim, como espécie exótica introduzida.

Sobre a Serrania Costeira, onde predomina a Floresta Ombrófila, observa-se um gradiente vegetacional: com a elevação da altitude, o aumento da declividade e a diminuição da profundidade do solo, as florestas tendem a apresentar porte cada vez menor e maior número de indivíduos. Somam-se a esse gradiente natural os distúrbios causados pelo histórico de uso em determinados trechos, por vezes evidenciados pela presença de dossel aberto.

A Floresta Ombrófila Densa Alto-montana é a floresta perenifólia presente no topo dos morros acima de $1.000 \mathrm{~m}$ de altitude, denominada também de matinha nebular (Klein 1978) ou mata de neblina (Hueck 1956), em virtude da presença de neblina em muitas horas por dia, em quase todos os dias do ano, mesmo na estação seca (Hueck 1956). Associados à neblina, outros fatores condicionantes são os solos rasos (litossolos), usualmente com afloramentos rochosos, e o clima frio (Garcia 2003). Um aspecto fisionômico característico nas matas nebulares é o baixo porte das espécies arbustivas e arbóreas. O nanismo dessas espécies é atribuído à oligotrofia e também aos efeitos do vento, como desgaste físico devido ao atrito e maior perda de água (Garcia 2003). Essas matas apresentam também em seu interior populações densas de bromélias e orquídeas terrícolas, pteridófitas, líquens, musgos e espécies de Chusquea (taquaras), que dão a essa formação uma fisionomia característica (Mantovani et al. 1990, Joly et al. 1991).

A ocorrência dessa vegetação mais baixa e sujeita à neblina em altitudes inferiores às estabelecidas pelo sistema de classificação de Veloso et al. (1991) já foi relatada em outros levantamentos na Serra do Mar (Araujo et al. 2005, Bertoncello et al. 2011) e de Paranapiacaba (Souza et al. 2006), mas essa condição não foi observada em nenhum trecho amostrado no Parque em decorrência da dificuldade de acesso. No interior do Parque Estadual Intervales, áreas similares foram descritas em extensão contínua sobre os topos das serras e em elevações montanhosas na porção nordeste, ou sobre morros isolados em altitudes mais elevadas (Mantovani et al. 2009).

A Floresta Ombrófila Densa Montana é a formação predominante no PETAR e nas unidades de conservação do entorno que integram o contínuo de Paranapiacaba (PECB, PEI e EEcX), com estrutura e extensão territorial aparentemente adequadas à perpetuação e manutenção da flora, se protegida dos impactos da ação humana. Essa região montanhosa também é considerada vital para a conservação da mastofauna da Floresta Atlântica, em especial para a população dos grandes felinos, pois o sul do estado de São Paulo e o norte do Paraná abrigam a última grande população de onças-pintadas (Panthera onca) da Mata Atlântica (Leite et al. 2002).

Em todo o contínuo, por causa da alta declividade e do relevo escarpado, o fundo de vale dos grandes rios foi historicamente o meio utilizado pelas populações humanas para a ocupação do território. Assim, trechos de Floresta Ombrófila Densa Submontana e Aluvial encontram-se geralmente mais degradados, em decorrência do corte raso da vegetação para a formação de roças ou extrativismo para lenha e carvão. Boa parte dessas áreas foi mapeada como vegetação secundária e alguns trechos foram ocupados por bambus, sendo então mapeados como Floresta Ombrófila Aberta.

A denominação Floresta Ombrófila Aberta foi utilizada pelo Projeto RADAMBRASIL para uma vegetação de transição entre a Floresta Amazônica e as áreas extra-amazônicas e com gradientes climáticos com mais de 60 dias secos por ano (Veloso et al. 1991). Embora o conceito tenha sido aplicado originalmente para áreas amazônicas, o termo Floresta Ombrófila Aberta consta do Decreto 750/93 e da Lei 11.428/2006, que tratam do domínio da Mata Atlântica. Veloso et al. (1991) também afirmaram que a faciação, ou seja, a fisionomia específica denominada "floresta com bambu", além de ocorrer na parte ocidental da Amazônia, estende-se também até a borda ocidental do Planalto Meridional no Estado do Paraná, onde o bambuzal domina áreas florestais onde houve exploração de madeiras nobres. Grandes áreas ocupadas por bambus foram registradas também para os Parques Estaduais da Serra do Mar (Araujo et al. 2005), Carlos Botelho (Souza et al. 2006), Intervales (Mantovani et al. 2009) e para a Estação Ecológica de Xitué (Souza et al. 2011).

Sabe-se que os bambus podem restringir a regeneração de espécies arbóreas e afetar a dinâmica das comunidades. Alguns dos mecanismos responsáveis por isso são o bloqueio à chegada de propágulos (Rother et al. 2009) e os danos físicos provocados às espécies arbóreas, causando a mortalidade de plântulas, além da redução na altura, na área basal e na densidade dos indivíduos (Griscom \& Ashton 2003, 2006). No PETAR, assim como nas demais UCs onde os bambus foram observados em elevada abundância, parece de fato haver um efeito negativo sobre a comunidade. Em 
alguns locais, após a morte dos bambus, abriu-se uma grande clareira que começou a ser dominada por lianas heliófitas, formando uma densa cobertura vegetal que possivelmente irá dificultar o estabelecimento da regeneração natural (Souza et al. 2011).

Não se sabe exatamente quais são os fatores que determinam a proliferação dos bambus e tampouco como se dá a dinâmica de expansão e retração das manchas. Acredita-se que o processo de ocupação pode ser desencadeado tanto por distúrbios naturais (como, por exemplo, escorregamentos e abertura de grandes clareiras) quanto por intervenções antrópicas (ex.: corte seletivo), que criam condições abióticas favoráveis ao desenvolvimento dessas espécies, sobretudo o aumento de intensidade luminosa (Mantovani et al. 2009). Contudo, ainda são escassas as informações sobre a dinâmica dos bambus e seus possíveis impactos sobre as demais espécies da comunidade nas áreas de Floresta Ombrófila. Estudos de longo-prazo sobre a ocorrência e estrutura populacional das diferentes espécies de bambu são essenciais para compreender os efeitos da ocupação dos bambus sobre a regeneração natural, analisar a necessidade de intervenção e propor medidas de restauração.

Presente em áreas ao longo dos cursos d'água, sujeitas à inundação temporária ou permanente, a formação Floresta Ombrófila Densa Aluvial, também conhecida como floresta ribeirinha ou ciliar, é representada por comunidades vegetais que refletem os efeitos das cheias dos rios nas épocas chuvosas ou nas depressões alagáveis todos os anos (Veloso et al. 1991). No caso do PETAR, foram amostradas somente áreas de inundação temporária, mas não se pode descartar a possibilidade de haver trechos permanentemente alagados no Parque, que certamente apresentarão composição florística distinta das áreas visitadas.

Em diversos trechos do PETAR são encontrados afloramentos rochosos com lápies, ranhuras que se formam por processos de dissolução das rochas e que ocorrem nos relevos de morros e morrotes cársticos associados à presença de rochas carbonáticas (Winge 2001). Nestes trechos, as árvores se fixam diretamente sobre as rochas (rupícolas) ou nas fendas entre elas (saxícolas). Trata-se então de um ambiente único no Parque, pois a água disponível para as plantas é proveniente da água de percolação, nos dias em que ocorre precipitação, ou da umidade relativa do ar proveniente de neblina. Tais fatores contribuem para a seleção das espécies ocorrentes nesta formação, relacionada à sua adaptabilidade morfológica e fisiológica, de maneira a resistir à deficiência hídrica, mesmo que por curtos períodos. Assim, nota-se a predominância de espécies decíduas ou semidecíduas sobre essas formações, com destaque para a abundância de leguminosas (Fabaceae), representadas por indivíduos de grande porte de caviúna (Machaerium scleroxylon), espécie ameaçada de extinção no estado de São Paulo. Destaca-se também a presença de pau-d'alhos (Gallesia integrifolia) e figueiras (Ficus spp.), que pelo hábito hemiepifítico (no caso das últimas), conseguem também se estabelecer com sucesso nessas áreas. Assim, sobre os afloramentos rochosos do PETAR, é possível que sejam encontrados encraves de florestas estacionais semideciduais ocorrendo lado a lado com as florestas ombrófilas densas e abertas. Esses habitats únicos são relevantes por apresentar fisionomia e florística próprias, contribuindo para a biodiversidade regional. Pesquisas voltadas para o inventário da flora local, para a ecofisiologia e para a fenologia das espécies ali presentes são altamente recomendadas para a melhor caracterização destas comunidades, que merecem atenção especial pois contêm, além de peculiaridades na vegetação, um sistema cárstico com diversas cavidades naturais que representam um dos maiores atrativos turísticos do Parque.

Situações de relevo menos declivoso e a proximidade com os grandes rios possibilitaram maior ocupação humana nas cotas altitudinais mais baixas, resultando em impactos sobre a vegetação ali presente. No Parque, essas áreas de vegetação secundária foram identificadas em vários estágios sucessionais, inferidos sobretudo pelo porte da vegetação e pela cobertura. Tais regiões foram provavelmente objeto de corte raso com finalidade agrícola ou de retirada intensa de árvores para a produção de carvão, e, portanto, são áreas abandonadas e sujeitas à regeneração natural, cujo sucesso e velocidade de colonização dependem do tempo de abandono, do uso ao qual foram submetidas e da disponibilidade de propágulos e dispersores no entorno. O tipo de embasamento geológico também pode influenciar o curso da sucessão e determinar as características dessas comunidades. Comparando áreas de vegetação secundária com mesma idade de abandono, Godoy (2001) observou que nos trechos sobre calcário as florestas eram menos densas e com árvores de maior porte. Nestas áreas, houve uma substituição de espécies de Melastomataceae (especialmente Tibouchina pulchra) e outras famílias típicas de trechos secundários da Floresta Ombrófila Densa por espécies de Fabaceae (especialmente Piptadenia gonoacantha, Inga marginata, Schyzolobium parahyba e Hymenaea courbaril), em decorrência de alterações nas características do solo.

\section{Composição florística}

Considerando-se a Floresta Atlântica lato sensu, são conhecidas 15.782 espécies de plantas vasculares, distribuídas em 2.257 gêneros e 348 famílias (Stehmann et al. 2009), o que corresponde a cerca de 5\% da flora mundial, estimada em 300.000 espécies de plantas (Judd et al. 2009). Mais da metade da riqueza (60\%) e a maior parte dos endemismos $(80 \%)$ da flora atlântica foram encontrados na Floresta Ombrófila Densa (Stehmann et al. 2009), o que evidencia a importância dessa formação florestal para a conservação da biodiversidade brasileira. Nesse cenário, é muito relevante o patrimônio natural composto pelos remanescentes localizados no estado de São Paulo, cuja maior parte se situa em área contínua de Floresta Ombrófila Densa sobre a Serra do Mar e a Serra de Paranapiacaba (Nalon et al. 2010).

No contínuo ecológico de Paranapiacaba, o PETAR é a unidade de conservação que apresenta o segundo maior registro no número de espécies. O Parque Estadual Carlos Botelho, com área pouco maior que o PETAR (37.797 ha), possui flora bem estudada e conta com o registro de 1.113 espécies (Souza et al. 2006). Já o Parque Estadual Intervales, embora com área mais extensa (41.704 ha), possui riqueza conhecida um pouco inferior, de 661 espécies de plantas (Mantovani et al. 2009). Para a Estação Ecológica de Xitué, que possui área bem menor que as demais (3.095 ha), são conhecidas 125 espécies (Souza et al. 2011).

Mesmo após o esforço recente de muitos taxonomistas para reunir o conhecimento existente sobre a flora atlântica brasileira (Stehmann et al. 2009), sabe-se que ainda há lacunas de conhecimento: entre 1990 e 2006 foram registradas 1.194 novas espécies em seus limites, o que representa $42 \%$ do total descrito para o Brasil no mesmo período (Sobral \& Stehmann 2009). Nesse contexto, os valores de riqueza de espécies vasculares das unidades de conservação das florestas ombrófilas paulistas também parecem subestimados. Registros de novas ocorrências para o estado e a descrição de espécies novas têm sido frequentemente encontrados na literatura científica (vide volumes da Flora Fanerogâmica do Estado de São Paulo, por exemplo).

No PETAR, a riqueza de espécies vegetais apresentada também está subestimada, tanto por terem sido coletados preferencialmente indivíduos arbustivos e arbóreos quanto pela falta de estudos de comunidades do local. As buscas às diferentes fontes de dados bibliográficos revelaram apenas um estudo dentro dos limites do Parque, realizado por Godoy (2001) e publicado parcialmente em Aidar et al. (2001). O potencial para abrigar maior riqueza específica é 
alto, pois o PETAR contém dentro de seus limites lentes carbonáticas inseridas numa matriz geológica composta por filitos, granitos, metabazitos e quartzitos (Karmann 1994), resultando em elevada heterogeneidade de solos e tipos de terrenos. Solos desenvolvidos sobre rochas carbonáticas apresentam maior disponibilidade de nutrientes para as plantas (Godoy 2001), sobretudo aqueles pouco desenvolvidos, onde as raízes das árvores encontram-se muito próximas do material de origem, rico em cálcio e magnésio. Quando sujeitos à precipitação intensa, como é o caso do PETAR, os nutrientes tendem a ser lixiviados rapidamente e, em locais onde há solos mais profundos de mesmo material de origem, a fertilidade pode diminuir.

Além das lacunas de conhecimento decorrentes das diferentes intensidades de coleta entre locais, há um forte viés com relação às formas de vida. Há um esforço desproporcional de levantamentos de espécies arbóreas e arbustivas, quando comparadas às demais (Durigan et al. 2008). Entre as diferentes formas de vida menos amostradas encontram-se espécies herbáceas, trepadeiras, epífitas, aquáticas microscópicas e até mesmo pertencentes a outros reinos, como os organismos unicelulares e os fungos. No caso particular do PETAR, atenção especial deve ser dada a este último reino, devido à grande quantidade de espécies de fungos bioluminescentes que vem sendo descoberta na última década (Desjardin et al. 2005, 2007, 2010).

Constatou-se que o PETAR abriga elevado número de espécies consideradas ameaçadas de extinção, informação que contribui significativamente para a atualização da lista de espécies ameaçadas no estado de São Paulo. Isto porque entre os critérios para a inclusão de uma espécie na lista está a ocorrência ou não em unidades de conservação, com maior peso quando nenhuma ocorrência é registrada nesses locais, colocando a espécie em situação aparentemente "desprotegida" (Souza et al. 2007). No entanto, é possível que boa parte das espécies presentes nessas listagens oficiais resultem do baixo esforço de coleta para outras formas de vida que não árvores, como é o caso de muitas epífitas consideradas ameaçadas de extinção.

No PETAR foram registradas cinco espécies consideradas presumivelmente extintas na natureza no estado de São Paulo, devido à ausência de coletas destas espécies em áreas naturais nos últimos 50 anos (Souza et al. 2007). No entanto, dentre as cinco espécies consideradas provavelmente extintas, as epífitas Tillandsia linearis e Galianthe pseudopeciolata foram coletadas em 1997, Peperomia emarginella em 2003 e o arbusto Bunchosia pallescens coletada neste estudo. Portanto, a única que ainda pode ser considerada presumivelmente extinta na natureza é a epífita Nidularium jonesianum pois, embora a exsicata não mencione a data de coleta, o coletor foi Moysés Kuhlmann, o mesmo citado para uma coleta da mesma espécie realizada em 1939 no município de Ribeira (exsicata SP 41638) e considerada a última coleta realizada em São Paulo por Moreira et al. (2007). Pode-se dizer, portanto, que os levantamentos de campo e a compilação criteriosa de dados secundários das unidades de conservação são ferramentas importantes para contribuir para a revisão da lista de espécies ameaçadas.

A presença de espécies ameaçadas em uma área protegida é um indicador da relevância de uma unidade de conservação de proteção integral para a conservação da biodiversidade. Já a presença de espécies exóticas invasoras na mesma unidade representa um vetor de degradação e, portanto, uma ameaça para a conservação das populações in situ.

Dentre as espécies exóticas registradas no PETAR, muitas são frutíferas e de provável introdução por populações humanas ou propagadas em áreas de vegetação nativa por serem apreciadas pela fauna. É o caso da mangueira (Mangifera indica) e do abacateiro (Persea americana), encontrados em pontos isolados e representados por poucos indivíduos, aparentemente não causando impactos significativos sobre a vegetação nativa. Já a goiabeira (Psidium guajava) foi observada em alta densidade em uma área antropizada e a uva-japonesa (Hovenia dulcis) no interior da floresta, portanto com comportamento invasor.

Plantações de Pinus spp. e áreas abandonadas de pastagem implantadas por antigos moradores foram encontradas nos núcleos Areado, Capinzal e Bulha d'água. Embora não se tenha observado impacto aparente de Pinus ao longo das trilhas percorridas, espécies deste gênero têm reconhecido potencial invasor de áreas naturais e, por isso, recomenda-se a erradicação destes plantios e sua conversão em floresta nativa. $\mathrm{O}$ mesmo procedimento deve ser adotado para as áreas de pastagens ocupadas por gramíneas africanas, que tendem a se proliferar com o revolvimento do solo, feito regularmente para manutenção de estradas. Gramíneas e outras espécies ruderais também invadem caminhos abandonados, ambientes ciliares sem cobertura florestal e, em menor escala, o interior das áreas onde há incidência de luz solar direta. O lírio-do-brejo (Hedychium coronarium) também é uma espécie que merece atenção. Trata-se de uma espécie exótica invasora muito abundante em vários trechos ribeirinhos, onde já são consideradas espécie-problema devido à capacidade de reprodução vegetativa, facilidade de dispersão e alta densidade populacional em áreas degradadas pelo assoreamento dos cursos d'água.

Além das exóticas, observou-se a ocorrência da espécie Dicranopteris flexuosa em abundância, mais especificamente nos topos de morros sujeitos a escorregamentos e áreas abertas. Embora seja nativa, esta espécie pode ser considerada uma espécie-problema em razão de sua velocidade de crescimento e modo de ocupação dos ambientes abertos, onde se formam densos tapetes de indivíduos, que provavelmente dificultam ou impedem a germinação e o crescimento de diversas espécies nativas. Uma das explicações para essa inibição pode ser a presença de compostos alelopáticos, que seriam tóxicos para determinadas espécies (Silva et al. 2011). Atenção deve ser dada também ao bambu nativo predominante nos trechos mapeados como Floresta Ombrófila Aberta (Guadua tagoara), o mesmo que recobre extensas áreas no contínuo de unidades de conservação da Serra de Paranapiacaba (Souza et al. 2006, Mantovani et al. 2009, Souza et al. 2011). No Parque Estadual Intervales, Araujo et al. (2009) encontraram estreita relação entre a ocorrência dessa espécie e as áreas utilizadas nas décadas de 50, 60 e 70 para a exploração do palmito e de roças. Para os autores, estas atividades podem ter ampliado a área naturalmente colonizada pelo taquaruçu, o que reforça a sua indicação como espécie-problema. Apesar do taquaruçu ser importante por fornecer alimentação e abrigo para muitas espécies da fauna (Rother et al. 2009), as características de rápida colonização de G. tagoara e seu comportamento invasor podem limitar o crescimento de outras populações vegetais, sendo importante seu manejo.

Embora a avaliação de espécies exóticas e invasoras não fosse o foco principal do estudo, o registro de ocorrência destas espécies contribuiu para o reconhecimento de interferências nas áreas. Como o processo de invasão biológica é gradativo, muitas vezes não é percebido enquanto ainda está na melhor fase para controle (Ziller \& Dechoum 2007). Dessa maneira, ainda que muitas exóticas registradas no PETAR não tenham sido caracterizadas como espécies-problema, recomenda-se a erradicação daquelas já estabelecidas ou invasoras de áreas naturais como medida preventiva. Os métodos de controle de plantas invasoras podem ser divididos em três grandes grupos: controle mecânico ou físico, controle químico e controle biológico. Em geral, são empregadas combinações desses métodos para ganhar eficiência, em vez de usar métodos isolados (Ziller \& Dechoum 2007). O trabalho deve ser iniciado com a análise prévia de cada situação de invasão e a revisão dos métodos disponíveis para seu controle, com registro do projeto técnico de erradicação. De acordo com as recomendações de Ziller \& Dechoum (2007), é importante considerar se as premissas assumidas como causas da invasão estão corretas e, caso não estejam, ter um plano alternativo para uma resposta rápida em caso de insucesso na primeira ação de controle. Após a execução da ação de controle, é necessário que seja estruturado um sistema de repetição dos tratamentos e de monitoramento para acompanhamento 
do sucesso da técnica, avaliando-se a necessidade de se repetir a ação e determinar sua frequência e periodicidade.

\section{Agradecimentos}

Aos taxonomistas João Aurélio Pastore, João Batista Baitello e Osny Tadeu Aguiar, pela identificação do material botânico. A Marcelo Del Bel pelo auxílio na obtenção de dados secundários, aos escaladores Dirceu de Souza e João Barbosa da Silva, e às estagiárias Ligia Braggion, Luiza Z. Pinheiro e Louraine M. S. Barril. Ao responsável pelo Parque, Fábio Leonardo Tomas, à Kátia Pisciotta e demais funcionários, pelo apoio logístico.

\section{Referências Bibliográficas}

AIDAR, M.P.M. 2000. Ecofisiologia das estratégias de utilização de nitrogênio em árvores da floresta neotropical. Tese de doutorado, Universidade Estadual de Campinas, Campinas.

AIDAR, M.P.M., GODOY, J.R.L., BERGMANN, J. \& JOLY, C.A. 2001. Atlantic Forest Succession over calcareous soil, Parque Estadual Turístico do Alto Ribeira - PETAR, SP. Rev. Bras. Bot. 24(4):455-469.

ANGIOSPERM PHYLOGENY GROUP - APG III. 2009. An update of the Angiosperm Phylogeny Group classification for the orders and families of flowering plants: APG III. Bot. J. Linn. Soc. 161:105-121. http://dx.doi. org/10.1111/j.1095-8339.2009.00996.x

ARAUJO, C.O., SOUZA, F.M., ARZOLLA, F.A.R.D.P., FRANCO, G.A.D.C., BAITELLO, J.B., TONIATO, M.T.Z., IVANAUSKAS, N.M., AGUIAR, O.T. \& CIELO-FILHO, R. 2005. Módulo Biodiversidade: Relatório Vegetação. In Plano de Manejo do Parque Estadual da Serra do Mar (M.C.W. BRITO \& L.R.C.N. OLIVEIRA, coords.). Instituto Florestal, São Paulo.

ARAUJO, L.S. 2009. As (fascinantes) Florestas com Bambus. Scient. Am. Brasil. 86:68-73.

BAILLIE, I.C. 1996. Soils of the humid tropics. In The Tropical Rain Forest: an ecological study (P.W. Richards). 2nd ed. Cambridge University Press, Cambridge, p.256-286.

BERTONCELO, R., YAMAMOTO, K., MEIRELES, L.D. \& SHEPHERD, J.G. 2011. A phytogeographic analysis of cloud forests and other forest subtypes amidst the Atlantic forests in south and southeast Brazil. Biodivers. Conserv. 20:3413-3433. http://dx.doi.org/10.1007/s10531-011-0129-6

BISBY, F.A., ROSKOV, Y.R., ORRELL, T.M., NICOLSON, D., PAGLINAWAN, L.E., BAILLY, N., KIRK, P.M., BOURGOIN, T. \& BAILLARGEON G., eds. 2010. Species 2000 \& ITIS Catalogue of Life: 2010. Annual Checklist. Species 2000: Reading, UK. www. catalogueoflife.org/annual-checklist/2010 (último acesso em 19/05/2010).

BRASIL. Ministério do Meio Ambiente. Anexo I da Instrução Normativa $\mathrm{n}^{\circ} 6$, de 23 de setembro de 2008. Lista Oficial das Espécies da Flora Brasileira Ameaçadas de Extinção. Diário Oficail da República Federativa do Brasil, Brasília, DF, 09 out. 2008. http://www.mma.gov.br/estruturas/ascom boletins/_arquivos/83_19092008034949.pdf (último acesso em 19/05/2010).

DESJARDIN, D.E., CAPELARI, M. \& STEVANI, C.V. 2005. A new bioluminescent Agaric from São Paulo, Brazil. Fungal Divers. 18:9-15.

DESJARDIN, D.E., CAPELARI, M. \& STEVANI, C.V. 2007. Bioluminescent Mycena species from São Paulo, Brazil. Mycologia. 99(2):317-327. PMid:17682785. http://dx.doi.org/10.3852/mycologia.99.2.317

DESJARDIN, D.E., PERRY, B.A., STEVANI, C.V., LODGE, D.J. \& NAGASAWA, E. 2010. Luminescent Mycena: new and noteworthy species. Mycologia. 102(2):459-465. http://dx.doi.org/10.3852/09-197

DURIGAN, G., MAMEDE, M.C.H., IVANAUSKAS, N.M., SIQUEIRA, M.F., JOLY, C.A., MOURA, C., BARROS, F., SOUZA, F.M., VILELA, F.E.S.P., ARZOLLA, F.A.R.P., FRANCO, G.A.D.C., CORDEIRO, I., KOCH, I., BAITELLO, J.B., LOMBARDI, J.A., LIMA, L.R., LOHMENN, L.G., BERNACCI, L.C., ASSIS, M.A., AIDAR, M.P.M., WANDERLEY, M.G.L., TONIATO, M.T.Z., RIBEIRO, M., GROPPO, M., CAVASSAN, O., SANO, P.T., RODRIGUES, R.R., FICHS, T.V. \& MARTINS, S.E. 2008. Fanerógamas. In Diretrizes para a conservação e restauração da biodiversidade no Estado de São Paulo (R.R. RODRIGUES \& V.L.R. BNONI, orgs.). Instituto de Botânica, Imprensa Oficial do Estado de São Paulo, São Paulo, p.104-109.
FOGAÇA, I.F., VIDAL, A.B.D. \& COSTA, P.H.F. 2010. Módulo Meio Antrópico: Socioeconomia. Relatório integrante do Plano de Manejo do Parque Estadual Turístico do Alto Ribeira. Fundação Florestal, São Paulo.

FORZZA, R.C., BAUMGRATZ, J.F., BICUDO, C.E.M., CARVALHO JÚNIOR, A.A., COSTA, A., COSTA, D.P., HOPKINS, M., LEITMAN, P.M., LOHMANN, L.G., MAIA, L.C., MARTINELLI, G., MENEZES, M., MORIM, M.P., COELHO, M.A.N., PEIXOTO, A.L., PIRANI, J.R., PRADO, J., QUEIROZ, L.P., SOUZA, V.C., STEHMANN, J.R., SYLVESTRE, L.S., WALTER, B.M.T. \& ZAPPI, D., eds. 2010. Catálogo de plantas e fungos do Brasil. Andrea Jakobsson Estúdio, Jardim Botânico do Rio de Janeiro, Rio de Janeiro.

GARCIA, R.J.F. 2003. Estudo florístico dos campos alto-montanos e matas nebulares do Parque Estadual da Serra do Mar - Núcleo Curucutu, São Paulo, SP, Brasil. Tese de doutorado, Universidade de São Paulo, São Paulo.

GODOY, J.R.L. 2001. Estrutura e composição específica da Mata Atlântica secundária de encosta sobre calcário e filito, no Parque Estadual Turístico do Alto Ribeira, Iporanga, SP. Dissertação de mestrado, Universidade de São Paulo, São Paulo.

GRISCOM, B.W. \& ASHTON, P.M.S. 2003. Bamboo control of forest succession: Guadua sarcocarpa in Southeastern Peru. Forest Ecol. Manag. 175:445-454. http://dx.doi.org/10.1016/S0378-1127(02)00214-1

GRISCOM, B.W. \& ASHTON, P.M.S. 2006. A self-perpetuating bamboo disturbance cycle in a neotropical forest. J. Trop. Ecol. 22:587-597. http://dx.doi.org/10.1017/S0266467406003361

HUECK, K. 1956. Mapa fitogeográfico do Estado de São Paulo. Boletim Paulista de Geografia, São Paulo, v.22, p.19-25.

INSTITUTO HÓRUS. 2011. Base de dados nacional de espécies exóticas invasoras. http://www.institutohorus.org.br/ (último acesso em 20/11/2011).

INTEGRATED TAXONOMIC INFORMATION SYSTEM - ITIS. Catalogue of Life 2010 Annual Checklist: indexing the world's known species. www. catalogueoflife.org/annual-checklist/2010/ (último acesso em 19/05/2010).

INTERNATIONAL UNION FOR CONSERVATION OF NATURE - IUCN. 2008. Lista vermelha de espécies ameaçadas de extinção da União Internacional para a Conservação da Natureza. http:// www.iucnredlist.org (último acesso em 19/05/2010).

IVANAUSKAS, N.M., MONTEIRO, R. \& RODRIGUES, R.R. 2000. Similaridade florística entre áreas de Floresta Atlântica no Estado de São Paulo. Braz. J. Ecol. 1(4):71-81.

JOLY, C.A., LEITÃO FILHO, H.F. \& SILVA, S.M. 1991. O patrimônio florístico - The floristic heritage. In Mata Atlântica - Atlantic Rain Forest (G.I. Câmara, coord.). Ed. Index Ltda. e Fundação S.O.S. Mata Atlântica, São Paulo.

JUDD, W.S., CAMPBELL, C.S., KELLOGG, E.A., STEVENS, P.F. \& DONOGHUE,M.J. 2009. Sistemática Vegetal: Um Enfoque Filogenético. 3rd ed. Artmed, Porto Alegre.

KARMANN, I. 1994. Evolução e dinâmica atual do sistema cárstico do Alto Vale do rio Ribeira de Iguape, sudeste do Estado de São Paulo. Tese de doutorado, Universidade de São Paulo, São Paulo.

KLEIN, R.M. 1978. Mapa Fitogeográfico do Estado de Santa Catarina: resenha descritiva da cobertura vegetal. In Flora Ilustrada Catarinense (R. Reitz, ed.). Herbário Barbosa Rodrigues, Itajaí.

KÖPPEN, W. 1948. Climatologia. Editora Fondo Cultura Economica, Mexico City.

LEITE, M.R.P., BOULHOSA, R., GALVÃO, P. \& CULLEN, L. 2002. Ecologia y conservacion del yaguar en los bosques atlanticos costeros de Brasil. In El Jaguar en el nuevo milenio. Una evaluacion de su estado, deteccion de prioridades y recomendaciones para la conservacion de los jaguares en America (R.A. Medellin, C. Chetkiewicz, A. Rabinowitz, K.H. Redford, J.G. Robinson, E. Sanderson \& A. Taber, eds.). Universidad Nacional Autonoma de Mexico, Wildlife Conservation Society, Mexico D. F., p.25-42.

LEPSCH, I.F., SARAIVA, I.R., DONZELI, P.L., MARINHO, M.A., SAKAI, E., GUILLAUMON, J.R., PFEIFER, R.M., MATTOS, I.F.A., ANDRADE, W.J. \& SILVA, C.E.F. 1990. Macrozoneamento das terras da região do rio Ribeira de Iguape, SP. Bol. Cient./ Inst. Agron. Campinas. 19:1-181.

LUEDER, D.R. 1959. Aerial photographic interpretation: principles and applications. McGraw-Hill, New York. 
MAGRO, T.C. 2010. Módulo Programas de Gestão: uso público. Fundação Florestal, São Paulo. Relatório integrante do Plano de Manejo do Parque Estadual Turístico do Alto Ribeira.

MAMEDE, M.C.H., SOUZA, V.C., PRADO, J., BARROS, F., WANDERLEY, M.G.L. \& RANDO, J.G. 2007. Livro Vermelho das Espécies Vegetais Ameaçadas do Estado de São Paulo. Instituto de Botânica, Imprensa Oficial, São Paulo.

MANTOVANI, W., RODRIGUES, R.R., ROSSI,L., ROMANIUC-NETO, S., CATHARINO, E.L.M. \& CORDEIRO, I. 1990. A vegetação na Serra de Paranapiacaba em Salesópolis, SP. In Simpósio de Ecossistemas da Costa Sul e Sudeste Brasileira: estrutura, função e manejo. ACIESP, São Paulo, p.348-384.

MANTOVANI, W., PAVÃO T., SANTOS, A.L., TOFFOLI, C.B., MARTINS, J.B., MELO, K.C., SANTOS, M.F. \& ARAÚJO, L.S. 2009. Vegetação. In Plano de Manejo do Parque Estadual Intervales (S.A. Furlan, coord.). Fundação Florestal, São Paulo.

MOREIRA, J.R. \& PIOVEZAN, U. 2005. Conceitos de manejo de fauna, manejo de população problema e o exemplo da capivara. In Documentos (M.G.S.P. Negrão, ed.). Embrapa Recursos Genéticos e Biotecnologia, Brasília, v.155, p.1-23.

MOREIRA, A.B., WANDERLEY, M.G.L. \& MARTINELLI, G. 2007. Bromeliaceae - Nidularium. In Flora Fanerogâmica do Estado de São Paulo (M.G.L. Wanderley, G.J. Shepherd, T.S. Melhem, \& A.M. Giulietti, eds.). FAPESP, Instituto de Botânica, São Paulo, v.5, p.95-107.

NALON, M.A., LIMA, L.M.P.R., WEINGARTNER, P., SOUZA, C.H.S., MONTAGNA, R.G., LIMA, I., MATSUKUMA, C.K., PAVÃO, M., KANASHIRO, M.M., YWANE, M.S.S., TEODORO, J.R. \& PASCHOAL, E. Sistema de informações florestais do Estado de São Paulo. http://www. iflorestal.sp.gov.br/sifesp/creditos.html (último acesso em 01/05/2010).

RIBEIRO, M.C., METZGER, J.P., MARTENSEN, A.C., PONZONI, F.J. \& HIROTA, M.M. 2009. The Brazilian Atlantic Forest: how much is left and how is the remaining forest distributed? Implications for conservation. Biol. Cons. 142:1141-1153. http://dx.doi.org/10.1016/j. biocon.2009.02.021

ROSSI, M. \& PIRES-NETO, A.G. 2010. Avaliação do Meio Físico - Solos. In Plano de Manejo do Parque Estadual Turístico do Alto Ribeira (C. LEONEL, K. PISCIOTTA \& M.I.A. BARROS, coords.). Fundação Florestal, São Paulo, p.175-199. http://www.fflorestal.sp.gov.br/ planodemanejoConsema.php (último acesso em 05/06/2011).

ROTHER, D. C.; RODRIGUES, R.R.; PIZO, M.A. 2009. Effects of bamboo stands on seed rain and seed limitation in a rainforest. Forest Ecol. Manag. 257:885-892. http://dx.doi.org/10.1016/j.foreco.2008.10.022

SILVA, V.S., CÂNDIDO, A.C.S., MULLER, C., LAURA, V.A., FACCENDA, O., SIMIONATTO, E., HESS, S.C. \& PERES, M.T.L.P. 2001. Potencial fitotóxico de Dicranopteris flexuosa (Schrad.) Underw. (Gleicheniaceae). Acta Bot. Bras. 25(1):95-104. http://dx.doi.org/10.1590/S010233062011000100012

SISTEMA DE INFORMAÇÃO AMBIENTAL DO BIOTA - SINBIOTA. http://sinbiota.cria.org.br/ (último acesso em 19/05/2010).

SMITH, A.R., PRYER, K.M., SCHUETTPELZ, E., KORALL, P. SCHNEIDER, H. \& WOLF, P.G. 2006. A classification for extant ferns. Taxon. 55(3):705-731. http://dx.doi.org/10.2307/25065646

SOBRAL, M. \& STEHMANN, J.R. 2009. An analysis of new angiosperm species discoveries in Brazil (1990 - 2006). Taxon. 58:227-232.

SOUZA, F.M., FRANCO, G.A.D.C., MATTOS, I.F.A., BAITELLO, J.B., TONIATO, M.T.Z., KANASHIRO, M., IVANAUSKAS, N.M., AGUIAR, O.T., CIELO-FILHO, R., SALINO, A., ROTHER, D.C., ARAUJO, L.S., LIMA, R.A.F., DITTRICH, V.A.O. \& SOUZA, V.C. 2006. Módulo Biodiversidade: Vegetação. Relatório integrante do Plano de Manejo do Parque Estadual Carlos Botelho. Instituto Florestal, São Paulo.
SOUZA, F.M., FRANCO, G.A.D.C., MATTOS, I. F. A., BAITELLO, J.B., TONIATO, M.T.Z., KANASHIRO, M.M., IVANAUSKAS, N.M., AGUIAR, O.T., CIELO-FILHO, R. \& RIBEIRO, A.P. 2011. Módulo Biodiversidade: Vegetação. Relatório integrante do Plano de Manejo da Estação Ecológica de Xitué. Instituto Florestal, São Paulo.

SOUZA, V.C. \& LORENZI, H. 2008. Botânica Sistemática: Guia ilustrado para identificação das famílias de Fanerógamas nativas e exóticas no Brasil, baseado em APG II. 2.ed. Instituto Plantarum, Nova Odessa.

SOUZA, V.C., MAMEDE, M.C.H., CORDEIRO, I., PRADO, J., BARROS, F., WANDERLEY, M.G.L., KAGEYAMA, P., CECCANTINI, G. \& RANDO, J.G. 2007. Critérios utilizados na elaboração da Lista Oficial das Espécies da Flora Ameaçadas de Extinção no Estado de São Paulo. In Livro Vermelho das Espécies Vegetais Ameaçadas do Estado de São Paulo (M.C.H. Mamede, V.C. Souza, J. Prado, F. Barros, M.G.L. Wanderley \& J.G. Rando, orgs.). Instituto de Botânica e Imprensa Oficial, São Paulo, p. 15-20.

SPECIESLINK. Sistema de informação distribuído para recuperação de dados de acervos de coleções biológicas e de observação em campo. http:// splink.cria.org.br/ (último acesso em 19/05/2010).

SPURR, S.H. 1960. Photogrammetry and Photo-Interpretation. Ronald Press, New York.

STEHMANN, J.R., FORZZA, R.C., SALINO, A., SOBRAL, M., COSTA, D.P. \& KAMINO, L.H.Y. 2009. Plantas da Floresta Atlântica. Jardim Botânico do Rio de Janeiro, Rio de Janeiro.

TROPICOS. http://www.tropicos.org/ (último acesso em 19/05/2010).

VELOSO, H.P., RANGEL FILHO, A.L.R. \& LIMA, J.C.A. 1991. Classificação da Vegetação Brasileira adaptada a um sistema universal. Fundação IBGE, Rio de Janeiro.

WALTER, H. 1986. Vegetação e zonas climáticas: tratado de ecologia global. Editora E.P.U., São Paulo.

WANDERLEY, M.G.L., SHEPHERD, G.J. \& GIULIETTI, A.M. 2001. Flora Fanerogâmica do Estado de São Paulo. FAPESP, HUCITEC, São Paulo, v.1.

WANDERLEY, M.G.L., SHEPHERD, G.J. \& GIULIETTI, A.M. 2002. Flora Fanerogâmica do Estado de São Paulo. FAPESP, HUCITEC, São Paulo, v.2.

WANDERLEY, M.G.L., SHEPHERD, G.J., GIULIETTI, A.M. \& MELHEM, T.S. 2003. Flora Fanerogâmica do Estado de São Paulo. FAPESP, RiMa, São Paulo, v.3.

WANDERLEY, M.G.L., SHEPHERD, G.J., MELHEM, T.S. \& GIULIETTI, A.M. 2005. Flora Fanerogâmica do Estado de São Paulo. FAPESP, RiMa, São Paulo, v.4.

WANDERLEY, M.G.L., SHEPHERD, G.J., MELHEM, T.S. \& GIULIETTI, A.M. 2007. Flora Fanerogâmica do Estado de São Paulo. FAPESP, Instituto de Botânica, São Paulo, v.5.

WANDERLEY, M.G.L., SHEPHERD, G.J., MELHEM, T.S., GIULIETTI, A.M. \& MARTINS, S.E. 2009. Flora Fanerogâmica de São Paulo. FAPESP, Instituto de Botânica, São Paulo, v.6.

WINGE, M., coord. 2001. Glossário Geológico Ilustrado. http://www.unb. br/ig/glossario/ (último acesso em 27/05/2010).

ZALBA, S.M. 2005. Introdução às Invasões Biológicas - Conceitos e Definições. In América do Sul invadida: A crescente ameaça das espécies exóticas invasoras (S. Matthews, K. Brand, eds.). GISP, p.4-5.

ZILLER, S.R. 2001. Plantas exóticas invasoras: a ameaça da contaminação biológica. Cienc. Hoje. 30(178):77-79.

ZILLER, S.R. \& DECHOUM, M.S. 2007. Degradação ambiental causada por plantas exóticas invasoras e soluções para o manejo em unidades de conservação de proteção integral. In A Botânica no Brasil pesquisa, ensino e políticas públicas ambientais (L.M. Barbosa \& N.A Santos-Júnior). Sociedade Botânica do Brasil, São Paulo, p.356-360. 